G $E \cup S$

Report file no.

22249

GRØNLANDS GEOLOGISKE UNDERSØGELSE Bulletin No. 97

\title{
KALEDONISCHE METAMORPHOSE DER PRAEKAMBRISCHEN CHARCOT LAND SERIE, SCORESBY SUND, OST-GRÖNLAND \\ VON
}

ALBRECHT STECK

MIT 18 FIGUREN UND 8 TABELLEN IM TEXT

WITH AN ENGLISH SUMMARY

KøBENHAVN

1971 


\section{GRøNLANDS GEOLOGISKE UNDERSØGELSE The Geological Survey of Greenland

\author{
Østervoldgade 10, DK-1350 København K
} \\ Denmark}

\section{BULLETINS}

(published in association with the series Meddelelser om Gronland)

No. 87 The stratigraphy and structure of the Ketilidian rocks of Midternæs, South-West Greenland. 1970 by A. K. Higgins (Meddr Gronland 189, 2).

No. 88 The plutonic history of the Tasiussaq area, South Greenland, with special reference to a high-grade gneiss complex. 1970 by Peter R. Dawes (Meddr Gronland 189, 3).

No. 89 The significance of the kakortokite in the evolution of the Ilimaussaq intrusion, South Greenland. 1970 by John Ferguson (Meddr Gronland $190,1)$.

No. 90 The chemistry and origin of some basement amphibolites between Ivigtut and Frederikshåb, South-West Greenland. 1970 by Feiko Kalsbeek and Bernard E. Leake (Meddr Gronland 190,4).

No. 91 Plutonic nodules in lamprophyric carbonatite dykes near Frederikshåb, South-West Greenland. 1970 by Brian J. Walton and Allan R. Arnold (Meddr Gronland 190,5).

No. 92 The geology of two small layered hornblende peridotite (picrite) plutons in South Greenland. 1970 by Jevan P. Berrangé (Meddr Gronland 192,1).

No. 93 Danian foraminifera from Nûgssuaq, West Greenland. 1970 by Hans Jørgen Hansen (Meddr Gronland 193, 2).

No. 94 Paleocene Ostracoda from Nûgssuaq, West Greenland. 1971 by Janina Szczechura (Meddr Gronland 193, 1).

No. 95 Contributions to the mineralogy of Ilimaussaq nos 20-21. I. On the mineralogy and paragenesis of tugtupite $\mathrm{Na}_{8} \mathrm{Al}_{2} \mathrm{Be}_{2} \mathrm{Si}_{8} \mathrm{O}_{24}(\mathrm{Cl}, \mathrm{S})_{2}$ from the Ilimaussaq alkaline intrusion, South Greenland. 1971 by H. Sørensen, M. Danø and O. V.Petersen (Meddr Gronland 181, 13). II. The colour and luminescence of tugtupite (beryllosodalite) from Ilimaussaq, South Greenland. 1971 by A.S. Povarennykh, A. N. Platonov, A. N. Tarashchan and V.P. Belichenko (Meddr Gronland 181, 14).

No. 96 The Precambrian, Eocambrian and early Palaeozoic stratigraphy of the Jørgen Brønlund Fjord area, Peary Land, North Greenland. 1971 by Hans F. Jepsen (Meddr Gronland 192, 2).

No. 97. Kaledonische metamorphose der praekambrischen Charcot Land serie, Scoresby Sund, Ost-Grönland. 1971 by Albrecht Steck (Meddr Gronland 192,3).

Bulletins of the Geological Survey of Greenland are asailable on exchange or may be purchased from the Survey. Copies may be purchased as parts of Meddelelser om Gronland from C. A. Reitzels Forlag, Norre Sogade 35, DK-1370 Copenhagen K, Denmark. 
GRØNLANDS GEOLOGISKE UNDERSØGELSE

Bulletin No. 97

\section{KALEDONISCHE METAMORPHOSE DER PRAEKAMBRISCHEN CHARCOT \\ IAND SERIE, SCORESBY SUND, OST-GRÖNLAND \\ VON}

ALBRECHT STECK

MIT 18 FIGUREN UND 8 TABELLEN IM TEXT

WITH AN ENGLISH SUMMARY

KØBENHAVN

1971 


\begin{abstract}
The metamorphism of the Charcot Land sequence, a succession of sediments, extrusives, tuffs and gabbro and granite intrusions, is described. These rocks, of Precambrian age, rest on a gneissic basement, and are exposed in a tectonic window beneath a Caledonian thrust sheet.

One principal metamorphic phase is distinguished, succeeded by a very weak retrograde phase. Locally around the gabbro intrusions traces of contact metamorphism are recorded.

The metamorphic assemblages in the tuffs and gabbros, the siliceous dolomites, and the quartzites and mica schists are described and illustrated separately. A progressive northerly increase in metamorphic grade is revealed, the isograds occurring in roughly concentric arcs around a centre in the northern part of the area.

Recrystallisation took place under temperature and pressure conditions of Barrovian type, and is probably Caledonian in age.
\end{abstract}




\section{INHALTSVERZEICHNIS}

Einleitung und Problemstellung . . . . . . . . . . . . . . . . . . . 5

Allgemeine Geologie $\ldots \ldots \ldots \ldots \ldots \ldots \ldots \ldots \ldots \ldots \ldots \ldots \ldots \ldots \ldots \ldots$

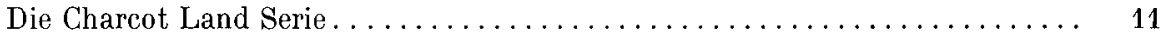

Die Marmore ............................. 12

Die Glimmerschiefer und Glimmerquarzite $\ldots \ldots \ldots \ldots \ldots \ldots \ldots \ldots \ldots \ldots$

Die Grünschiefer und Amphibolite .................. 13

Die Metagabbros .............................. 14

Die Metagranite im westlichen Charcot Land . . . . . . . . . . 14

Ein Tillit oder Tilloid wahrscheinlich eocambrischen Alters . . . . . . . . . 16

Metamorphose basischer Tuffe und Gabbros .................. 18

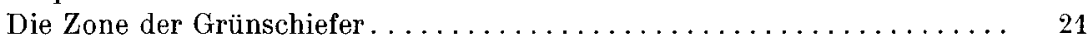

Die Zone der Amphibolite $\ldots \ldots \ldots \ldots \ldots \ldots \ldots \ldots \ldots \ldots \ldots \ldots$

Metamorphose kieseliger Dolomite ... . . . . . . . . . . . . . . . 37

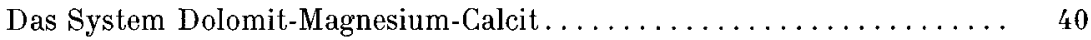

Isograde in Quarziten und Glimmerschiefern . . . . . . . . . . . . . . 42

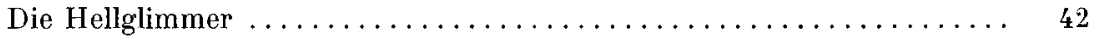

Die Paragenesen der Stilpnomelan-Chlorit-Zone (Zone der Grünschiefer) 44

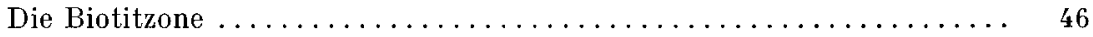

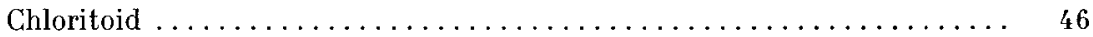

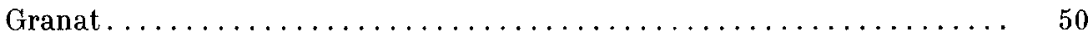

Staurolith .............................. 51

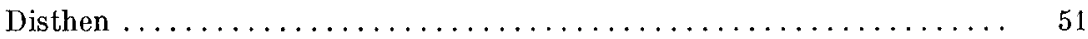

Die Nebengemengteile der Metapelite $\ldots \ldots \ldots \ldots \ldots \ldots \ldots \ldots \ldots \ldots \ldots$

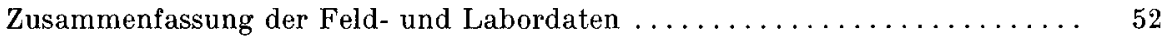

Aufbau und regionale Stellung der metamorphen Serie $\ldots \ldots \ldots \ldots \ldots 2$

Die Ursache der Regionalmetamorphose . . . . . . . . . . . . . 52

Die Abfolge der Isograde und Paragenesenzonen. . . . . . . . . . . 53

Folgerungen aus den Beziehungen zwischen Deformation und

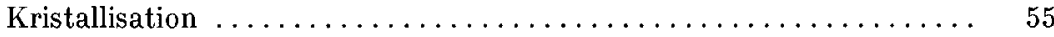

Diskussion $\ldots \ldots \ldots \ldots \ldots \ldots \ldots \ldots \ldots \ldots \ldots \ldots \ldots \ldots \ldots \ldots \ldots$

Physikalische Bedingungen (Vergleich mit andern metamorphen Serien, P-T-Gradient, Zusammensetzung der mobilen Phasen oder Phasenge-

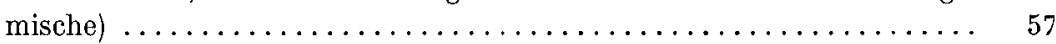

Chemisches Gleichgewicht $\ldots \ldots \ldots \ldots \ldots \ldots \ldots \ldots \ldots \ldots \ldots \ldots$

Systematische Stellung der metamorphen Serie . . . . . . . . . . 60



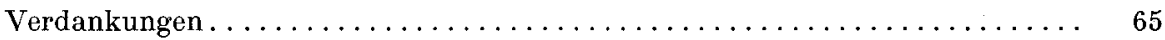

Literaturverzeichnis . . . . . . . . . . . . . . . . . . . 66 


\section{EINLEITUNG UND PROBLEMSTELLUNG}

Im Sommer 1968 bot sich mir die Gelegenheit an einer Expedition der "Grønlands Geologiske Undersøgelse" (Grönländischer Geologischer Dienst) in den Scoresby Sund, NE-Grönland, teilzunehmen. Innerhalb von sechs Wochen kartierte ich ein Gebiet von ungefähr 1000 Quadratkilometern beidseitig des Daugaard-Jensen Gletschers in Charcot Land und im nordwestlichen Hinks Land. Das rechte Ufer des DaugaardJensen Gletschers wurde bereits im Jahre 1957 von Prof. E. WEn k erstmals kartiert. Im darauffolgenden Sommer untersuchte Dr. P. Vogt den südwestlichen Teil von Hinks Land (P. Vogt, 1965). Prof. Wenk und Dr. VoGT stellten mir in grosszügiger Weise ihre Feldkarten, Feldbücher, Probesammlungen und unpublizierten Rapporte zur Verfügung und teilten mir manche wertvolle Felderfahrung mit, wofür ich beiden an dieser Stelle sehr herzlich danken möchte. Das Studium dieses Materials und anregende Diskussionen mit Prof. Wenk gaben den Anstoss zu den vorliegenden Untersuchungen, deren Thema wie folgt formuliert wurde: "Beschreibung und Deutung der kaledonischen Metamorphose der Charcot Land Serie zwischen dem Krummedal und dem Nordvestfjord."

Der kurze Polarsommer, welcher nur sechs Wochen Feldarbeit erlaubt, und die Absicht die folgenden Laboruntersuchungen innerhalb einer nützlichen Frist abzuschliessen, bedingten eine sorgfältige Zielsetzung, welche sich in folgenden wichtigsten Punkten zusammenfassen lässt:

Erstellen einer geologischen Detailkarte im Massstab 1:50000 unter besonderer Berücksichtigung der Charcot Land Serie und ihrer Petrogenese. (Die Geologische Karte und eine Strukturkarte der untersuchten Region werden mit einer ausführlichen petrographischen Beschreibung in einer späteren Arbeit erscheinen).

Abklären, ob die Charcot Land Serie von einer oder mehreren Metamorphosen oder nur durch eine, aber plurifazielle Metamorphose überprägt wurde. 


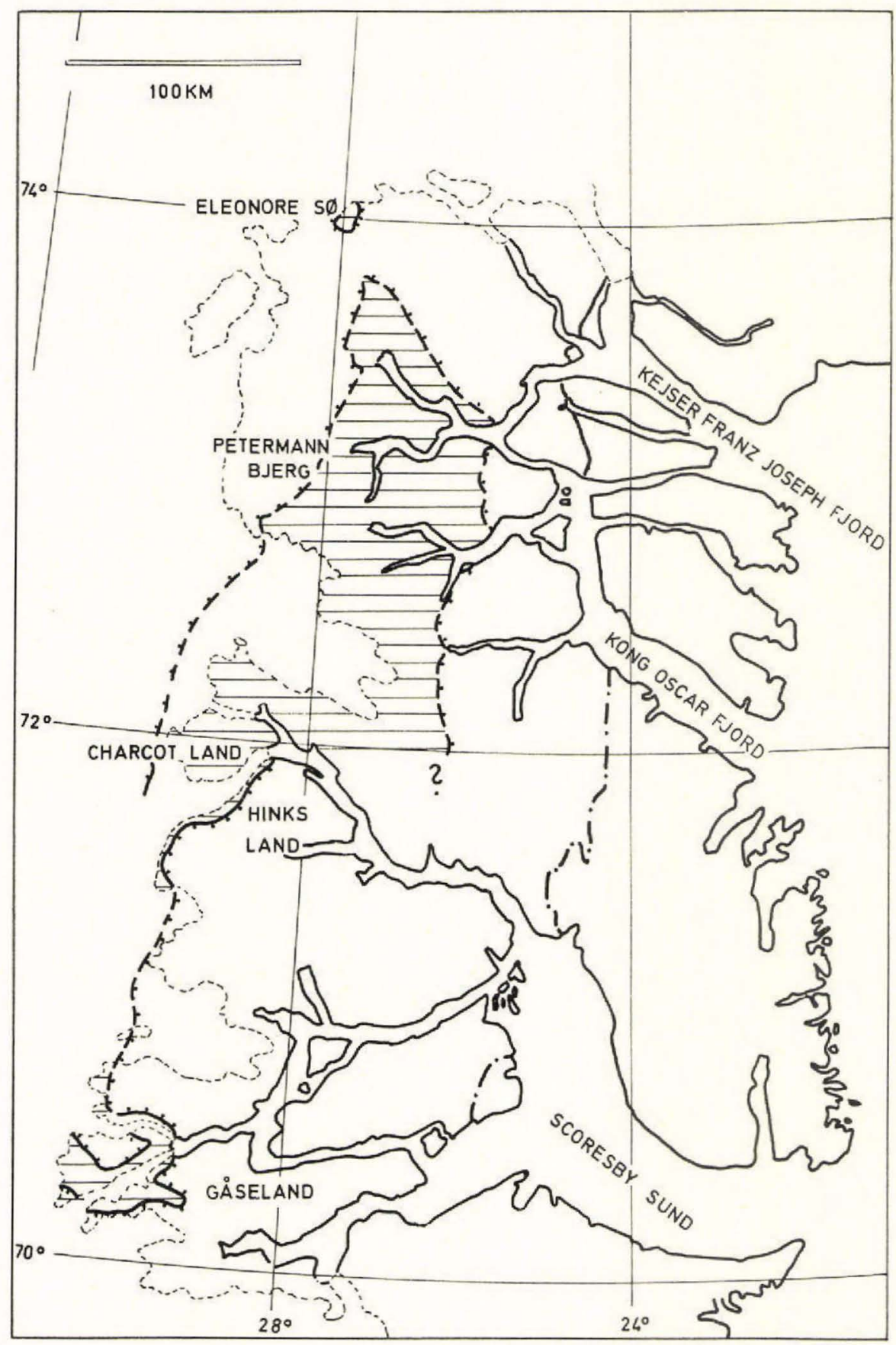

Fig. 1. 
Bestimmen der Isograde und Mineralparagenesenzonen in metamorphen kieseligen Dolomiten, in Grünschiefern und Amphiboliten und in Metapeliten der gleichen Serie.

Ableiten der möglichen Metamorphosereaktionen aus den Naturbeobachtungen.

Das bearbeitete Gebiet befindet sich an einer Schlüsselstelle des kaledonischen Gebirges. Charcot Land und Hinks Land liegen nämlich am westlichen Rande des heute durch die Erosion bis in den Unterbau freigelegten $\mathrm{N}$-streichenden kaledonischen Gebirgszuges, im Grenzbereich zwischen Oberbau und Unterbau, d.h. in einem Gebiet, wo die kaledonischen Metamorphite von der Amphibolit in die Grünschieferfazies übergehen. Hier verfolgte und erlebte ich an frischen, vom Gletscher blankpolierten Aufschlüssen, wie in einem Bilderbuch, die komplexe Entwicklungsgeschichte der Gesteine.

Fig. 1. Kartenskizze von Ost-Grönland zwischen $70^{\circ}$ und $74^{\circ}$ nördlicher Breite. Mit waagrechter Schraffur ist ein autochthoner Komplex hervorgehoben, zu welchem der Charcot Land Komplex, das Grundgebirgsfenster von Gåseland, die Grünschieferserie vom Eleonore Sø und ein grosser Teil des "Zentralen Metamorphen Komplexes" gehören. Diese ursprünglich nordwestlichste Einheit des kaledonischen Gebirges wurde im Verlaufe der Orogenese - und zwar zeitlich zur Hauptsache vor und während der kaledonischen Regionalmetamorphose - von einer Decke in nordwestlicher Richtung überfahren, welche aus einer Grundgebirgsplatte und ihren autochthonen Sedimenten besteht. Mit ausgezogener Linie sind Teile der Deckengrenze festgehalten, welche als solche von Wenk (1961b), P. Vogt (1965) Henriksen \& Higgins (1969) und von F. Keller und mir kartiert wurden. Gestrichelte Linien zeigen den von mir vermuteten weiteren Verlauf der Deckengrenze. Kriterien, welche für diese grosstektonische Unterteilung sprechen, sollen in den Erläuterungen zur geologischen Karte von Charcot Land und NW-Hinks Land diskutiert werden.

Als strich-punktierte Linie ist die Stauningsalpenrandverwerfung auf der Karte eingezeichnet.

Fig. 1. Sketch map of East Greenland between $70^{\circ}$ and $74^{\circ} \mathrm{N}$ lat. The horizontal ruling marks an autochthonous complex which contains the Charcot Land Complex, the Precambrian basement window of Gåseland, the greenschists of Eleonore Sø and a great part of the "Central Metamorphic Complex" of East Greenland. This original north-west unit of the Caledonian mountain chain has been overthrust, during orogenesis, by a nappe consisting of a basement sheet and its autochthonous sedimentary cover. The thrust partly predates, and is partly coeval with, the Caledonian regional metamorphism.

Continuous lines show the lower limit of the nappes, observed by Wenk (1961 b), P. Vogt (1965), Henriksen \& Higgins (1969), F. Keller and the author. Discontinuous lines indicate the presumed continuation of this limit. Criteria which support this tectonic subdivision will be discussed in the explanation to the geological map of Charcot Land and NW Hinks Land in a separate paper. Alternate dots and dashes indicate the Stauning Alper boundary fault. 


\section{ALLGEMEINE GEOLOGIE}

Die geologische Karte im Massstab 1:100000 von Charcot Land und NW-Hinks Land mit einer ausführlichen Beschreibung der Region wird in den Meddelelser om Grønland erscheinen.

In der kartierten Region lassen sich zwei Baueinheiten unterscheiden: In einem tektonischen Fenster ist der gewölbeförmige Charcot Land Komplex aufgeschlossen, welcher von der Hinks Land Decke überlagert wird. Die Hauptmasse des Charcot Land Komplexes besteht vorwiegend aus hellen Gneissen, in welchen Reliktstrukturen ein polymetamorphes Grundgebirge verraten. In flachen Mulden steht die metamorphe Charcot Land Serie an. Diese wird von jüngeren Metagabbros und Metagraniten durchsetzt. Schmale Kontaktaureolen begleiten die grösseren Gabbromassen. In Hinks Land folgt die Charcot Land Serie über $80 \mathrm{~km}$ dem Inlandeis und dem rechten Ufer des Daugaard-Jensen Gletschers. Wenk (1961 b) und P. Vogt (1965), welche im westlichen Hinks Land erste Feldaufnahmen durchführten, korrelieren die präexistierenden Sedimente der Charcot Land Serie mit dem Marmor-Grünschieferhorizont an der Basis der Eleonore Bay Group im $200 \mathrm{~km}$ südlich gelegenen Gåseland und der Petermann Bjerg Region auf $73^{\circ}$ nördlicher Breite.

Auf einem Nunatak am Rande des Inlandeises westlich von Charcot Land überlagert ein prächtiger epimetamorpher eokambrischer Tillit (oder Tilloid) einen Metagranit, dessen Apophysen Teile der Charcot Land Serie durchschlagen. Das polymetamorphe Grundgebirge, die Charcot Land Serie mit den verschiedenen Gabbros und Graniten sowie der Tillit erfuhren gemeinsam eine progressive metamorphe Ueberprägung während dếr. kaledonischen Orogenese. Interferierend mit der Hauptkristallisation wurden die Gesteine verschiefert und verfaltet. Ebenfalls synkristallin erfolgte die Ueberschiebung der Hinks Land Decke. Diese besteht analog wie der Charcot Land Komplex aus einer polymetamorphen Grundgebirgslamelle in der Basis, auf welcher wahrscheinlich in autochthoner Stellung die metamorphe Krummedal Serie liegt. Die Metamorphose der Krummedal Serie ist älter als die Ueberschiebung der Hinks Land Decke. 

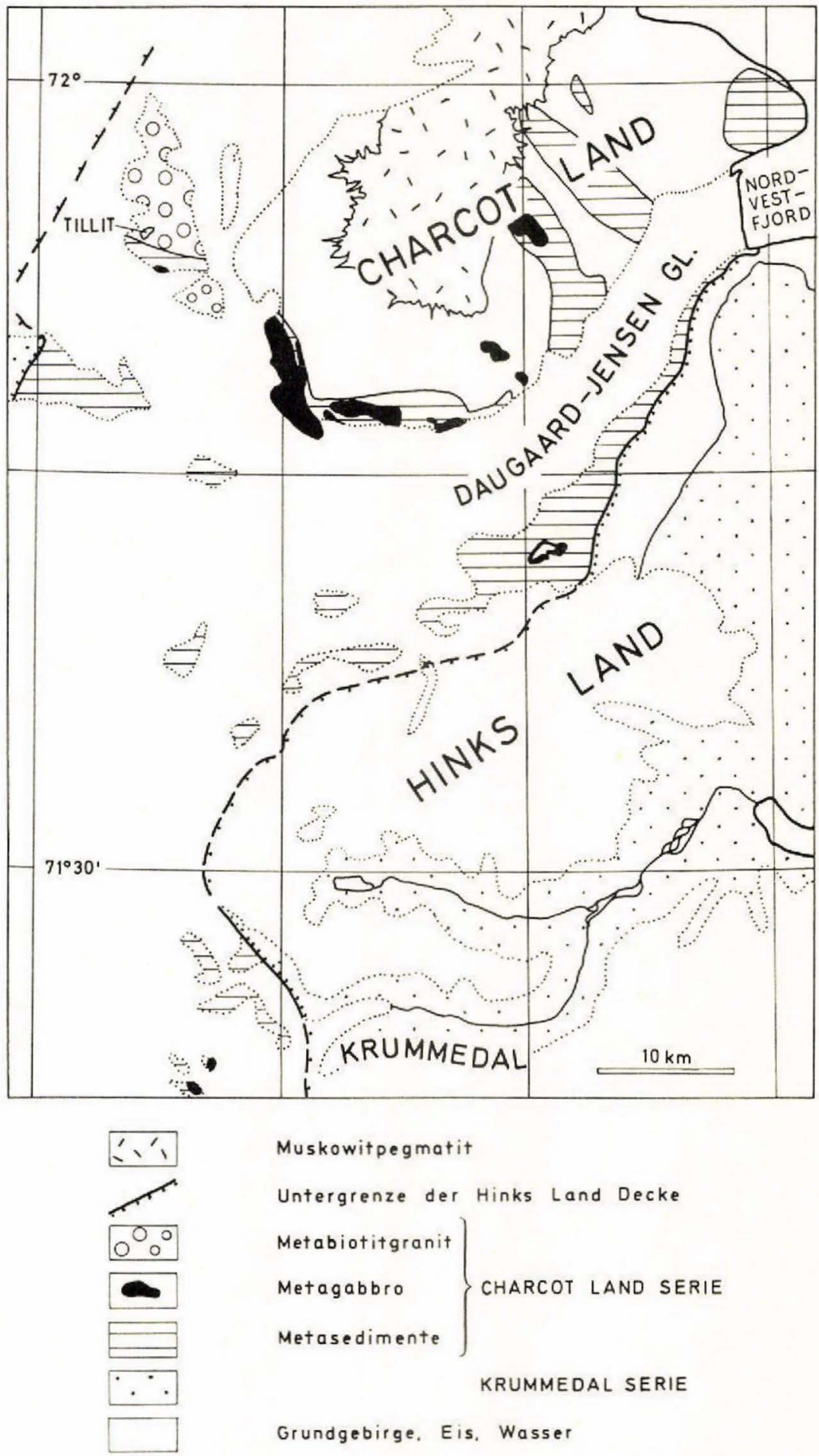

Muskowitpegmatit

Untergrenze der Hinks Land Decke

Metabiotitgranit

$\left.\begin{array}{l}\text { Metagabbro } \\ \text { Metasedimente }\end{array}\right\}$ CHARCOT LAND SERIE

KRUMMEDAL SERIE

Grundgebirge. Eis, Wasser

Fig. 2. Kartenskizze der untersuchten Region.

Fig. 2. Sketch map of the investigated region. 
Nach der Hauptkristallisation und nach der Deckenüberschiebung, aber spätkinematisch in Bezug auf die kaledonische Faltung, wölbte sich der Charcot Land Komplex um minimal $5000 \mathrm{~m}$ domförmig auf. Gleichzeitig fand die Platznahme einer Pegmatitmasse in Kern des Gewölbes statt.

Als jüngste Gesteine durchsetzen tertiäre Besaltgänge, als dekameter bis $50 \mathrm{~m}$ mächtige vertikale Platten in N-S-Richtung über Distanzen von vielen Zehnern, oft über hundert Kilometer das kaledonische Rumpfgebirge. Reste einer Basaltdecke überlagern heute noch weite Gebiete des südlichen Scoresby Sundes (Wenk, 1961 a).

Die präkambrisch abgelagerten Sedimente der Charcot Land Serie und die etwa gleichaltrigen und jüngeren basischen und sauren Magmatite und der eocambrische Tillit erfuhren - wenn wir von den schmalen Kontaktaureolen der basischen Intrusiva absehen - nur die eine regionalmetamorphe Umkristallisation während der kaledonischen Orogenese. Im Folgenden soll die allgemeine Petrographie dieser Metamorphite, an welchen wir die progressive Metamorphose in einem $80 \mathrm{~km}$ langen Profilstreifen von der Stilpnomelan - bis in die Disthenzone untersuchten, skizziert werden. 


\section{DIE CHARCOT LAND SERIE}

Wenk (1961 b) vergleicht und verbindet Profile der GrönlandiumSedimente der Petermann Bjerg Region, von Hinks Land, Gåseland und vom Alpefjord. Er erkennt eine auffallende Aehnlichkeit zwischen den drei ersten Profilen der Nunatak Region (Haller \& KulP, 1962). WeNK schreibt S. 35: "Along the western margin of the "Central Metamorphic Complex" of the Caledonian mountain chain the character of the late pre-Cambrian sediments, in fact varies very little in a N-S direction." In der Petermann Bjerg Region in Hinks Land und in Gåseland beginnt die präkambrische Serie mit einem einige hundert Meter mächtigen Horizont, welcher aus Grüngesteinen, Marmoren und Glimmerschiefern besteht. Nur in Gåseland fand WENK eine sehr gering mächtige "Basal Psephitic Series" an der Basis der "Marble-Chlorite-Phyllite Series". Die Grüngestein-Marmor Serie wie sie P. Vogt (1965) nennt, wird von mehr als tausend Metern Glimmerschiefern oder Phylliten und darüber einer mehrere tausend Meter mächtigen Abfolge von gebankten Quarziten, mit Dolomit- und Glimmerschieferhorizonten überlagert, welche meiner Ansicht nach wahrscheinlich nicht zur gleichen Serie gehört.

Die Grüngestein-Marmor Serie folgt in unserem engeren Untersuchungsgebiet als etwa $2000 \mathrm{~m}$ mächtiger Horizont an der Basis der Hinks Land Ueberschiebung dem westlichen Rand von Hinks Land vom Krummedal im Süden bis hinauf an den Nordvestfjord. In Charcot Land liegt sie in Mulden dem ebenfalls kaledonisch metamorphen kristallinen Grundgebirge auf. Sie stellt eine Folge von metamorphen marinen Sedimenten dar, welche von ebenfalls metamorphen Gabbrostöcken und -lagergängen und Intrusivgraniten mit ihren aplitischen Apophysen und Gängen durchsetzt wird. Die sehr heterogene Sediment- und Eruptivgesteinsassoziation bezeichnen wir nach dem Nunatak Charcot Land als Charcot Land Serie.

Während der kaledonischen Metamorhpose erfuhren die Gesteine der Charcot Land Serie im allgemeinen nur eine mässige Plättung und Streckung. Nur an der Basis der Hinks Land Decke wurden die Grünschiefer in einer etwa $1000 \mathrm{~m}$ mächtigen Zone zu Blastomyloniten mit einzelnen postkristallinen Ruschelzonen ausgewalzt. Die primäre Stoff- 
bänderung blieb nach der Ueberprägung durch die kaledonische Metamorphose praktisch unverändert erhalten. Zur Ausbildung einer deutlichen metamorphen Bänderung kam es nur an einzelnen Stellen im nördlichen Charcot Land, in der Disthenzone der Regionalmetamorphose.

Typisch für die Charcot Land Serie ist ein sehr auffälliger lateraler Wechsel in der Lithofazies. Im Norden besteht die Serie zu etwa gleichen Teilen aus Marmoren, Amphiboliten und Glimmerschiefern, während gegen Süden zu die Metapelite gegenüber den hier vorherrschenden Grüngesteinen zurücktreten. Im südlichen Teil von Charcot Land wird die Serie von zahlreichen Metagabbro- und einigen Metagranitintrusivstöcken durchsetzt. Die mineralogische Zusammensetzung der ehemaligen Pelite, Mergel, Quarzite, Calcit- und Dolomitmarmore und basischen Tuffe wechselt mit dem Grad der kaledonischen Regionalmetamorphose von Süden nach Norden. Manche Primärstrukturen blieben während und nach der Umkristallisation konserviert. Das Studium solcher Relikte erlaubte in vielen Fällen, die präexistierenden Gesteine genauer zu bestimmen.

\section{Die Marmore}

An den Steilufern des Daugaard-Jensen Gletschers leuchten die weissen Marmore der Charcot Land Serie auf viele Kilometer sichtbar aus dem sonst dunklen Paragesteinsverband hervor. Sie werden aus den Hauptkomponenten Quarz, Calcit und Dolomit bzw. ihren metamorphen Paragenesen aufgebaut. Beimengungen von Mineralien anderer Zusammensetzung sind - die metasomatisch beeinflussten schmalen Kontakthöfe der Metagabbrostöcke ausgenommen - selten. Mindestens zu 90\% sind die Marmore aus Kalkstein hervorgegangen; diesem sind in $\mathrm{dm}$ bis einigen m mächtigen konkordanten Horizonten kieselige Dolomite, bzw. ihre metamorphen Derivate zwischengelagert. Etwas dunkler gefärbte, glimmerführende Bänder zeigen gelegentlich die primäre Schichtung an. Lagen von Quarzknauern, welche zum sedimentären S parallel verlaufen, erscheinen besonders in den Dolomithorizonten angereichert. Die sekundär erzeugte Streckung der Knauern zeigt dagegen, parallel zur allgemein dominierenden b-Achse des Gefüges, in der Regel nach SE.

\section{Die Glimmerschiefer und Glimmerquarzite}

Die Glimmerschiefer und Glimmerquarzite bilden selbständige Horizonte, gehen aber auch oft fliessend ineinander über. Seltener sind Uebergänge zu den Grünschiefern. Der Mineralbestand variiert auch in diesen Gesteinen mit steigendem Metamorphosegrad. Im Meter- bis Decameterbereich wechselt die chemische Zusammensetzung oft sehr unregelmässig. 
So beobachten wir z.B. in der Zone der Amphibolite nebeneinander alle möglichen Uebergänge zwischen Glimmerschiefern, Granatglimmerschiefern, Hornblende-Granat-Glimmersehiefern und Glimmeramphiboliten. Die Glimmerquarzite und die später noch zu besprechenden Amphibolite bilden meist stofflich homogenere Zonen. In diesen Parametamorphiten zeichnen die Stoffbänderung und die seltenen Konglomerathorizonte die ursprüngliche Schichtung ab. Geopetale Gefüge, welche einen sichern Nachweis der primären Lagerung erlauben, sind selten.

\section{Die Grünschiefer und Amphibolite}

Die modale Zusammensetzung von fünfzig Grüngesteinsproben, geordnet nach steigendem Metamorphosegrad zeigt die Fig. 10. Fünf mineralogisch stark variierende Grünschiefer und Amphibolite und ein Metagabbro weisen einen sehr ähnlichen Chemismus auf (Tabelle 1). Alle Amphibolite mit Ausnahme einiger Metagabbros führen als Haupt- und Nebengemengteil Quarz.

Schöne und auffällige Reliktstrukturen ermöglichen vielfach eine genauere Bestimmung des prämetamorphen Gesteines. Der Nachweis eines konkordanten Pillowhorizontes in der Zone der Oligoklasamphibolite ist von besonderer Bedeutung. In der gleichen Zone in Charcot Land fanden wir zur Stoffbänderung konkordante Lagen von Quarzitgeröllen, welche in eine Hornblendematrix eingebettet sind. Häufig zeigen die Metabasite auch eine warvenartige Bänderung sedimentären Ursprungs. Solche Feinrhythmite beschrieb bereits P. VoG'T (1965) vom Eingang des Krummedals. VoGT hat schon die vulkanitische oder vorwiegend tuffogene Herkunft der Grünschiefer erkannt. Seine Sammlung von schwachmetamorphen Grünschiefern enthält sehr schöne Vulkanitreliktstrukturen (Tafel IIa in P. Vogt, 1965). Deutlich sind in einigen Grünschiefern präexistierende Hyaloklastitstrukturen abgebildet, wobei die Glassubstanz vollständig durch einen jungen Mineralbestand ersetzt ist.

Die Gabbrostöcke und -lagergänge und auch die Intrusivgranite, welche in unmittelbarer Nachbarschaft der basischen Eruptivgesteine intrudierten, stehen sicher in einem unmittelbaren genetischen Zusammenhang mit dem synsedimentären basischen Vulkanismus. Zusammenfassend lässt sich sagen, dass es sich bei den Grünschiefern und Amphiboliten um subaquatische, gemischt detritisch-vulkanische Ablagerungen handelt. Eine subaquatische Sedimentation muss schon deshalb angenommen werden, weil ja die Grüngesteine mit Marmoren wechsellagern. Wahrscheinlich unmittelbar nach der Ablagerung folgte die Intrusion der Gabbro- und Granitschmelzen. 
Ein Kuriosum sind prämetamorphe Quarz-Axinitgänge, welche in den Grünschiefern der innersten Teile des Krummedal-gebietes auftreten (P. VoGt, 1965). Die Bestimmung des Borminerals wurde von uns röntgenographisch bestätigt. Während der kaledonischen Metamorphose wurde der Axinit teilweise durch Aktinolith verdrängt. Wohin bei dieser Reaktion das Bor gewandert ist, konnten wir nicht feststellen. Turmalin - eine häufige metamorphe Neubildung in Metapeliten - fehlt praktisch in allen Grüngesteinen.

\section{Die Metagabbros}

Die Metagabbros formen regelmässig begrenzte Stöcke und Lagergänge mit scharfen Kontakten, welche bevorzugt parallel zur sedimentären Schichtung verlaufen. An den Kontakten mit den Marmoren erzeugten die als heisse Massen intrudierten Gabbros vielerorts Kalksilikatfelse mit Wollastonit, Klinopyroxen, Vesuvian, Grossular, Epidot und Tremolit und Magnetitskarn. Die Kontakthöfe sind in der Regel nur einige Centimeter bis einige Meter und nur an wenigen Stellen über $100 \mathrm{~m}$ breit. Die präexistierende gross- und richtungsloskörnige Textur der Gabbros blieb während der kaledonischen Umkristallisation erhalten, indem der primäre braune Amphibol durch jungen Aktinolith oder blaugrüne, bzw. grüne Hornblende, die Pyroxene durch Amphibol und die basischen Plagioklase durch Oligoklas oder Albit mit Epidotneubildungen pseudomorph verdrängt wurden. Diese normale grobkörnige Fazies geht an den Kontakten fliessend in eine bis einige Meter breite, mittelbis feinkörnige Randfazies über. Innerhalb der Gabbrostöcke beobachtet man helle, feldspatreiche Varietäten und dunkle, manchmal nahezu ultrabasische Hornblendegesteine, welche allmählich ineinander übergehen. Die Fig. 10 enthält die Modalbestände von elf Metagabbroproben. Die beiden schwachmetamorphen Proben 103392 und 103396 von den Nunatakkern am Eingang des Krummedals führen reichlich primären Klinopyroxen, welcher nur randlich in Aktinolith umgewandelt wurde. Der Gehalt an Epidot-Klinozoisit-Einschlüssen der Plagioklase wechselt sehr stark von Probe zu Probe. Bei den präexistierenden basischen Intrusivgesteinen handelte es sich demnach um Gabbros und (oder) Diorite.

\section{Die Metagranite im westlichen Charcot Land}

Die Hauptmasse des Tillitnunataks besteht aus einem Metaaplitstock im Süden und einem grobkörnigen Metagranit mit roten Kalifeldspäten und grünen Plagioklasen im Norden, welcher mit Apophysen Teile der Charcot Land Serie durchschlägt. Die Struktur des Granites ist in der Regel homogen grobkörnig bis porphyrisch, wobei die grössten Körner 
bis $2 \mathrm{~cm}$ Durchmesser erreichen. An manchen Stellen beobachtet man auch eine schlierige Paralleltextur von hellen, feldspatreichen und dunklen Biotit- bzw. Chlorit-reichen Bändern. Der Metaaplit, welcher den Kegelförmigen südlichsten Nunatakgipfel Pkt. 1840 aufbaut, zeigt eine typische pan- bis hypidomorphe Ganggesteinsstruktur. In einer Metabiotitgranit- und einer Metabiotitaplitprobe bestimmten wir mit dem Punktzähler folgende Mineralbestände:

Probe 102829

Metabiotitgranodiorit

Quarz...........................

Mikroklin..........

Plagioklas ..........

Biotit + Chlorit .....

Hellglimmer ........

Epidot + Accessorien
Probe 102818

Metabiotitaplit

$29,5 \mathrm{Vol} \% \quad$ Quarz $\ldots \ldots \ldots \ldots . .27 \quad \mathrm{Vol} \%$

$13 \quad$ Mikroklin ........ 39

49,5 Plagioklas........ 21

$5,5 \quad$ Biotit + Chlorit.... 7

1,5 Epidot......... 5,5

$1,0 \quad$ Titanit + Accessorien $\quad 0,5$

100,0

Als Accessorien führen beide Gesteine Titanit, Zirkon, Apatit und Magnetit. Der Epidot im Metabiotitaplit ist ein eisenreicher Pistazit bis Orthit, welcher mit wenig Sericit als Umwandlungsprodukt in den saussuritisierten Plagioklasen auftritt. Der primäre rotbraune Biotit ist teilweise durch Chlorit und feinschuppigen grünen Biotit, Titanit und Magtit verdrängt worden.

Im gegenüberliegenden Charcot Land treten ähnliche aber bereits stärker vergneisste Metabiotitgranite auf. Die Ueberprägung durch die kaledonische Metamorphose nimmt eindeutig gegen Osten zu. Die rote und grüne Färbung der primären Feldspäte verschwindet in der Zone der Oligoklas-Amphibolite endgültig. Die Grenze zwischen den monometamorphen Biotitgraniten und den Gneissen des Grundgebirges konnte in den wenigen Feldtagen nicht genau auf der Karte festgelegt werden. Möglicherweise gehören noch grössere Teile der leukokraten Charcot Land Gneise zu diesen Metagraniten. Ein Indiz hierfür sind präkaledonisch intrudierte, jetzt metamorphe Aplite, welche im Gebiet der Pillowlaven westlich See Pkt. 670 und in der Ostwand des Gipfel, Pkt. $1280 \mathrm{~m}$ die hellen Gneise und die überlagernden präkambrischen Sedimente der Charcot Land Serie durchschlagen. Einige Aplite durchsetzen auch die Metagabbrostöcke im westlichen Charcot Land. Wir vermuten auf Grund ihrer stratigraphischen Stellung, dass die lokal angehäuften und nur mit geringem Zeitintervall geförderten basischen und sauren Extrusiv- und Intrusivgesteine dem gleichen magmatischen Zyklus angehören. 


\section{EIN TILLIT ODER TILLOID WAHRSCHEINLICH EOCAMBRISCHEN ALTERS}

Auf einem Nunatak westlich von Charcot Land bei Pkt. 2060 überlagert ein schön ausgebildeter mächtiger Tillit oder Tilloid den Granit mit den roten und grünen Feldspäten, welcher mit Apophysen Teile der Charcot Land Serie durchschlägt. Die primäre Auflagerungsfläche, welche flach nach NW einfällt, ist an einzelnen vertikalen kaledonischen Scherflächen verstellt. Besonders in den südlichen Teilen des Sedimentvorkommens ist der Tillit parallel zu diesen Scherflächen verschiefert und in Richtung einer steilen Mikrofältelung gestreckt. Die Korngrösse der Tillitkomponenten variiert zwischen Bruchteilen eines Millimeters und 4 Metern. In der Regel ist das grobe Material mit Körnern grösser $1 \mathrm{~mm}$ in einer sehr feinen, schwarzgrauen tonigen Matrix, mit feinrhythmischer Bänderung, wie sie für Glazialtone typisch ist, eingebettet.

Nach dem mikroskopischen Befund besteht die Matrix aus einem Detritus von granitischer Zusammensetzung. Das ursprünglich feinste Material ist stets rekristallisiert. Ein Karbonatzement, wie man ihn häufig in Tilloiden, d.h. Wildflyschen, antrifft, fehlt.

Schätzungsweise $80 \%$ der Tillitgerölle bestehen aus Metagraniten und Gneissen. Häufig fanden wir den Granit mit den roten und grünen Feldspäten, welcher im Liegenden des Tillites ansteht. Die restlichen $20 \%$ der Gerölle sind feinkörnige Tonschiefer, Marmore basische Vulkanite und Grünschiefer, wie sie in der Charcot Land Serie verbreitet sind. Es besteht einzig ein Unterschied im Volumenverhältnis von Grüngesteinen und Tonschiefern, indem in der benachbarten Charcot Land Serie die metamorphen Tuffe und Gabbros vorherrschen, während im Tillit Tonschiefer häufiger sind. In den Geröllen und der Matrix fanden wir die gleichen kaledonischen epizonalen Neukristallisate von Albit, Hellglimmer, Chlorit, Stilpnomelan und Epidot-Klinozoisit, wie in den Metagraniten im Liegenden und den benachbarten basischen und pelitischen Metamorphiten der Charcot Land Serie.

Eine zeitliche Korrelation unseres Tillites mit der Tillit Group, welche nach Haller \& KulP (1962) ins oberste Präkambrium gestellt, nach Katz (1961) zum Eocambrium gerechnet wird, drängt sich auf. Das Sedi- 
ment ist nämlich einerseits jünger als der Granit des "Tillitnunataks», welcher mit Apophysen Teile der wahrscheinlich präkambrischen Charcot Land Serie durchschlägt; andererseits wurden die Gerölle, Blöcke und die Matrix des Sedimentes einheitlich von der jüngeren kaledonischen Regionalmetamorphose überprägt. Ausserdem fehlen im Tillit Gerölle der in Chareot Land häufigen spätkaledonischen Turmalin-Muskowit-Pegmatite, während er die meisten Gesteinstypen der "Kerngneise" und der Charcot Land Serie als Komponenten führt. Damit ist auch eine zeitliche Verbindung mit einem sicher älteren, von WeNk $(1961$ b) in Gåseland in der Basis der wahrscheinlich präkambrischen Grüngestein-Marmorserie entdeckten Tillit ausgeschlossen. 


\section{METAMORPHOSE BASISCHER TUFFE UND GABBROS}

Die Gesteine der Charcot Land Serie bestehen zu ungefähr 60 Volumenprozent aus basischen Metamorphiten. Die Analysen von 6 Proben aus der Zone der Grünschiefer und der Zone der Amphibolite, welche sich durch verschiedene Mineralbestände unterscheiden, ergaben einheitlich basaltische Chemismen, die allerdings extrem zwischen denjenigen von ozeanischen Tholeiitbasalten und ozeanischen Alkalibasalten (nach ENGEL et al., 1965) variieren, wobei extreme Unterschiede zwischen den $\mathrm{Na}_{2} \mathrm{O} /$ $\mathrm{K}_{2} \mathrm{O}$-Werten bestehen (Tabelle 1 ). In den vom Gletscher blank polierten Aufschlüssen verraten gut konservierte Reliktstrukturen die Ursprungsgesteine: Tuffe mit Sandstein- und Konglomeratbänken, Pillowlaven und massige, weitgehend richtungslos körnige Gabbros als Stöcke und Lagergänge. Unter dem Mikroskop erweist sich der Mineralbestand als monometamorph, wenn man von den zweifach überprägten, schmalen Kontaktaureolen der Metagabbros absieht. Bereits P. VoGT und Wen K (mündliche Mitteilung) haben im Felde eine von Süden gegen Norden zunehmende Metamorphose erkannt und mich zu der vorliegenden Untersuchung angeregt. Der Anstieg des Metamorphosegrades offenbart sich dem Feldgeologen am auffälligen Wechsel der Gesteinsbeschaffenheit beim Hornblende-Isograd. Die am Eingang des Krummedales und in den Nunatakkern verbreiteten dichten, feinkörnigen Aktinolith-Chloritfelse werden mit dem ersten Auftreten von Hornblende am Daugaard-Jensen Gletscher durch "saubere chloritarme oder -freie, grobkörnigere Amphibolite abgelöst (Fig. 3). Nach der Gesteinsbeschaffenheit nennen wir im folgenden den niedriger metamorphen Bereich Zone der Grünschiefer. Diese Zone ist sehr ähnlich der "Aktinolith-Grüngesteins-Fazies", wie sie TH. VoGT (1927) vom Sulitelmadistrikt in Norwegen beschreibt. Das nördlich anschliessende Verbreitungsgebiet der Albit-, Oligoklas- und AndesinAmphibolite wird als Zone der Amphibolite bezeichnet. Die Zonen dürfen nicht mit den Faziestypen von Esк оLA (1920) verwechselt werden. An der Zonengrenze vollzieht sich, wie wir noch zeigen werden, ein bedeutender Wechsel in den Mineralparagenesen sowohl der basischen als auch der pelitischen Metamorphite. 
Tabelle 1. RF Analysen von basischen Metamorphiten der Charcot Land Serie

\begin{tabular}{|c|c|c|c|c|c|c|}
\hline & $\begin{array}{c}1 \\
103389\end{array}$ & $\begin{array}{c}2 \\
103777\end{array}$ & $\begin{array}{c}3 \\
\text { NW } 193\end{array}$ & $\begin{array}{c}4 \\
\text { NW } 198\end{array}$ & $\begin{array}{c}5 \\
102802\end{array}$ & $\begin{array}{c}6 \\
117309\end{array}$ \\
\hline $\mathrm{SiO}_{2}$. & 49,3 & 46,0 & 45,4 & 51,7 & 43,9 & 48,9 \\
\hline $\mathrm{Al}_{2} \mathrm{O}_{3}$. & 13,4 & 16,1 & 14,9 & 14,6 & 16,2 & 14,4 \\
\hline $\mathrm{Fe}_{2} \mathrm{O}_{3} \ldots \ldots$ & 1,1 & 2,4 & 2,8 & 2,5 & 1,9 & 2,5 \\
\hline $\mathrm{FeO} \ldots \ldots \ldots$ & 12,6 & 8,2 & 10,8 & 6,0 & 12,3 & 11,6 \\
\hline$\ldots \ldots$ & 0,2 & 0,1 & 0,2 & 0,1 & 0,1 & 0,1 \\
\hline$\ldots \ldots$ & 7,2 & 9,2 & 9,2 & 8,6 & 10,0 & 7,9 \\
\hline $\mathrm{CaO} \ldots \ldots \ldots$ & 7,6 & 8,6 & 8,7 & 9,4 & 5,8 & 7,7 \\
\hline $\mathrm{Na}_{2} \mathrm{O}$. & 3,5 & 1,8 & 3,3 & 2,6 & 3,2 & 3,6 \\
\hline $\mathrm{K}_{2} \mathrm{O} \ldots \ldots$ & 0,7 & 2,6 & 0,3 & 0,5 & 1,9 & 0,1 \\
\hline $\mathrm{TiO}_{2} \ldots \ldots \ldots$ & 1,9 & 0,9 & 1,5 & 0,6 & 1,5 & 1,2 \\
\hline $\mathrm{P}_{2} \mathrm{O}_{\overline{\mathbf{a}}} \ldots \ldots \ldots$ & 0,2 & 0,1 &, 2 & 0,1 & 0,2 & 0,2 \\
\hline \multirow[t]{2}{*}{$\mathrm{H}_{2} \mathrm{O} \ldots \ldots \ldots$} & 2,9 & 3,5 & 3,0 & 2,8 & 2,7 & 1,8 \\
\hline & 100,6 & 99,5 & 100,3 & 99,3 & 99,7 & 100,0 \\
\hline $\mathrm{CaO} / \mathrm{Na}_{2} \mathrm{O}$. & 2 & 4,8 & 2,6 & 3,6 & 1,8 & 2,1 \\
\hline $\mathrm{Fe}_{2} \mathrm{O}_{3} / \mathrm{FeO} \ldots$ & 0,87 & 0,29 & 0,26 & 0,42 & 0,15 & 0,22 \\
\hline $\mathrm{Na}_{2} \mathrm{O} / \mathrm{K}_{2} \mathrm{O} \quad \ldots$ & 5 & 0,7 & 11 & 5,2 & 1,7 & 36 \\
\hline
\end{tabular}

Philips-Einkanalvacuumspectrometer: Ag- und Cr-Strahlung;

Analysatorkristalle KAP, LIF, PE und ADP; $2 \mu$-Fenster, DF Zähler,

Vacuum besser 0,2 torr; $\mathrm{Na}_{2} \mathrm{O}$-Gehalte spektrographisch bestimmt.

Eichung mit internationalen Gesteinsstandards.

Analytiker: W. B. STERN

103389 Grünschiefer (metamorpher Tuff), HG (= Hauptgemengteile): Quarz, Albit, Aktinolith, Chlorit, Stilpnomelan, Pistazit; Acc (=Accessorien): Titanit.

103777 Metamorpher Gabbro, HG: Albit, Aktinolith, Pistazit, Chlorit; Acc: Mikrolin, Muskowit, Titanit, Erz.

NW 193 Grünschiefer (metamorpher Tuff), HG: Quarz, Albit, grüner Aktinolith, Pistazit, Stilpnomelan, Titanit; Acc: Chlorit.

NW 198 Grünschiefer (metamorpher Tuff), HG: Quarz, Albit, Aktinolith, Chlorit, Pistazit; Acc: Muskowit.

102802 Amphibolit (metamorpher Tuff), HG: Quarz, Oligoklas, Aktinolith, grüne Hornblende, brauner Biotit, Erz; Acc. Apatit.

117309 Amphibolit (metamorpher Tuff?), HG: Quarz, Albit, Oligoklas, blaugrüne Hornblende.

Erläuterung zu den Probenummern: Die 6-stelligen Zahlen bezeichnen Proben aus der Sammlung des "Gronlands Geologiske Undersøgelse», Kopenhagen. Diese Sammlung wird in Kopenhagen aufbewahrt. Die Nummern mit vorangestelltem NW beziehen sich auf Handstücke der Sammlung von Prof. Dr. E. Wenk und die mit Vo G gekennzeichneten Nummern auf Proben der Sammlung von Dr. P. Vogt. Beide Sammlungen sind im Mineralogischen Institut der Universität Basel deponiert. 

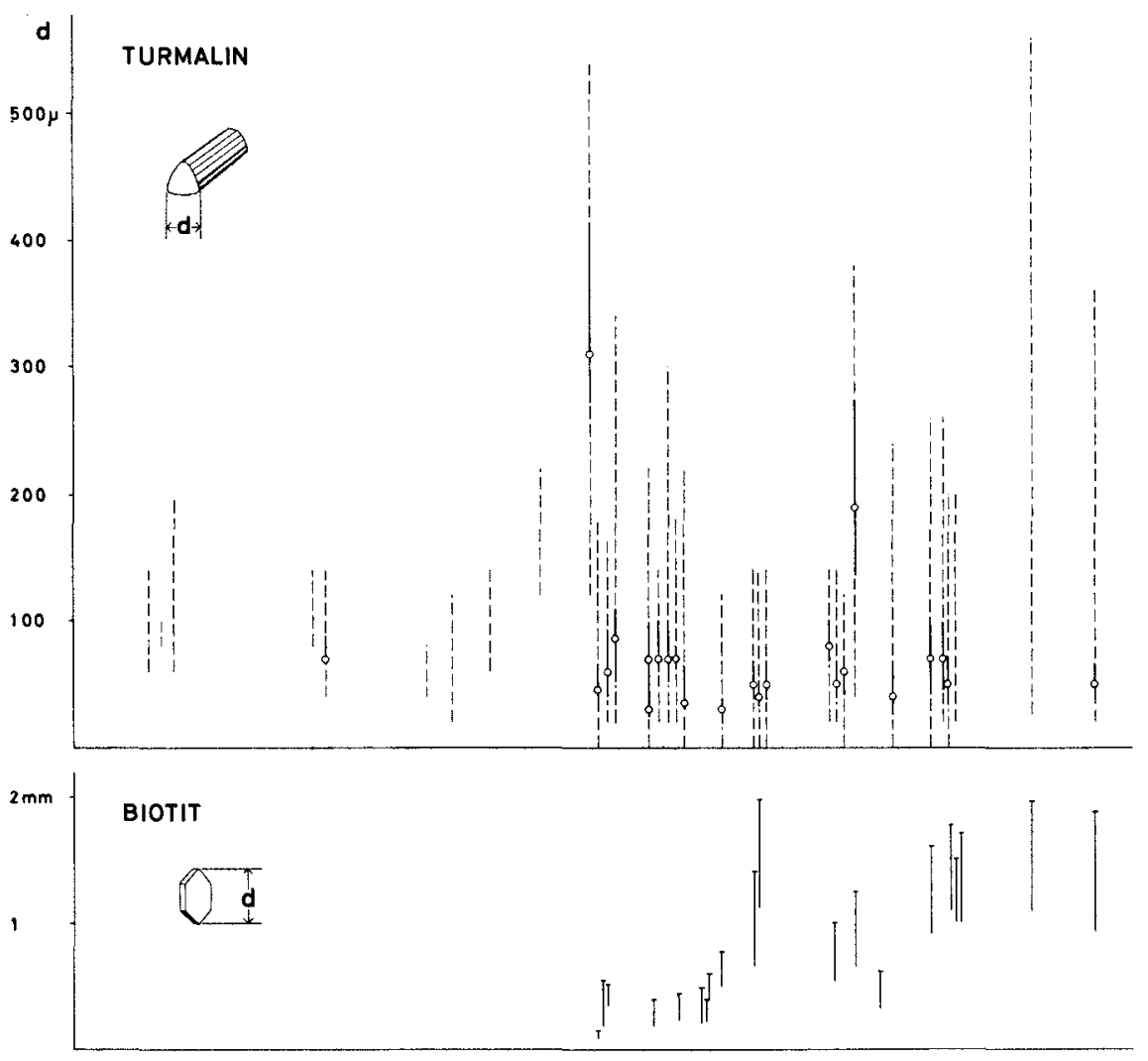

$2 \mathrm{~mm}$

\section{CHLORIT}
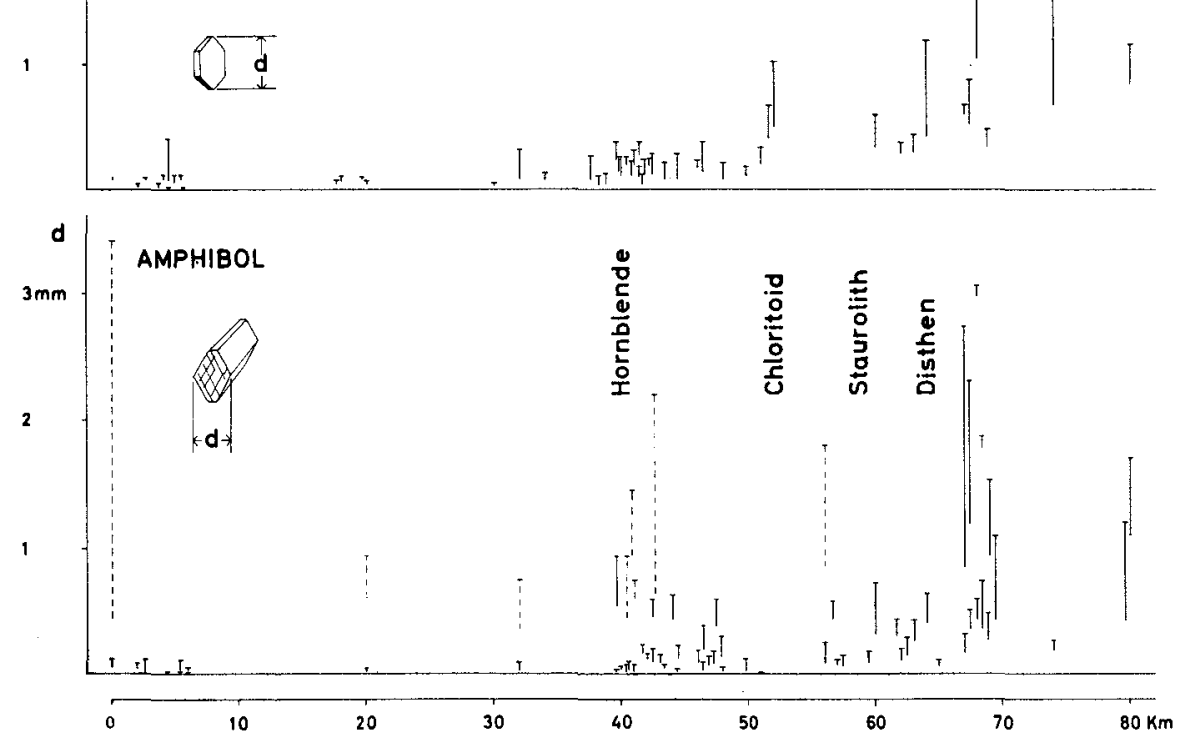

Fig. 3. 
Wir bestimmten an über 60 Gesteinsproben, welche lückenlos die basischen Metamorphite von der Stilpnomelanzone bis in die Disthenzone belegen, die Mineralparagenesen in Dünnschliffen und röntgenoptisch und ergänzten die Untersuchungen durch chemische Analysen.

\section{Die Zone der Grünschiefer}

Die Metabasite dieser Zone sind sehr feinkörnige, graugrüne, schiefrig bis hornfelsartig splitterig, brechende und in letzterem Falle sehr zähe Gesteine. Die mikroskopisch und mit Röntgenpulveraufnahmen identifizierten Mineralbestände sind auf der Fig. 10 zusammengestellt. Die Bestimmung der Modelbestände ist bei den feinkörnigen metamorphen Tuffen ungenau. Das Volumenverhältnis zwischen Albit und Quarz konnte nicht ermittelt werden. Es wurden folgende Mineralgruppen beobachtet:

Fig. 3. Korngössenvariation in der metamorphen Charcot Land Serie. Turmalin: Der Turmalin tritt als häufiger Nebengemengteil in Glimmerschiefern auf. Der Turmalingehalt der Gesteine nimmt beim Biotit-Isograd sprunghaft zu. Das Mineral bildet hier häufig Porphyroblasten. Der Prismendurchmesser von 40-80 Körner pro Schliff wurde bestimmt und die Daten jeweils in einem Histogramm ausgewertet. $0=$ Schwerpunkt der Durchmesser, ausgezogene Linie $=50 \%$ Streuung, gestrichelte Linie $=$ $100 \%$ Streuung. Die Korndurchmesser der Mehrzahl der Turmaline in den verschiedenen Epi- bis Mesometamorphiten sind gleich.

Biotit: Die 10 grössten Korndurchmesser von Biotit wurden in jedem Dünnschliff bestimmt. Die Körner werden mit zunehmendem Metamorphosegrad grösser. Chlorit: Eine ähnliche Korngrössenverteilung zeigen die Chlorite. Die meisten grossen Chlorite sind pseudomorph nach Biotit kristallisiert. Die Korngrössenverteilung ist also nur zu einem Teil direkt vom Metamorphosegrad abhängig. Die Messungen erfolgten analog wie beim Biotit.

Amphibol: Eine deutliche Zunahme der Korngrösse von links nach rechts zeigen die Amphibole (Aktinolith und Hornblende) (ausgezogene Linien). Nur die pseudomorph nach präexistierenden Hornblenden gewachsenen Amphibole (gestrichelte Linien) in Metagabbros sind auch im niedrig temperierten Bereich viel grösser als die Aktinolithe der Grünschiefer.

Fig. 3. Variation of mineral size in the progressive metamorphic Charcot Land supracrustal sequence.

"Turmalin": Tourmaline is a common accessory mineral in the mica schists. The content of tourmaline increases markedly at the biotite isograd and then this mineral frequently forms porphyroblasts. In each thin section the diameter of 40 to 80 grains has been measured. The open circles indicate the most frequent size, the unbroken line the variation of $50 \%$, and the dashed line the spread of all measurements in each thin section.

"Biotit", "Chlorit" and "Amphibol": On the three diagrams concerning biotite, chlorite and amphibole, the variation in size of the ten largest crystals seen in each thin section is represented by a straight line. An increase of grain size with grade of metamorphism from left to right is obvious. The stippled lines in the "Amphibol" diagram show the grain-size variation of actinolite or hornblende which have grown as pseudomorphs after pre-existing hornblendes in Precambrian hornblende gabbros. 
1) Quarz-Muskowit-Chlorit-Erz

2) Quarz-Albit-Muskowit-Chlorit

3) Quarz-Albit-Muskowit-Chlorit-Calcit

4) Quarz-Chlorit-Titanit-Turmalin-Erz

5) Quarz-Albit-Chlorit-Stilpnomelan-Calcit

6) Quarz-Albit-Chlorit-Stilpnomelan-Aktinolith-Epidot-CalcitTitanit-Erz

7) Quarz-Albit-Chlorit-Aktinolith-Epidot

8) Albit-Chlorit-Stilpnomelan-Aktinolith-Epidot-Calcit

9) Albit-Chlorit-Stilpnomelan-Calcit

10) Albit-Mikrolin-Muskowit-Aktinolith-Epidot-Titanit-Erz

11) Albit-Chlorit-Aktinolith-Epidot-Titanit

12) Muskowit-Chlorit-Calcit

Diese Mineralbestände stellen wahrscheinlich keine reinen Paragenesen der kaledonischen Metamorphose dar. Der Stilpnomelan kristallisierte sicher unter den P-T-Bedingungen der kaledonischen Regionalmetamorphose; andere Mineralien wie z.b. Quarz, Albit, Chlorit, Muskowit, Aktinolith und Epidot können sowohl präexistierenden, als auch kaledonisch metamorphen Paragenesen angehören. Nur Quarz, Albit und selten auch Calcit bilden gelegentlich polygonale Mosaikgefüge. Hier und da formt der Calcit auch idiomorphe Porphyroblasten. Oft zeichnet die junge Mineralgeneration prämetamorphe Strukturen nach. Albitleisten bilden in einigen metamorphen Tuffen die präexistierende ophitische Textur ab. Pseudomorphosen von Aktinolith nach brauner Hornblende oder Pyroxen (Uralitisierung) sind verbreitet, wobei Flecken von brauner Hornblende und Pyroxen als gepanzerte Relikte (Eskola in Barth et al., 1939) konserviert wurden. Eine Textfigur, die Wiseman (1934, Fig. 4a) von einem »Epidiorit« aus dem Schottischen Hochland zeigt, könnte ebensogut nach einem Dünnschliff eines Metagabbros der Charcot Land Serie (Proben 103392 oder 103396) gezeichnet sein. Das Bild stellt einen Chlorit-Biotit-Augit-Epidot-Amphibolit dar, in welchem die Augite im Kern von blassgrüner Hornblende ( = Aktinolith) auftreten. Einzig der Biotit jener Gesteine fehlt in den Metabasiten der Charcot Land Serie. Auch nach der kaledonischen Kristallisation heben sich die Metagabbros durch ihre grobkörnige Struktur von den dichten Meta-Tuffen ab. Die Hornblenden wurden unter weitgehender Beibehaltung ihrer Kornform (pseudomorph) in Aktinolith umgewandelt.

Die retrograde Metamorphose erfolgte wahrscheinlich sowohl allometamorph, während der jungen kaledonischen Kristallisation, als auch während einer präkambrischen Autometamorphose.

Grösstenteils kristallisierten die Grünschiefer bestimmt auch aus 


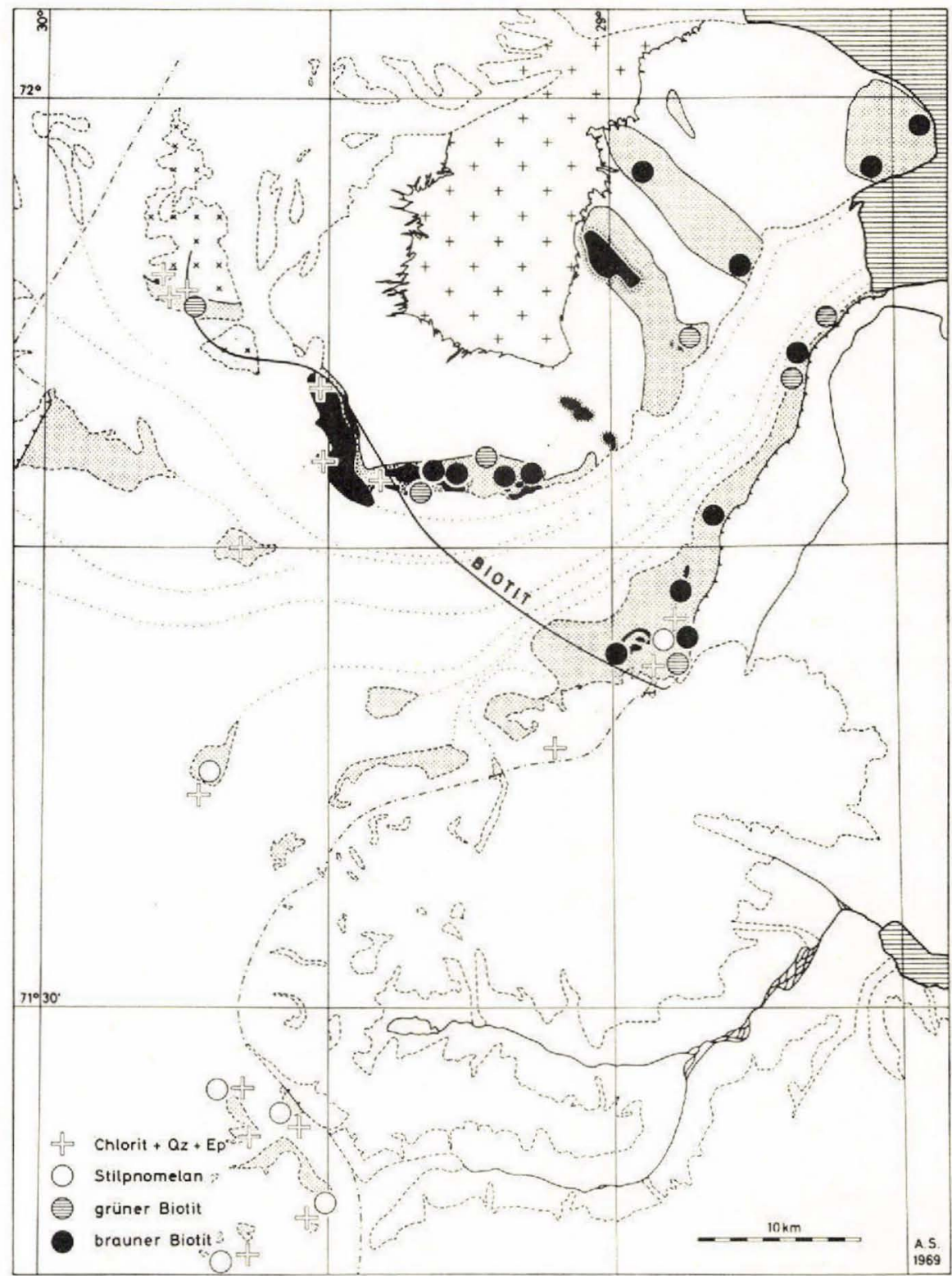

Fig. 4. Verteilung von Stilpnomelan, grünem Biotit, braunem Biotit und der Paragenese Chlorit-Quarz-Epidot in metamorphen basischen Tuffen und Gabbros.

Fig. 4. Distribution of stilpnomelane, green biotite, brown biotite and the chloritequartz-epidote-paragenesis in the metamorphosed gabbros and basic tuffs.

niedriger temperierten Mineralgesellschaften der Tuffe und Laven, z.T. wahrscheinlich auch direkt aus vulkanischem Glas, z.B. der Hyaloklastite und der Pillowlaven. 


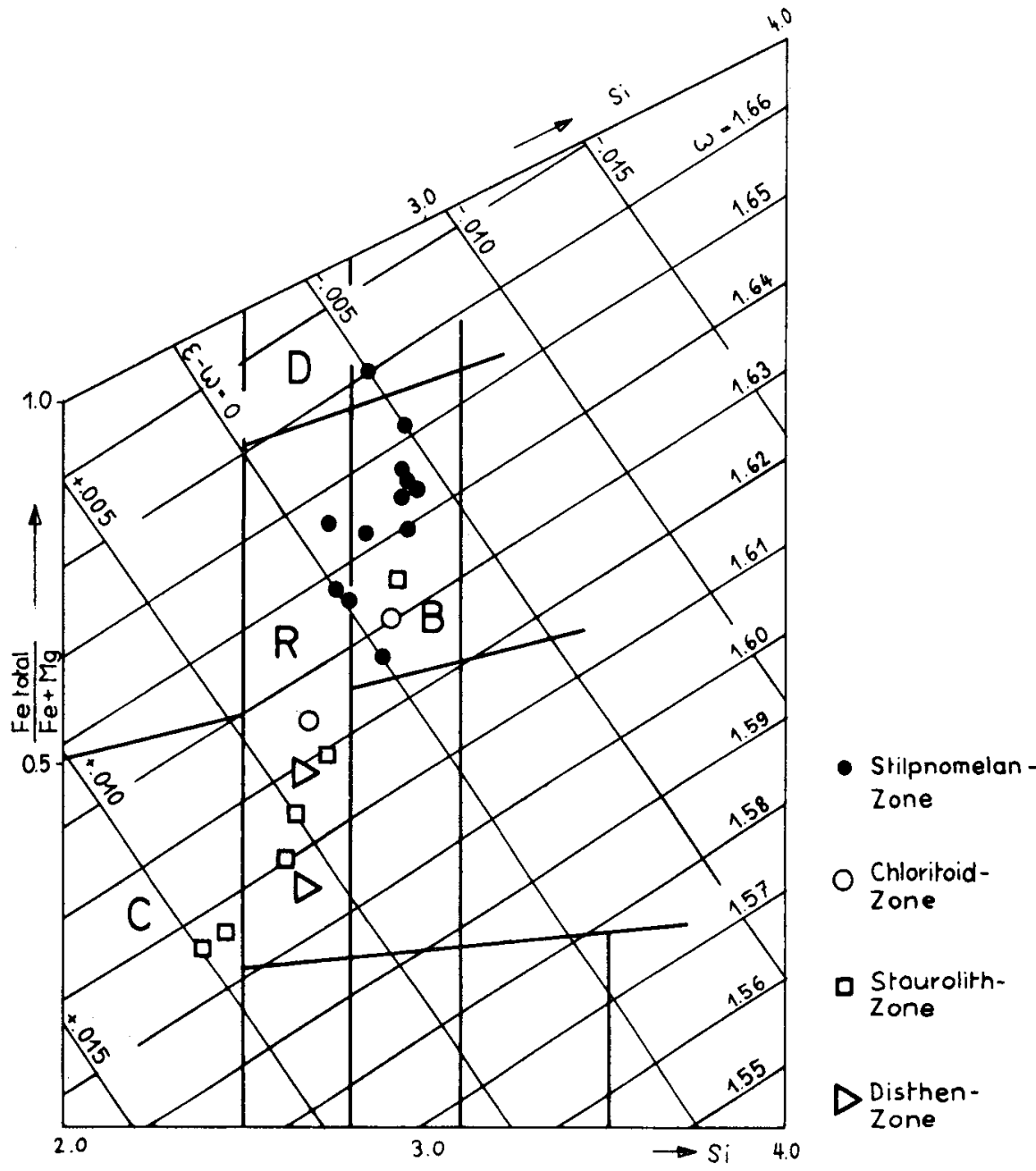

Fig. 5. Lichtbrechung n $\omega$ und Doppelbrechung $n \varepsilon-n \omega$ von Chloriten im Diagramm von Hey (1954) dargestellt. Mit zunehmendem Metamorphosegrad nimmt die Lichtbrechung ab und die Doppelbrechung zu, dies entspricht einer Zunahme des Magnesiumgehaltes und einer Abnahme des Eisen- und Siliziumgehaltes. $(\mathrm{C}=$ Corundophyllit, $\mathrm{R}=$ Ripidolit, $\mathrm{B}=$ Brunsvigit und $\mathrm{D}=$ Daphnit).

Fig.. 5. Refractive index $n \omega$ and double refraction $n \varepsilon-n \omega$ of chlorites (diagram after HEY, 1954). The refractive index decreases and the double refraction increases with grade of metamorphism. This corresponds to an increase of magnesium- and aluminium-content of the chlorites with grade of metamorphism. $(\mathrm{C}=$ corundophyllite, $\mathrm{R}=$ ripidolite, $\mathrm{B}=$ brunsvigite and $\mathrm{D}=$ daphnite).

\section{Mineralbeschreibung}

Der Plagioklas ist in allen Gesteinen der Zone, auch in Calcitparagenesen, ein reiner Albit.

Die Chlorite gehören nach dem Nomenklaturvorsehlag von HEY (1954) zur Gruppe der Brunsvigite und eisenreichen Ripidolite, d.h. es 
Tabelle 2. Lichtbrechung $\mathrm{n} \gamma$ und Doppelbrechung $\Delta$ von Chloriten der progressio metamorphen Charcot Land Serie

\begin{tabular}{|c|c|c|c|c|c|c|c|}
\hline \multirow{2}{*}{$\frac{\text { Probe Nr. }}{103773}$} & \multirow{2}{*}{$\frac{\mathrm{n} \gamma}{1,660}$} & \multirow{2}{*}{$\frac{\Delta}{\div 0,005}$} & \multicolumn{2}{|c|}{ Farbe } & \multirow{2}{*}{$\begin{array}{l}\text { Interferenzfarbe } \\
\text { blaugrau }\end{array}$} & \multirow{2}{*}{$\frac{\text { Paragenese }}{\mathrm{Qz}, \mathrm{Ab}, \mathrm{Stilp}, \mathrm{Ch}, \mathrm{Cc}}$} & \multirow{2}{*}{$\frac{\text { Zone }}{\text { Stilpnomelan }}$} \\
\hline & & & farblos & - hellgrün & & & \\
\hline Vo-G 7 & 1,651 & $\div 0,005$ & blassgelb & - hellgrün & blaugrau & $\mathrm{Mu}, \mathrm{Ch}, \mathrm{Cc}$ & Stilpnomelan \\
\hline 103389 & 1,646 & $\div 0,004$ & farblos & - hellgrün & blaugran & Ab, Stilp, Ch, Akt, Pi & Stilpnomelan \\
\hline Vo-G 8 & 1,645 & $\div 0,001$ & blassgelb & - hellgrün & blaugrau & Qz, Ch, Tit, Tu, Erz & Stilpnomelan \\
\hline Vo-G 2 & 1,643 & $\div 0,004$ & blassgelb & - hellgrün & blaugrau & $\mathrm{Qz}, \mathrm{Ab}$, Stilp, Ch, Akt, Cc & Stilpnomelan \\
\hline 102833 & 1,643 & $\div 0,004$ & blassgelb & - hellgrün & blauviolett & $\mathrm{Qz}, \mathrm{Mu}, \mathrm{Ch}, \mathrm{Ap}, \mathrm{Erz}$ & Stilpnomelan \\
\hline 102834 & 1,643 & $\div 0,0035$ & blassgelb & - hellgrün & rot-blauviolett & $\mathrm{Qz}, \mathrm{Mu}, \mathrm{Ch}, \mathrm{Cc}, \mathrm{Erz}$ & Stilpnomelan \\
\hline Vo-G 13 & 1,641 & $\div 0,002$ & blassgelb & - hellgrün & blau & $\mathrm{Qz}, \mathrm{Mu}, \mathrm{Ch}, \mathrm{Tu}$ & Stilpnomelan \\
\hline Vo-G 6 & 1,638 & $\div 0,003$ & blassgelb & - hellgrün & blaugrau & $\mathrm{Qz}, \mathrm{Ab}, \mathrm{Ch}, \mathrm{Akt}, \mathrm{Kz}$ & Stilpnomelan \\
\hline 103392 & 1,638 & $\div 0,000$ & farblos & - blassgrün & blaugrau & $\mathrm{Ab}, \mathrm{Ch}, \mathrm{Akt}$ & Stilpnomelan \\
\hline 103494 & 1,634 & $\div 0,000$ & blassgelb & - hellgrün & blau-rotviolett & $\mathrm{Qz}, \mathrm{Mu}, \mathrm{Ch}, \mathrm{Erz}$ & Stilpnomelan \\
\hline 117310 & 1,634 & $\div 0,002$ & blassgelb & - hellgrün & blau-rotviolett & $\mathrm{Qz}, \mathrm{Mu}, \mathrm{Bi}, \mathrm{Ch}, \mathrm{Gr}, \mathrm{Tu}, \mathrm{Ru}, \mathrm{Erz}$ & Staur./Disthen \\
\hline 102886 & 1,630 & $\div 0,001$ & farblos & - hellgrün & blau-rotviolett & $\mathrm{Qz}, \mathrm{Ab}, \mathrm{Bi}, \mathrm{Ch}, \mathrm{Ho}, \mathrm{Kz}, \mathrm{Cc}$ & Stilpnomelan \\
\hline 103513 & 1,626 & $+0,000$ & blassgelb & - hellgrün & blau-rotviolett & $\mathrm{Qz}, \mathrm{Ab}$, Stilp, Ch, Tu, Cc & Stilpnomelan \\
\hline 102978 & 1,623 & $+0,003$ & blassgelb & - hellgrün & normal & $\mathrm{Qz}, \mathrm{Bi}, \mathrm{Ch}, \mathrm{H}_{0}, \mathrm{Z}_{0}, \mathrm{Tu}, \mathrm{Erz}$ & Chloritoid \\
\hline 117305 & 1,618 & $+0,003$ & blassgelb & - hellgrün & grüngrau & Qz, Olig, Bi, Ch, Ep, Ma & Staur/Disthen \\
\hline 117359 & 1,618 & $+0,004$ & farblos & - blassgrün & grüngrau & Qz, Olig, And, Bi, Ch, Gr, Ho, Kz, Di, Erz & Disthen \\
\hline 102996 & 1,614 & $+0,005$ & blassgelb & - hellgrün & grüngrau & Qz, Olig, Bi, Ch, Ho, Gr, St, Tu, Ap, Erz & Staur/Disthen \\
\hline 102998 & 1,610 & $+0,006$ & blassgelb & - hellgrün & normal & Qz, Olig, And, Bi, Ch, St, Di, Ho, Ap, Erz & Staur/Disthen \\
\hline 117351 & 1,606 & $+0,006$ & farblos & & normal & Qz, Olig, Bi, Ch, Ho, Gr, Di, Tu, Ep, Ti & Staur/Disthen \\
\hline 102989 & 1,606 & $+0,009$ & blassgelb & - hellgrün & normal & $\mathrm{Qz}$, Olig, Bi, Ch, Anth, Mo, Cc, Erz & Staur/Disthen \\
\hline 102725 & 1,606 & $+0,010$ & blassgelb & - hellgrün & normal & Qz, Olig, Bi, Ch, Gr, Tu, St, Di, Ru, Erz & Staur/Disthen \\
\hline
\end{tabular}

$\mathrm{Qz}=\mathrm{Quarz}, \mathrm{Ab}=$ Albit, Olig $=$ Oligoklas, And = Andesin, $\mathrm{Mu}=$ Muskowit, Bi = Biotit, Stilp = Stilpnomelan, Ch $=\mathrm{Chlorit}, \mathrm{Akt}=\mathrm{Akti}-$ nolith, $\mathrm{Ho}=$ Hornblende, Anth $=$ Anthophyllit, $\mathrm{Gr}=$ Granat, $\mathrm{St}=$ Staurolith, Di $=$ Disthen, Tu $=$ Turmalin, Pi $=\mathrm{Pistazit}$, Kz $=\mathrm{Klino}-$ zoisit, $\mathrm{Z}_{\mathrm{o}}=$ Zoisit, $\mathrm{Ti}=$ Titanit, $\mathrm{Mo}=$ Monazit, $\mathrm{Ap}=$ Apatit, $\mathrm{Cc}=$ Calcit, $\mathrm{Ma}=$ Magnetit, $\mathrm{Ru}=\mathrm{Rutil}$. 


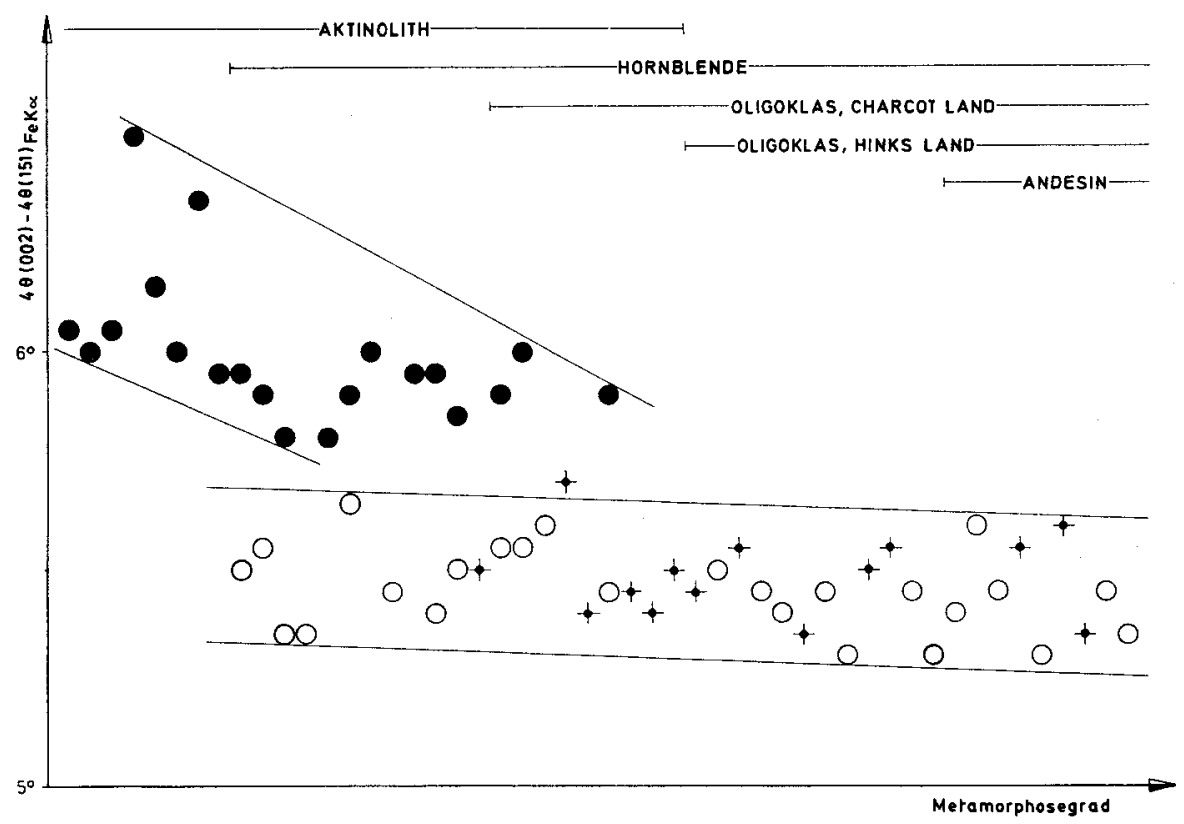

Fig. 6. Das Diagramm zeigt die Variation der $4 \theta\left({ }_{002}\right)-4 \theta\left({ }_{151}\right) \quad($ FeK $\alpha)-$ Werte der Amphibole mit von links nach rechts zunehmendem Metamorphosegrad.

$$
\begin{aligned}
& \text { Punkt = Aktinolith } \\
& \text { Kreis = blaugrüne Hornblende } \\
& \text { Kreuz = grüne Hornblende }
\end{aligned}
$$

Fig. 6. Diagram showing the variation of $4 \theta(062)-4 \theta(151)(\mathrm{FeK} \alpha)$ values of amphiboles with grade of metamorphism.

Infilled circle: actinolite; open circle: blue-green hornblende; cross : green hornblende.

sind Si und Fe reiche Orthochlorite. Die Bestimmung wurde röntgenographisch und optisch durchgeführt (Fig. 5 und Tabelle 2).

Der häufige Stilpnomelan unterscheidet sich von den Oxychloriten und den Biotiten der Zone der Amphibolite durch seine homogenen leuchtenden Farben, das fehlende »mottling" bei gekreuzten Nicols, die spiessigen Kristalle mit Querbrüchen und röntgenographisch durch die $\mathrm{d}\left({ }_{(001}\right)$-Linie bei $12 \AA$. Die Farbe parallel $n \gamma$ variiert, oft im selben Schliff, zwischen grün und goldbraun. Stilpnomelan tritt fast in allen metamorphen Tuffen, häufig neben Quarz, Albit, Chlorit, Aktinolith, Calcit und Epidot auf, findet sich äusserst selten in der Gesellschaft von Muskowit und fehlt auch in den meisten Metagabbros. Andernorts, z.B. in den Zentralalpen (E. Niggli \& C. NiggLi, 1965) kristallisierte der Stilpnomelan auch vielfach neben Muskowit. In Charcot Land sind die muskowitführenden Gesteine wahrscheinlich schon zu aluminiumreich und zu eisenarm, so dass an Stelle von Stilpnomelan Muskowit und Mikroklin kristallisierten. Die Vergesellschaftung mit Calcit ist auch aus South Westland, New Zealand 


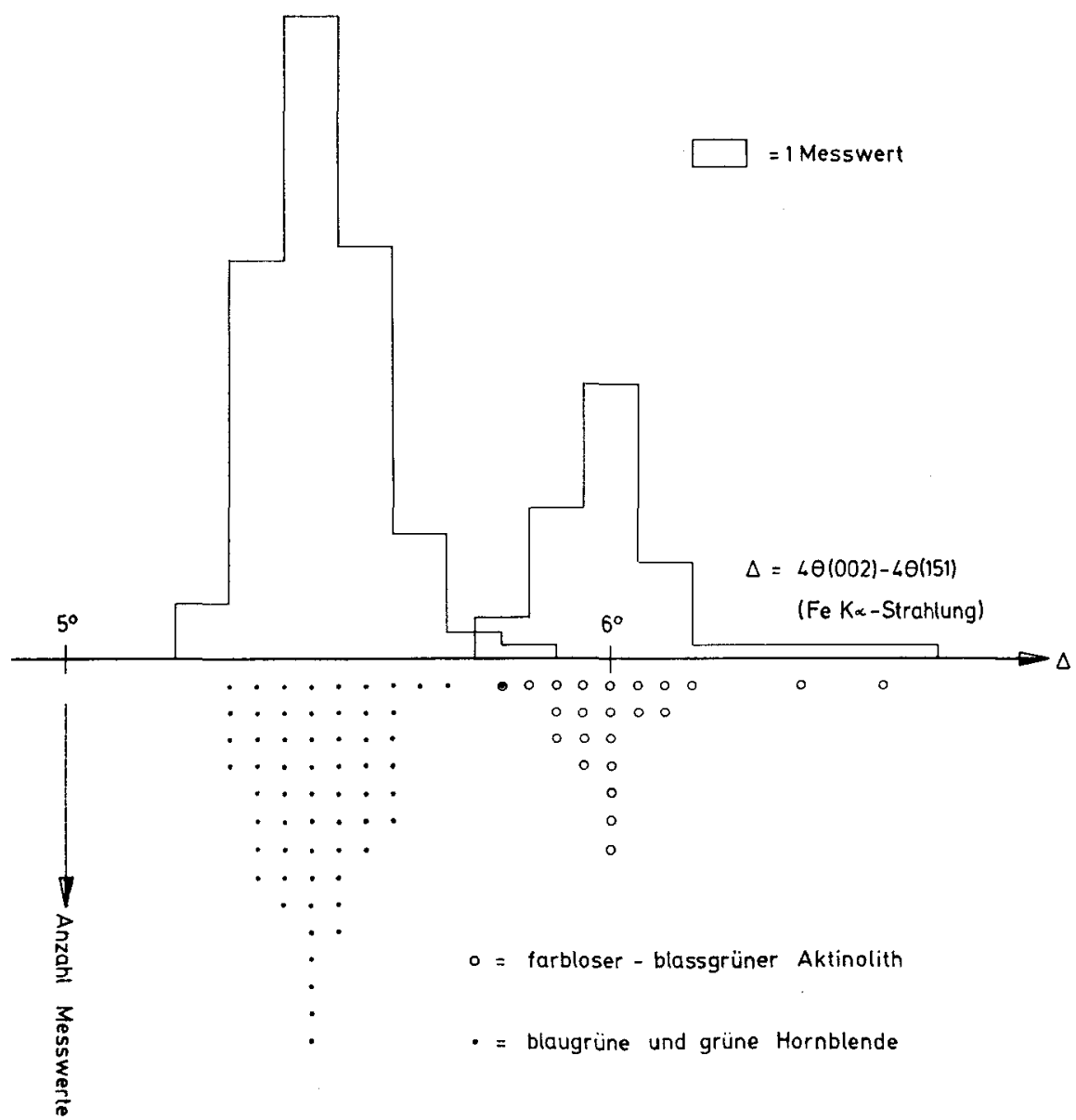

Fig. 7. Histogramm der Daten der Fig. 6.

Fig. 7. Histogram of the data of fig. 6 .

(Brown, 1967) und den Schweizeralpen bekannt (BEarth, 1959; E. Niggli, 1960; E. Niggli \& C. Niggli, 1965). E. Niggli und Streckeisen (1968) weisen darauf hin, dass in vielen Gebieten der Stilpnomelan als späte Bildung der Metamorphose postkinematisch gewachsen ist. In den metamorphen Tuffen von Charcot Land kristallisierte der Stilpnomelan in der Regel ebenfalls postdeformativ. An einigen Stellen fanden wir auch Kristalle, welche nach ihrem Wachstum zerschert wurden, andernteils bildete sich Stilpnomelan auch auf jungen Scherflächen wieder.

Der Amphibol ist stets ein farbloser bis blassgrüner Aktinolith, welcher in den Metagabbros die Hornblenden pseudomorph verdrängte jedoch auch in selbständigen Kristallen neu kristallisierte. Relikte von braunen, grünen und stark bestäubten Hornblenden im Kern von Aktinolithen der Metagabbros sind häufig. Auch in den feinkörnigen metamor- 
phen Tuffen gibt es sicher jungen kaledonischen Aktinolith. Röntgenoptisch unterscheiden sich die Aktinolithe durch den grösseren Abstand der $\mathrm{d}\left({ }_{\text {oog }}\right)$-Linie und der $\mathrm{d}\left({ }_{151}\right)$-Linie von den grünen und blaugrünen Hornblenden (Fig. 6 und Fig. 7). Chemisch konnten die Resultate von TilLEY (1938) und Wiseman (1934) bestätigt werden, wonach die Aktinolithe der schwachmetamorphen Grüngesteine stets aluminiumärmer sind als die Hornblenden aus höhermetamorphen Gesteinen (Tabelle 5).

Epidot findet sich in fast jedem Schliff, oft in mehr als $5 \mathrm{Vol} \%$. Nach der stark variierenden Doppelbrechung $(\Delta=0,006-0,045)$ treten alle Mischglieder zwischen Pistaziten und eisenarmen Klinoziositen auf.

Titanit ist ein weiterer häufiger Nebengemengteil.

\section{Die Zone der Amphibolite}

Eine bedeutende isochemische Veränderung in den Paragenesen und eine auffällige Sammelkristallisation kennzeichnen den Beginn der Zone der Amphibolite. Das Gefüge wird homogener und die Korngrösse nimmt beachtlich zu (Fig. 3). Als neue Mineralphasen erscheinen blaugrüne oder grüne Hornblende und ungefähr gleichzeitig brauner oder olivgrüner Biotit.

Die intensiv gefärbten Hornblenden koexistieren zuerst in einer vier Kilometer breiten Zwei-Amphibolzone mit farblosem oder blassgrünem Aktinolith. - Die seltenen Fälle, in welchen Aktinolith retrograd zusammen mit Quarz, Albit, Chlorit, Calcit und Epidot auf Klüften der Amphibolite kristallisierte, gehören nicht zur kaledonischen Hauptmetamorphose. - Der Aktinolith bildet häufig den blassen Kern einer blaugrünen, seltener grünen Hornblende. Oft sind aber auch beide Amphibole parallel oder unregelmässig miteinander verwachsen, oder sie kristallisierten in selbständigen Individuen nebeneinander. Die Uebergänge zwischen den zwei Amphibolen sind oft messerscharf, manchmal scheinen sie aber auch fliessend zu sein. Mikrosondenanalysen von Prof. Schwander zeigten, dass optisch einheitliche, farblose Aktinolithe, die neben Hornblende auftreten, keineswegs homogen sind (102802). Sie enthalten bereits feine Lamellen von Al-reichen Hornblenden. Miyashiro (1958) und Shidô (1958) betrachten die Koexistenz der zwei Amphibole im Grenzbereich der Aktinolith- und der Hornblendezone als ein gutes Indiz für eine Mischungslücke bei niedrigen Temperaturen. Die beiden Japaner unterscheiden ausserdem innerhalb ihrer Hornblendezone eine erste niedrigtemperierte Region mit nur blaugrüner und eine anschliessende höher metamorphe Zone mit grüner Hornblende. Eine ähnliche Unterteilung ist in Charcot Land nicht möglich; hier kommen beide Varietäten unregelmässig verteilt nebeneinander vor (Fig. 8).

Mit dem ersten Erscheinen von Hornblende ist Chlorit neben Quarz und Epidot nicht mehr stabil. Zwar finden wir den Chlorit noch gelegent- 


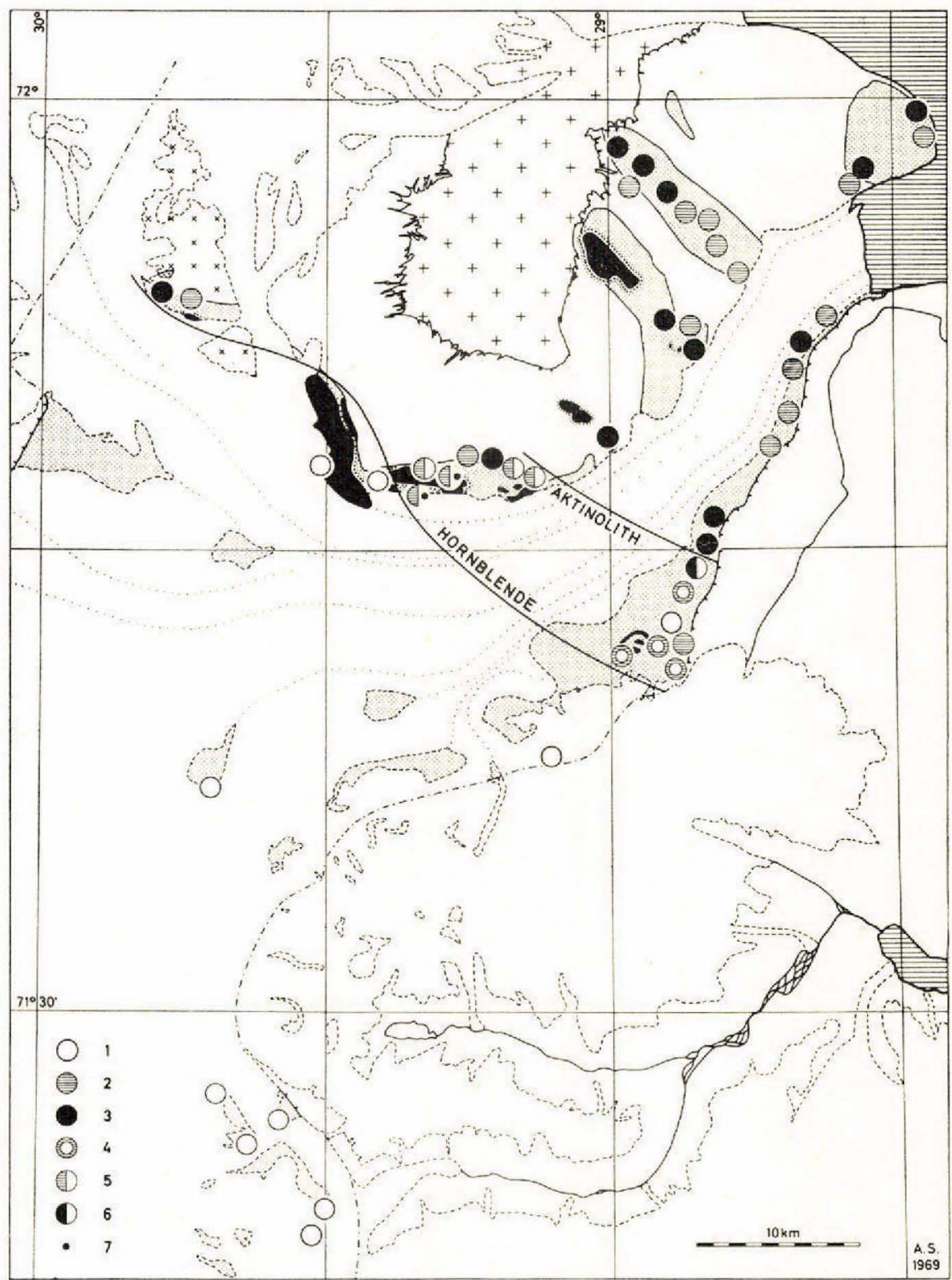

Fig. 8. Verteilung der Amphibole in metamorphen Gabbros und basischen Tuffen.

$1=$ Aktinolith $\quad 2$ = blaugrüne Hornblende $3=$ grüne Hornblende

$4=$ Aktinolithkern mit Rand von blaugrüner Hornblende $5=$ Aktinolith und blaugrüne Hornblende als selbständige koexistierende Individuen im gleichen

Dünnschliff. $\quad 6$ = Aktinolith und grüne Hornblende als selbständige koexistierende Individuen im gleichen Dünnschliff. $\quad 7=$ Riebeckit.

Fig. 8. Distribution of amphiboles in metamorphosed gabbros and basic tuffs. 1 : actinolite, 2 : blue-green hornblende, $3:$ green hornblende, 4 : actinolite with rim of blue-green hornblende, 5 : actinolite and blue-green hornblende in separate grains, 6 : actinolite and green hornblende in separate grains, 7 : riebeckite. 
lich neben den zwei Mineralien, stets bildete er sich dann eindeutig sekundär nach Hornblende oder besonders nach Biotit.

Nach Th. Vogt (1927), Miyashiro (1958) und Shidô (1958) lassen sich das aluminiumreiche Tschermakmolekül der Hornblende und der Anorthitanteil des Plagioklases durch die Reaktion von Chlorit, Epidot, Aktinolith und Quarz nach folgenden Gleichungen bilden:

$$
\underset{\text { Chlorit }}{3 \mathrm{H}_{8} \mathrm{Mg}_{5} \mathrm{Al}_{2} \mathrm{Si}_{3} \mathrm{O}_{18}}+\underset{\text { Epidot }}{\operatorname{\mathrm {HCa}_{2}} \mathrm{Al}_{2} \mathrm{Si}_{3} \mathrm{O}_{13}}+\underset{\text { Quarz }}{7 \mathrm{SiO}_{2}}=
$$

$5 \mathrm{H}_{2} \mathrm{Ca}_{2} \mathrm{Mg}_{3} \mathrm{Al}_{4} \mathrm{Si}_{6} \mathrm{O}_{24}+2 \mathrm{CaAl}_{2} \mathrm{Si}_{2} \mathrm{O}_{8}+10 \mathrm{H}_{2} \mathrm{O}$ (Miyashiro, 1958)

Tschermakmolekül Anorthitmolekül

$14 \mathrm{H}_{8} \mathrm{Mg}_{5} \mathrm{Al}_{2} \mathrm{Si}_{3} \mathrm{O}_{18}+24 \mathrm{HCa}_{2} \mathrm{Al}_{3} \mathrm{Si}_{3} \mathrm{O}_{13}+\mathrm{H}_{2} \mathrm{Ca}_{2} \mathrm{Mg}_{5} \mathrm{Si}_{8} \mathrm{O}_{24}+28 \mathrm{SiO}_{2}=$ Chlorit Epidot Aktinolith Quarz

$25 \mathrm{H}_{2} \mathrm{Ca}_{2} \mathrm{Mg}_{3} \mathrm{Al}_{4} \mathrm{Si}_{6} \mathrm{O}_{26}+44 \mathrm{H}_{2} \mathrm{O}$, (Miyashiro, 1958)

Tschermakmolekül

Diese Gleichungen erklären, warum Chlorit in den Epidot- und Quarz-führenden Amphiboliten der Charcot Land Serie als primäre Bildung fehlt, während nur der quarzfreie aber epidotreiche Metagabbro 102795 aus dieser Zone Chlorit in primärer Paragenese führt (Fig. 10).

Als weiteren jungen Amphibol fanden wir in zwei Metagabbroproben einen riebeckitähnlichen Alkaliamphibol mit deutlich blauviolettem Pleochroismus in kleinen, nicht näher bestimmbaren spiessigen Aggregaten, verwachsen mit grüner und blaugrüner Hornblende.

In der Probe 102989 koexistiert ein eisenreicher Anthophyllit (Tabelle 3) mit grüner Hornblende. Das gelblichbraune faserige Mineral fanden wir als häufigen Gemengteil in Hornblendeglimmerschiefern in einem etwa $50 \mathrm{mal} 100 \mathrm{~m}$ messenden Aufschlussbereich innerhalb der StaurolithDisthen-Zone beim Andesin-Isograd der Amphibolite.

In den basischen Metamorphiten tritt ungefähr gleichzeitig mit der aluminiumreichen Hornblende erstmals ein olivgrüner oder brauner Biotit auf. Beim Hornblende-Isograd erscheint er auch erstmals in Metapeliten. In den intermediären und basischen Gesteinen führt die Kristallisation von Biotit und von Hornblende zum Verschwinden des Stilpnomelans (Fig. 4). Kaledonischer Stilpnomelan mit Biotit oder Hornblende wurden nirgends nebeneinander beobachtet.

Im südlichen Teil der hier epizonalen Hornblende Zone steht wie im noch schwächer temperierten Bereich der Grünschiefer ein Albit im Gleichgewicht mit Epidot und Calcit. Unmittelbar südlich des Staurolith-Isogrades tritt erstmals Oligoklas, anfänglich koexistierend mit Albit und dann allein auf (Fig. 9). Von hier nimmt der Ca- und Al-gehalt der Amphibolit- 
Tabelle 3. Chemismus und Optik des Anthophyllites der Probe 102989.

\begin{tabular}{crrrrc}
\hline $\mathrm{SiO}_{2}$ & $\mathrm{Al}_{2} \mathrm{O}_{3}$ & $\mathrm{Fe}_{2} \mathrm{O}_{3}$ & $\mathrm{MgO}$ & $\mathrm{CaO}$ & $\mathrm{Na}_{2} \mathrm{O}$ \\
\hline $47 \ldots \ldots \ldots \ldots$ & 4,8 & 15,5 & 14,5 & 0,6 & 0,4 \\
$49 \ldots \ldots \ldots$ & 7,0 & 21,6 & 15,1 & 0,6 & 0,5 \\
$53 \ldots \ldots \ldots \ldots$ & 7,6 & 22,1 & 16,8 & 0,6 & 0,8 \\
$55 \ldots \ldots \ldots$ & 7,6 & 22,1 & 17,2 & 0,6 & 1,1 \\
\hline & 9,5 & & 0,6 & \\
\hline
\end{tabular}

Analytiker: H. ScHWANDER.

$100 \cdot \mathrm{Mg}:\left(\mathrm{Mg}+\mathrm{Fe}^{+2}\right)=58,7$

$\mathrm{n} \alpha=1,637 \mathrm{n} \beta=1,6415 \mathrm{n} \gamma=1,657 \pm 0,002 \quad 2 \mathrm{Vz}=77,5^{\circ}$

Die Beziehungen zwischen den optischen Grössen und dem Eisen-Magnesiumverhältnis im Anthophyllit stimmen sehr gut mit den Daten in DeEr, Howie \& Zussman (1962, Bd. 2, S. 221, Fig. 59) überein. Es handelt sich beim untersuchten Mineral um ein eisenreiches Endglied der Anthophyllitmischkristallreihe.

plagioklase gegen Norden zu. Innerhalb der Disthenzone führen einige Amphibolite neben Oligoklas auch Andesin. Die Plagioklase sind, wie dies auch WenK \& KeLLER (1969) aus den alpidischen Metamorphiten der Zentralalpen beschrieben, häufig inverszonar. Die Kalk-Natronfeldspäte wurden optisch und röntgenographisch bestimmt. Die Identifizierung der Albite und Oligoklase mit der U-Tisch-Methode erschien vorerst fast hoffnungslos, da diese sauren Plagioklase nur sehr selten als verzwillingte Körner auftreten. Schliesslich erhielten wir aber doch brauchbare Daten, indem wir einerseits Kristalle mit zwei messbaren Spaltbarkeiten bestimmten und im gleichen Schliff die Lichtbrechung $\left(\mathrm{n} \alpha^{\prime}\right.$ und $\left.\mathrm{n} \gamma^{\prime}\right)$ mit derjenigen des Einbettungsmittels $(\mathrm{n}=1,532)$ und von Quarz verglichen. Die stets gut verzwillingten Andesine liessen sich dagegen leicht optisch als solche nachweisen. Ausserdem wurden von 30 Amphibolitproben die Plagioklase mit dem Magnetscheider separiert und anschliessend mit Guinier-Röntgenaufnahmen nach den Diagrammen von Bambau er et al. (1967) identifiziert. Die letztere Methode gibt nur Durchschnittswerte, welchen niemals der gleiche Aussagewert zukommt, wie den auf dem U-Tisch gewonnenen Daten (vergl. z.B. Wenk \& Keller, 1969).

Ein braunroter Granat tritt ungefähr beim Chloritoid-Isograd der Metapelite erstmals als seltener Gemengteil auf.

Hellglimmer enthält nur die Probe 117359 mit der Paragenese Plagioklas (An 30-40), Hornblende, Muskowit, Paragonit, Disthen, Granat, Calcit und Erz. Der Paragonit verdrängt in diesem Gestein primär kristallisierten Plagioklas. 


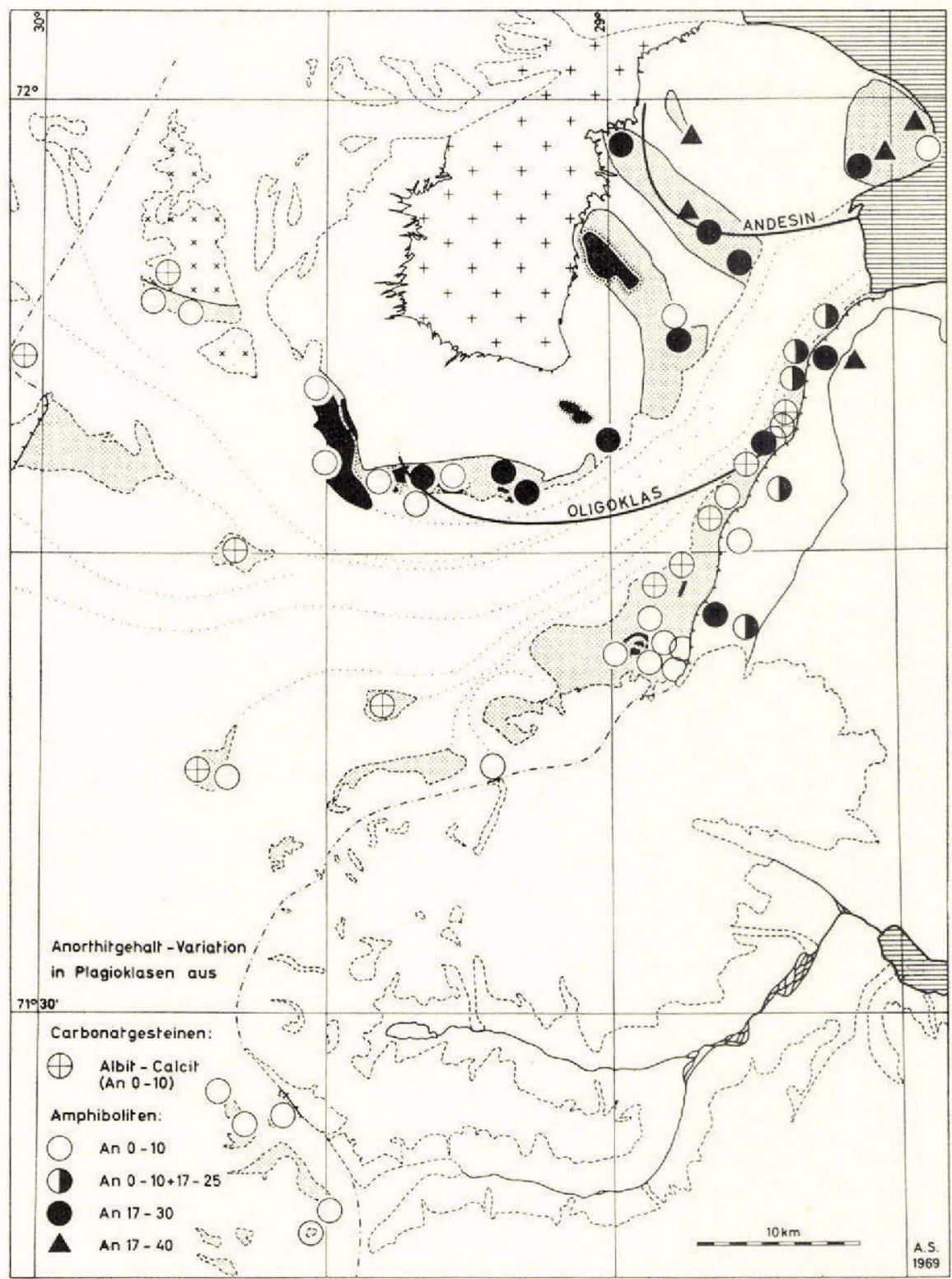

Fig. 9. Verteilung der Plagioklase mit verschiedenen Anorthitgehalten in metamorphen Gabbros und basischen Tuffen und der Albit-Calcitparagenesen.

Fig. 9. Distribution of plagioclase with different anorthite contents in basic metamorphites, and of the albite-calcite paragenesis in carbonate-bearing rocks.

Die Variation des Modus von 50 basischen Metamorphiten wird durch die Figur 10 dokumentiert. Neben den Haupt- und Nebengemengteilen Hornblende, Plagioklas, Quarz, Biotit führen die Amphibolite der Hornblendezone häufig Epidot-Klinoziosit, Titanit, Calcit und Erz. 


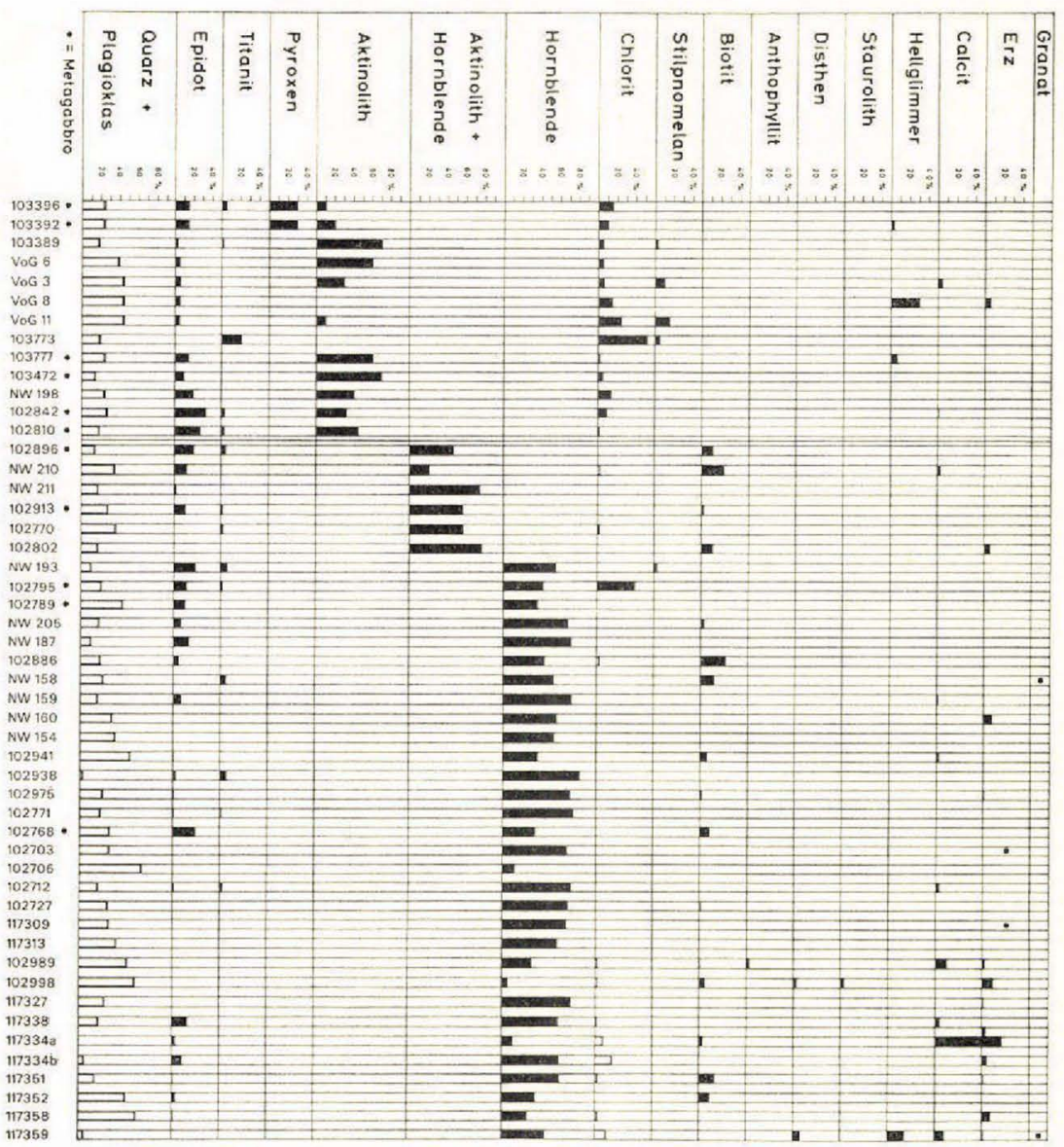

Fig. 10. Modus von 50 metamorphen Gabbros und basischen Tuffen.

Fig. 10. Modes of 50 metamorphosed gabbros and basic tuffs.

Quarz tritt als normaler primärer Haupt- oder Nebengemengteil der Amphibolite auf, nur in einigen Metagabbros scheint er zu fehlen.

Chlorit fehlt, wie bereits erwährit, als primärer Gemengteil in den Amphiboliten, welche Quarz und Epidot oder Quarz und Calcit führen. Als Produkt einer sekundären Diaphtorese nach Biotit oder Hornblende bestimmten wir das wasserreiche Phyllosilikat in ungefähr der Hälfte der Amphibolitproben. Die optische Bestimmung der Chlorite aus Metasemipeliten und basischen Metamorphiten ergab eine stetige Abnahme der Lichtbrechung und Variation der Doppelbrechung von der Stilpnomelan - bis zur Disthenzone (Fig. 5), was nach dem Diagramm von Hey (1954) einer relativen Zunahme des Magnesium - und Aluminiumgehaltes bzw. einer Abnahme des Totaleisens und des Siliziums entspricht. Die Variation scheint in keiner direkten Beziehung zum Eisen-Magnesium-Verhältnis in den Muttergesteinen zu stehen, da gerade die Magnetitreichen Proben 
Tabelle 4. Verzeichnis der Aktinolith-Grünschiefer- und Amphibolitproben, mit Angabe der Anorthitgehalte der Plagioklase und der $4 \theta_{(002)}-4 \theta_{(151)}$ $\left(\mathrm{FeK} \alpha_{1}\right)$-Werte der Amphibole.

1. Kolonne: Probenummer.

2. Kolonne: Mineralbestand (Mineral in Klammer: Relikt des präexistierenden Altbestandes oder postmetamorphe diaphtorische Neubildung). $Q z=$ Quarz, $\mathrm{Ab}=$ Albit, Olig = Oligoklas, And = Andesin, $\mathrm{Se}=$ Scapolith, $\mathrm{Mu}=$ Muskowit, $\mathrm{Bi}=$ Biotit, Stilp $=$ Stilpnomelan, $\mathrm{Ch}=$ Chlorit, Akt $=$ Aktinolith, $\mathrm{Ho}_{0}=$ Hornblende, Anth $=$ Anthophyllit, $\mathrm{Gr}=$ Granat, St $=$ Staurolith, $\mathrm{Di}=$ Disthen, $\mathrm{Tu}=$ Turmalin, $\mathrm{Pi}=$ Pistazit, $\mathrm{Kz}=$ Klinozoisit, $\mathrm{Zo}=$ Zoisit, $\mathrm{Ti}=$ Titanit, $\mathrm{Mo}=$ Monazit, $\mathrm{Ap}=$ Apatit, $\mathrm{Ce}=$ Calcit, $\mathrm{Ma}=$ Magnetit, $\mathrm{Ru}=$ Rutil, $\mathrm{MG}=$ Metagabbro, $\mathrm{Pa}=$ Paragonit.

3. Kolonne: Anorthitgehalt der Plagioklase.

3.1: Unterscheidung von Albit und Oligoklas durch Vergleich der Lichtbrechung mit dem Einbettungsmittel der Dünnschliffe $(n=1,532)$.

3.2: Röntgenoptisch ermittelter An-Gehalt an Hand der Differenz $2 \theta_{131}$ $2 \theta_{1 \overline{3} 1}\left(\mathrm{FeK} \alpha_{1}\right)$.

3.3: Optisch mit dem Universaldrehtisch bestimmte Variation des Anorthitgehaltes.

4. Kolonne: Variation der Differenz $4 \theta(002)-4 \theta\left({ }_{151}\right)\left(\mathrm{FeK} \alpha_{1}\right)$ der Amphibole.

Zone der Aktinolith-Grünschiefer:

\begin{tabular}{|c|c|c|c|c|c|c|c|}
\hline 1. & 2. & & 3.1 & 3.2 & 3.3 & 4 & \\
\hline 103396 & Ab, Akt, Ch, gr.Stilp, Hellgl, Ti, Cc, (Py) & $\mathrm{MG}$ & $\mathrm{Ab}$ & & & & \\
\hline 103392 & $\mathrm{Ab}, \mathrm{Akt}, \mathrm{Ch}, \mathrm{Pi},(\mathrm{Py}),(\mathrm{Ho})$ & $\mathrm{MG}$ & $\mathrm{Ab}$ & & & 6,05 & $(5,4)$ \\
\hline 103389 & $\mathrm{Qz}, \mathrm{Ab}, \mathrm{Akt}, \mathrm{Ch}, \mathrm{Stilp}, \mathrm{Pi}$ & & $\mathrm{Ab}$ & 2,5 & & 6,0 & \\
\hline Vo G 2 & $\mathrm{Qz}, \mathrm{Ab}, \mathrm{Akt}, \mathrm{Ch}$, Stilp, Cc & & $\mathrm{Ab}$ & 4 & & 6,05 & \\
\hline Vo G 3 & $\mathrm{Qz}, \mathrm{Ab}, \mathrm{Akt}, \mathrm{Ch}, \mathrm{Stilp}, \mathrm{Pi}, \mathrm{Cc}$ & & $\mathrm{Ab}$ & & & & \\
\hline Vo G4 & $\mathrm{Qz}, \mathrm{Ab}, \mathrm{Akt}, \mathrm{Ch}$, Stilp, Cc, (Py) & & $\mathrm{Ab}$ & 4 & & 6,5 & \\
\hline Vo G 6 & $\mathrm{Qz}, \mathrm{Ab}, \mathrm{Akt}, \mathrm{Ch}, \mathrm{Ep},(\mathrm{Py})$ & & $\mathrm{Ab}$ & & & & \\
\hline Vo G10 & $\mathrm{Qz}, \mathrm{Ab}, \mathrm{Akt}, \mathrm{Ch}, \mathrm{Stilp}, \mathrm{Ti}, \mathrm{Cc},(\mathrm{Ax})$ & & $\mathrm{Ab}$ & 2,5 & & 6,15 & \\
\hline Vo G11 & $\mathrm{Qz}, \mathrm{Ab}, \mathrm{Akt}, \mathrm{Ch}$, Stilp, Pyrit, Cc, (Ax) & & $\mathrm{Ab}$ & 2,5 & & & \\
\hline 103777 & $\mathrm{Ab}, \mathrm{Mi}, \mathrm{Akt}, \mathrm{Ch}, \mathrm{Mu}, \mathrm{Pi}, \mathrm{Ti}, \mathrm{Erz}$ & MG & $\mathrm{Ab}$ & 0 & & 6,0 & \\
\hline 103472 & $\mathrm{Ab}, \mathrm{Akt}, \mathrm{Ch}, \mathrm{Ti},(\mathrm{Ho})$ & $\mathrm{MG}$ & $\mathrm{Ab}$ & & & 6,35 & \\
\hline 102842 & $\mathrm{Ab}, \mathrm{Akt}, \mathrm{Ch}, \mathrm{Pi}, \mathrm{Cc}, \mathrm{Ti}, \mathrm{Ru}, \mathrm{Erz}$ & MG & $\mathrm{Ab}$ & 2,5 & & 5,95 & \\
\hline \multicolumn{8}{|c|}{ Zone der Amphibolite: } \\
\hline 102810 & Ab, Akt, bgHo, Kz, Sc, Ch, Ti, Erz & $M G$ & $\mathrm{Ab}$ & 4 & & 5,95 & 5,5 \\
\hline 102896 & $\mathrm{Qz}, \mathrm{Ab}, \mathrm{Akt}, \mathrm{bgHo}, \mathrm{brBi}, \mathrm{Pi}, \mathrm{Ti}$ & $M G$ & $\mathrm{Ab}$ & 2,5 & & 5,9 & 5,55 \\
\hline NW 210 & Qz, Ab, Akt, bgHo, grBi, Pi, Ti, Cc & & $\mathrm{Ab}$ & 2,5 & $0-5$ & 5,8 & 5,35 \\
\hline NW 211 & $\mathrm{Ab}, \mathrm{bgHo}, \mathrm{Ti}, \mathrm{Ap}$ & & $\mathrm{Ab}$ & & & & 5,35 \\
\hline NW 193 & $\mathrm{Qz}, \mathrm{Ab}$, bgAkt, Ch, Stilp, Ep, Ti & & $\mathrm{Ab}$ & & & 5,8 & \\
\hline NW 195 & $\mathrm{Qz}, \mathrm{Ab}, \mathrm{Akt}, \mathrm{bgHo}, \mathrm{brBi}, \mathrm{Pi}, \mathrm{Ti}$ & & $\mathrm{Ab}$ & & & 5,9 & 5,65 \\
\hline NW 198 & Qz, Ab, Akt, Hellgl, Ch, Pi & & $\mathrm{Ab}$ & & & 6,0 & \\
\hline 102827 & $\mathrm{Ab}, \mathrm{Akt}$, grHo, $\mathrm{Pi}, \mathrm{Ti}, \mathrm{Erz}$ & & $\mathrm{Ab}$ & & & & \\
\hline 102831 & $\mathrm{Qz}, \mathrm{Ab}, \mathrm{bgHo}, \mathrm{Pi}, \mathrm{Or}, \mathrm{Ti}, \mathrm{Erz},(\mathrm{Ch})$ & & $\mathrm{Ab}$ & & & & 5,45 \\
\hline 102817 & $\begin{array}{l}\mathrm{Ab}, \text { Akt, bgHo, Bi, Hellgl, } \mathrm{Pi}, \mathrm{Ti}, \mathrm{Erz} \\
\quad(\mathrm{brHo}, \operatorname{grHo}, \mathrm{Py})\end{array}$ & $\mathrm{MG}$ & $\mathrm{Ab}$ & & & 5,95 & \\
\hline 102795 & $\mathrm{Ab}, \mathrm{Akt}, \mathrm{bgHo}$, Rieb, Pi, grBi, Ti, Ap & $\mathrm{MG}$ & $\mathrm{Ab}$ & 2,5 & & 5,95 & 5,4 \\
\hline 102913 & Qz, Ab, Akt, bgHo, brBi, Pi, Kz, Ti, Erz & $\mathrm{MG}$ & $\mathrm{Ab}$ & & & 5,85 & 5,5 \\
\hline NW 205 & $\mathrm{Qz}, \mathrm{Ab}, \mathrm{Akt}, \mathrm{grHo}, \mathrm{Ch}, \mathrm{Cc}, \mathrm{Ma}$ & & $\mathrm{Ab}$ & & & (fort & $\begin{array}{l}5,5 \\
\text { z.) }\end{array}$ \\
\hline
\end{tabular}


Tabelle 4 (fortsetz.)

\begin{tabular}{|c|c|c|c|c|c|c|c|}
\hline 1. & 2. & & 3.1 & 3.2 & 3.3 & & 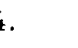 \\
\hline \multicolumn{8}{|c|}{ Oligoklas-Isograd in Charcot Land } \\
\hline 102790 & Qz, Olig, Akt, bgHo, brBi, Kz, Or, Ti & $\mathrm{MG}$ & $\mathrm{Ab}$ & & $17-20$ & 5,9 & 5,55 \\
\hline 102789 & $\begin{array}{l}\mathrm{Qz}, \mathrm{Ab}, \mathrm{Akt}, \mathrm{bgHo}, \mathrm{Rieb}, \mathrm{Pi}, \mathrm{Zo}, \mathrm{Ap} \\
\quad(\mathrm{Ch})\end{array}$ & $\mathrm{MG}$ & $\mathrm{Ab}$ & 2,5 & $0-5$ & 6,0 & 5,55 \\
\hline 102775 & Qz, Olig, bgHo, grBi, Pi, Kz, Ti & & Olig & & & & 5,6 \\
\hline 102772 & Olig, grHo, Pi, Kz & & Olig & & & & 5,7 \\
\hline 102771 & Qz, Olig, grHo, brBi, Pi, Ti, Erz & & Olig & & $20-25$ & & 5,4 \\
\hline 102770 & Qz, Akt, bgHo, Ga, Ch, Erz & & & & & 5,9 & 5,45 \\
\hline 102801 & Ho & & & & & & 5,45 \\
\hline 102802 & Qz, Olig, Akt, grHo, brBi, Erz, Ap & & Olig & & $21-24$ & & 5,4 \\
\hline
\end{tabular}

Beginn der Aktinolith-freien Amphibolite und Oligoklasgrenze in Hinks Land NW 187 Olig, grHo, brBi, Pi

102886 Qz, Ab, grHo, brBi, Kz, Cc, (Ch)

NW 160 Qz, Ab, bgHo, Pi, Cc, Erz

NW 159 Olig, grHo, Pi, Cc

NW 154 Qz, Ab, bgHo, Pi, Cc, Erz

102941 Qz, Ab, Olig, bgHo, grBi, Pi, Tu, Cc,

$$
\text { Erz, (Ch) }
$$

102938 Qz, Ab, Olig, grHo, grBi, Pi, Cc, (Ch)

102975

$\mathrm{Ab}$, Olig, bgHo, grBi, Erz

Olig

$\mathrm{Ab} \quad 2,5$

5,45

$\mathrm{Ab} \quad 0$

5,5

Olig 18

5,55

$\mathrm{Ab} \quad 4$

5,45

102768

Olig, grHo, brBi, Kz, Tu, Ti, Cc, Ap, Erz MG

Ab Olig 28

$3,80-10,20$

5,4

Ab Olig

$0-9,18$

5,35

Olig 22

102706

Qz, Olig, bgHo, grBi, Pi, Cc, Erz

Olig

5,45

102703

Qz, Olig, grHo, Pi, Ti, Erz

102727 Qz, Olig, grHo, brBi, Ga, Ti, Cc, Erz

102991 Qz, Olig, bgHo, grBi, Mu, Ga, St, Pi,

$$
\text { Tu, Ap, Ma, (Ch) }
$$

102996 Qz, Olig, bgHo, grBi, Ga, St, Tu, Mo, Ap, Ma

\section{Olig}

Olig

Olig

$17,5-25$

5,3

5,5

$18-23$

5,55

5,45

Olig $\quad 17-25$

Andesin-Isograd

102998 Qz, Olig-And, bgHo, brBi, Ga, St, Di,

$$
\mathrm{Pi}, \mathrm{Or}, \mathrm{Ap},(\mathrm{Ch})
$$

117309 Qz, Ab, Olig, bgHo, Erz

117313 Qz, Olig, bgHo, brBi, Ti, Cc, Erz, (Ch)

117327 Olig, grHo, Erz

117334 Qz, bgHo, Pi, brBi, Cc, Erz, (Ch)

117338 Qz, Olig, grHo, Pi-Kz, Ti, Cc

102985

117351

$$
\text { And }
$$

Qz, Olig-And, bgHo, brBi, Di, Ga, Tu,

$$
\mathrm{Ti}, \mathrm{Pi}
$$

$\begin{array}{ccl}\text { Olig } & 25-34 & \\ \mathrm{Ab} \text { Olig } & & 5,6 \\ & & 5,4 \\ \text { Olig } & 5,55 \\ & & 5,3 \\ \text { Olig } & 5,6\end{array}$

117352 Qz, Olig, grHo, brBi, Pi-Kz, Ti, Cc, Erz

Qz, And, bgHo, Mu, Pa, brBi, Di,

$\mathrm{Ga}, \mathrm{Cc}, \mathrm{Ma}$

23-38

23-29 5,35

2,5 
Tabelle 5. Chemismus pon Amphibolen (Bestimmung mit der RMS).

\begin{tabular}{|c|c|c|c|c|c|c|c|c|}
\hline Probe Nr. & Amphibol & $\mathrm{SiO}_{2}$ & $\mathrm{Al}_{2} \mathrm{O}_{3}$ & $\mathrm{Fe}_{2} \mathrm{O}_{3}$ & $\mathrm{MgO}$ & $\mathrm{CaO}$ & $\mathrm{Na}_{2} \mathrm{O}$ & $\begin{array}{c}4 \theta(002)-4 \theta(151) \\
\left(\mathrm{FeK} \alpha_{1}\right)\end{array}$ \\
\hline \multirow[t]{5}{*}{102896} & \multirow{5}{*}{$\begin{array}{l}\text { Aktinolith } \\
\text { mit } \\
\text { Hornblende- } \\
\text { rand }\end{array}$} & 45,5 & 6,0 & 5,6 & 0,3 & 11,3 & 0,8 & \multirow[t]{2}{*}{$5,55(\mathrm{H})$} \\
\hline & & 48 & 6,0 & 16,7 & 11,1 & 11,3 & 0,8 & \\
\hline & & 54 & 7,3 & 17,5 & 11,5 & 12,2 & 1,3 & \multirow[t]{3}{*}{$5,9(\mathrm{~A})$} \\
\hline & & 54 & 7,3 & 17,9 & 12,1 & 12,2 & 2,2 & \\
\hline & & & 13,4 & & & 12,3 & & \\
\hline \multirow[t]{4}{*}{ NW 210} & \multirow{2}{*}{$\begin{array}{l}\text { Aktinolith } \\
\text { mit }\end{array}$} & 44 & 3 & 15,9 & 9,7 & 11,9 & 0,5 & \multirow[t]{2}{*}{$5,8(A)$} \\
\hline & & 46 & 3 & 17,3 & 11,0 & 12,4 & 0,6 & \\
\hline & \multirow{2}{*}{$\begin{array}{l}\text { Hornblende- } \\
\text { rand }\end{array}$} & 54 & 12,7 & 19,1 & 11,0 & 12,4 & 1,2 & \multirow[t]{2}{*}{$5,35(\mathrm{H})$} \\
\hline & & 56 & & 19,3 & 13,6 & & 1,5 & \\
\hline \multirow[t]{4}{*}{ NW 198} & \multirow[t]{4}{*}{ Aktinolith } & 50 & 3,5 & 13,5 & 14,5 & 12,6 & 0,5 & \multirow{4}{*}{6,0} \\
\hline & & 56 & 4,5 & 14,7 & 14,5 & 12,6 & 0,6 & \\
\hline & & 56,5 & 4,5 & 14,7 & 14,5 & 12,6 & 0,9 & \\
\hline & & 57 & 4,6 & 15,1 & 14,5 & 13,8 & 0,9 & \\
\hline \multirow[t]{3}{*}{ NW 193} & grüner & 44 & 7,2 & 24,5 & 9,0 & 12,0 & 1,3 & \multirow[t]{3}{*}{$5,8(\mathrm{~A})$} \\
\hline & \multirow[t]{2}{*}{ Aktinolith } & 46,5 & 7,2 & 26 & 9,0 & 12,5 & 1,4 & \\
\hline & & 52 & & & & & 1,5 & \\
\hline \multirow[t]{4}{*}{102771} & \multirow[t]{2}{*}{ Hornblende I } & 42 & 15,7 & 23,9 & 6,2 & 12,5 & 1,3 & \multirow[t]{2}{*}{5,4} \\
\hline & & 44 & & & & & & \\
\hline & \multirow[t]{2}{*}{ II } & 44 & 15,2 & 24,4 & 6,2 & 12,5 & 1,4 & \multirow[t]{2}{*}{5,4} \\
\hline & & 44,5 & & & & & & \\
\hline \multirow[t]{4}{*}{102802} & \multirow[t]{3}{*}{ Aktinolith } & 46 & 1,6 & \multirow[t]{3}{*}{33} & \multirow[t]{3}{*}{12,6} & 2,5 & 0,4 & \\
\hline & & 49 & 3,0 & & & 8,1 & 1,3 & \\
\hline & & 57 & & & & & & \\
\hline & Hornblende & 47 & 15,0 & 21,0 & 7,6 & 11,2 & 1,2 & $5,4(\mathrm{H})$ \\
\hline \multirow[t]{2}{*}{102703} & \multirow[t]{2}{*}{ Hornblende } & 44,2 & 13,7 & 20,0 & 7,6 & 11,4 & 1,2 & \multirow[t]{2}{*}{5,5} \\
\hline & & & 14,2 & 20,5 & 8,0 & 11,8 & 1,5 & \\
\hline \multirow[t]{3}{*}{117327} & Hornblende & 42,5 & 12,9 & 22,6 & 6,4 & 11,7 & 1,5 & 5,55 \\
\hline & & 44 & 13,7 & 24,1 & 6,4 & & & \\
\hline & & 45 & & 24,1 & 7,1 & & & \\
\hline 117309 & Hornblende & 41 & 15,1 & 21,2 & 7,3 & 10,8 & 1,2 & 5,6 \\
\hline & & 43 & 16,0 & & & & 1,5 & \\
\hline & & 45 & & & & & 1,7 & \\
\hline
\end{tabular}

Analy tiker: H. SCHWANDER

102996, 102998 und 117359 Fe-arme Chlorite führen. Wir vermuten, dass der Chlorit der Zone der Amphibolite nach Ueberschreiten der höchsten Metamorphosetemperaturen, aber noch vor einem vollständigen Temperaturausgleich innerhalb der regionalmetamorphen Zone als Produkt einer zwangsläufig eintretenden Diaphtorese an Stelle der wasserarmen Hornblenden und Biotite in den mit Porenwasser gefüllten Metamorphiten neu kristallisierte. Die Variation des $\mathrm{Mg}$-Fe-bzw. Al-Si-Verhältnisses der Chlorite (Fig. 5) würden dann ein Abbild des Temperaturgradienten während dieser späten Episode der kaledonischen Regionalmetamorphose geben. 


\section{METAMORPHOSE KIESELIGER DOLOMITE}

Kieselige Dolomite, bzw. ihre metamorphen Derivate, welche in der Natur häufig in chemisch sehr reiner Form auftreten, sind für die zonale Gliederung und Typisierung einer Faziesserie besonders wertvoll. Die Gleichgewichtsbedingungen zwischen den Paragenesen des Systems $\mathrm{SiO}_{2}$ $\mathrm{CaO}-\mathrm{MgO}-\mathrm{CO}_{2}-\mathrm{H}_{2} \mathrm{O}$ gelten experimentell und theoretisch als gut untersucht; d.h. wir können viele Feldbefunde schon weitgehend mit den rechnerischen Daten und den Laborergebnissen erklären (Mетz \& TrommsdorfF, 1968). Diese Kenntnisse basieren auf zahlreichen Studien (Eskola, 1920, 1939; Bowen, 1940; Watanabe, 1943; Tilley, 1948; James, 1955; Engel \& Engel, 1960; Guitard, 1966, Trommsdorff, 1966) und einer intensiven theoretischen und experimentellen Bearbeitung des Problemkreises durch die Amerikaner Bowen, 1940; Greenwood, 1962; Weers, 1956; Turner, 1967 und die Göttingerschule (Metz \& Winkler, 1963; Metz，1966，1967; Winkler, 1967; Metz, Puhan \& Winkler (im Druck) und Metz \& TrommsdorfF, 1968).

In der Charcot Land Serie fanden wir ideale Bedingungen. Mächtige Calcitmarmorhorizonte mit meter- bis dekameter-dicken Quarz- DolomitLagen, bzw. ihren metamorphen Aequivalenten, lassen sich von der Stilpnomelanzone im Süden bis in die Disthenzone am Nordvestfjord verfolgen. In den Marmoren, welche in der Regel kaum verunreinigt sind, kristallisierten reine Paragenesen des Systems $\mathrm{CaO}-\mathrm{MgO}-\mathrm{SiO}_{2}-\mathrm{H}_{2} \mathrm{O}\left(-\mathrm{O}_{2}\right)$. Nach den optischen und röntgenographischen Untersuchungen an den gesammelten Proben lassen sich drei Zonen mit den folgenden Mineralparagenesen abgrenzen (Fig. 11): schaft

Im niedrigst temperierten Bereich tritt die primäre Mineralgesell-

$$
\text { Quarz - Dolomit - Calcit }
$$

auf. Wir dürfen annehmen, dass die drei Mineralien in thermodynamischem Gleichgewicht umkristallisierten, da die Gesteine während der kaledonischen Metamorphose intensiv durchbewegt wurden.

Die Talkzone lässt sich nur durch wenige Punkte belegen.

$$
\begin{aligned}
& \text { Quarz - Talk - Calcit } \\
& \text { Talk - Calcit - Dolomit und } \\
& \text { Talk - Tremolit - Calcit - Graphit }
\end{aligned}
$$




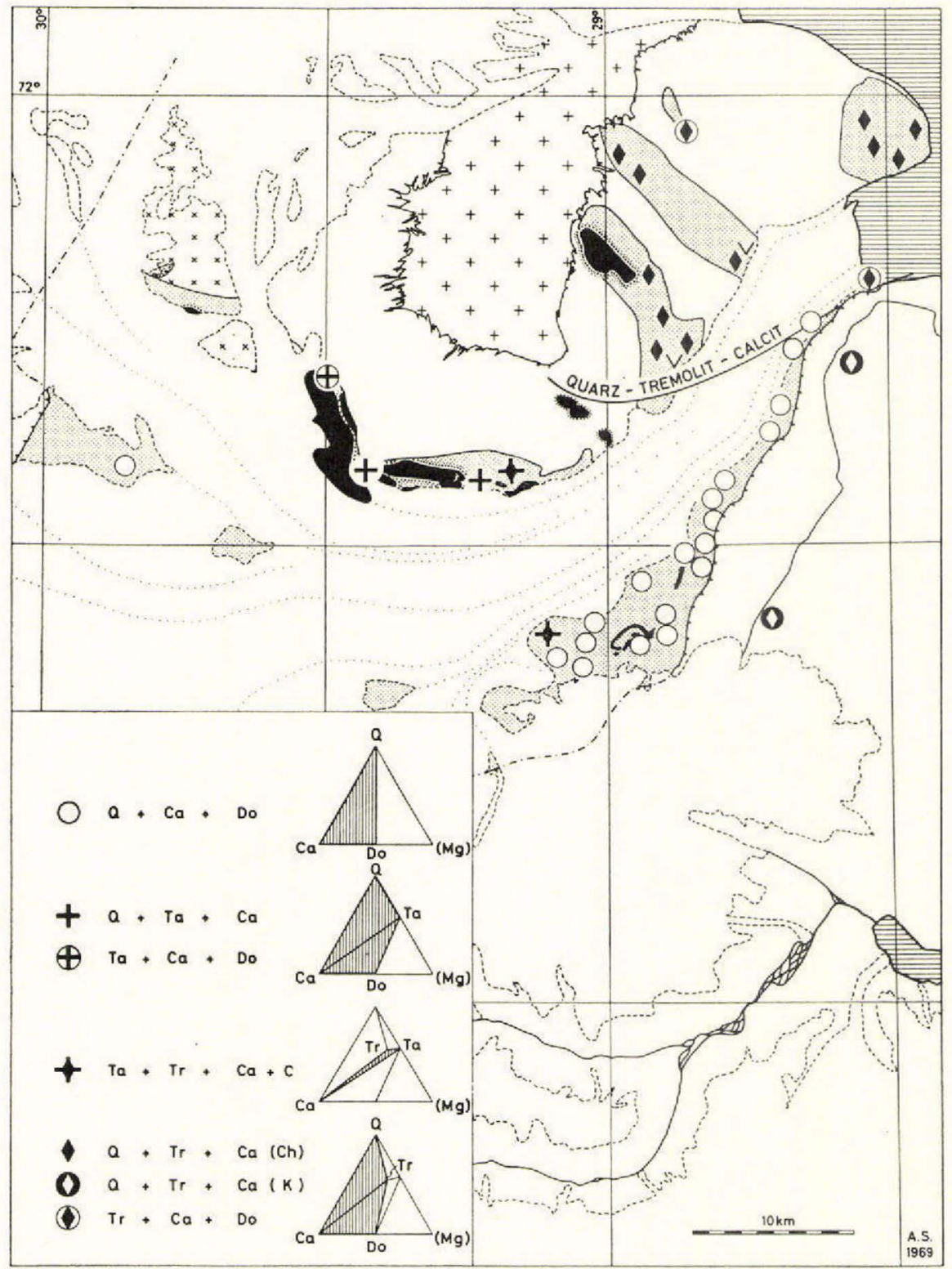

Fig. 11. Verbreitung der Paragenesen in metamorphen kieseligen Dolomiten. $\mathrm{Q}=$ Quarz, $\mathrm{Ca}=$ Calcit, $\mathrm{Do}=$ Dolomit $, \mathrm{Ta}=\mathrm{Talk}, \mathrm{Tr}=$ Tremolit, $\mathrm{C}=$ Graphit,

$\mathrm{V}=$ Vesuvian, $\mathrm{Mg}=\mathrm{MgO}, \mathrm{Ch}=$ Charcot Land Serie, $\mathrm{K}=$ Krummedal Serie.

Fig. 11. Distribution of the parageneses in metamorphosed siliceous dolomites. $\mathrm{Q}=$ quartz, $\mathrm{Ca}=$ calcite, $\mathrm{D} 0=$ dolomite, $\mathrm{Ta}=$ talc, $\mathrm{Tr}=$ tremolite, $\mathrm{C}=$ graphite, $\mathrm{V}=$ vesuvianite $, \mathrm{Mg}=\mathrm{MgO}, \mathrm{Ch}=$ Charcot Land sequence, $\mathrm{K}=$ Krummedal sequence. 
sind die beobachteten Paragenesen. Ein einzelnes Vorkommen von Talk Tremolit - Calcit - Graphit innerhalb der Quarz-Dolomit-Zone dürfte bei einer stark abweichenden Zusammensetzung der Gasphase, wahrscheinlich bei einem hoben $\mathrm{H}_{2} \mathrm{O}$-Partialdruck kristallisiert sein. Inwiefern auch der Sauerstoffgehalt der Gasphase die Bildungsbedingungen beeinflusst, wissen wir nicht. Nach dem issobaren $\mathrm{T}-\mathrm{X}_{\mathrm{CO}_{2}}-$ Phasengleichgewichtsdiagramm von Metz \& Trommsdorff, 1968 dürfte sich Talk nach der Reaktionsgleichung

$$
3 \text { Dolomit }+4 \text { Quarz }+\mathrm{H}_{2} \mathrm{O} \rightleftharpoons 1 \text { Talk }+3 \text { Calcit }+3 \mathrm{CO}_{2}
$$

gebildet haben. Die Möglichkeit, dass Talk diaphtoritisch Tremolit verdrängte, ist unwahrscheinlich, da das Mineral am richtigen Ort innerhalb der progressiv metamorphen Serie, nämlich zwischen der Quarz-DolomitZone und der Tremolit-Zone auftritt. Eine Talk-Zone wird erstmals von Tilley (1948) aus einer kontaktmetamorphen Dolomitserie von Skye, Schottland beschrieben. Guitard (1966) erwähnt sie aus den Pyrenäen. In beiden Gebieten dürfte genügend Wasser in der Gasphase die reichliche Bildung des Phyllosilikates ermöglicht haben. Aehnliche Verhältnisse wie in Charcot Land fand Trommsdorf (1966) in den Zentralalpen, wo Dolomit und Quarz an einzelnen Stellen erst zu Talk und dann zu Tremolit und an andern Orten direkt zu Tremolit reagierten. Das lokale Auftreten der Talkparagenesen lässt sich durch ein örtlich erhöhtes $\mathrm{X}_{\mathrm{H}_{2} \mathrm{O}}$ im Gestein erklären.

Nördlich anschliessend folgen als höchstmetamorphe Bildungen die beiden Tremolitparagenesen

$$
\begin{aligned}
& \text { Quarz - Tremolit - Calcit } \\
& \text { Tremolit - Calcit - Dolomit }
\end{aligned}
$$

Die Amphibolprismen sind vielfach streng in b geregelt, an einigen Stellen durchsetzen sie aber auch wirr S-flächen und Kleinfalten. Das heisst, der Tremolit ist syn- und postkinematisch kristallisiert. Die parakristalline Durchbewegung, welche wir für die gut geregelten Tremolitmarmore annehmen, beschleunigte sicher die Einstellung eines thermodynamischen Gleichgewichtes.

Hier gelten nach MEтz \& TrommsdorfF folgende Gleichungen:

2 Talk +3 Calcit $\rightleftharpoons 1$ Tremolit +1 Dolomit $+1 \mathrm{CO}_{2}+1 \mathrm{H}_{2} \mathrm{O}$

5 Dolomit +8 Quarz $+\mathrm{H}_{2} \mathrm{O} \rightleftharpoons 1$ Tremolit +3 Calcit $+7 \mathrm{CO}_{2}$

2 Dolomit +1 Talk +4 Quarz $\rightleftharpoons 1$ Tremolit $+4 \mathrm{CO}_{2}$

Tremolit und Dolomit bilden sich nach der ersten Gleichung nur bei einem $\mathrm{X}_{\mathrm{CO}_{2}}$ grösser 0,95, d.h. dort, wo die Paragenese Tremolit-DolomitCalcit auftritt, fanden die Reaktionen bei einem sehr hohen $\mathrm{CO}_{2}-$ Partialdruck statt. Die nur spärlichen Talk-Vorkommen zeigen indirekt ebenfalls 
einen sehr hohen $\mathrm{CO}_{2}-$ Partialdruck an; nach den experimentellen Untersuchungen sollte schon bei einem $\mathrm{X}_{\mathrm{CO}_{2}}$ kleiner 0,95 eine breite Talk-Zone entstehen. Unsere Beobachtungen bestätigen Trom msdorffs (1966) Annahme, wonach bei der Metamorphose kieseliger Dolomite - falls ein geschlossenes System vorliegt - sofort ein hoher Gasdruck mit einem hohen $\mathrm{X}_{\mathrm{CO}_{2}}$ aufgebaut wird, da bei den verschiedenen Reaktionen in beträchlicher Menge $\mathrm{CO}_{2}$ frei wird.

Den Einfluss des $\mathrm{X}_{\mathrm{O}_{2}}$ auf die Gleichgewichtstemperaturen kennen wir nicht. Diesbezügliche Experimente und Berechnungen fehlen. Sicher hat aber der Sauerstoffdruck der Gasphase variiert, denn gelegentlich enthalten die Marmore Graphit und als accessorische Erzmineralien entweder Pyrit, Hämatit oder Magnetit.

Als weitere Gemengteile führen die Marmore stets in sehr geringer Menge (kleiner $0,5 \mathrm{Vol} \%$ ) Chlorit und einen nicht näher bestimmten Hellglimmer, z.T. sicher Phlogopit, dann in unreinen Gesteinen in der Stilpnomelanzone Stilpnomelan und Albit und in der Tremolitzone Epidot Vesuvian, Plagioklas und Aktinolith.

\section{Das System Dolomit-Magnesium-Calcit}

Nach den Experimenten von Graf \& Goldsmith (1955) nimmt del Magnesiumgehalt des Calcites in der Paragenese Calcit-Dolomit mit steigender Bildungstemperatur zu. Ihre Untersuchungen und diejenigen von ENGEL \& ENGEL (1958) an natürlichen Vorkommen bestätigen die praktische Anwendbarkeit des Magnesium-Calict-Dolomit Thermometers.

Leider standen für unsere Bestimmungen, welche nach der von Goldsmith, Graf \& Joensuu (1955) ausgearbeiteten Methode mit dem Röntgendiffraktometer durchgeführt wurden, nur wenig geeignete Proben zur Verfügung. Die Messwerte sind in der Tabelle 6 zusammengefasst; sie bestätigen eine generelle Zunahme des Mg-gehaltes mit der Bildungstemperatur. Die aus dem Phasengleichgewichtsdiagramm von Graf \& Goldsmith extrapolierten Temperaturen dürften als minimale Werte angesehen werden, da einerseits nur bei idealen Bedingungen im Gestein die experimentell ermittelte Mg-Menge im Calcitgitter eingebaut wird (ENGeL \& Engel, 1958) und anderseits die Magnesium-Calcite wahrscheinlich sehr leicht retrograd umkristallisieren und sich entmischen, dies besonders in der an vielen Stellen noch postkristallin deformierten Charcot Land Serie.

Die ermittelten Temperaturen liegen alle 100-200 $\mathrm{C}$ unterhalb der auf Grund experimenteller Daten erwarteten Werte.

Gleiche Messungen an dolomitfreien Tremolit- und Talk-Marmoren ergaben abweichende, nicht interpretierbare Werte. 
Tabelle 6. Magnesiumgehalt des Calcites in Calcit-Dolomitmarmoren.

\begin{tabular}{|c|c|c|c|c|c|c|}
\hline Probe Nr & Paragenese ${ }^{1}$ ) & $\begin{array}{c}d_{11 \overline{2}}-\text { Cal- } \\
\left.\text { (it }^{2}\right)\end{array}$ & $\begin{array}{c}\mathrm{Mol}^{\%} \% \\
\mathrm{MgCO}_{3}\end{array}$ & $\begin{array}{r}\text { Bildung } \\
\text { tu }\end{array}$ & mpera- & Mineralzone \\
\hline & & & Calcit $\left.{ }^{3}\right)$ & $\mathrm{lkb}$ & $5 \mathrm{~kb}$ & \\
\hline 102868 & Qz-Cc-Do & 3,0283 & 3,3 & $460^{\circ} \mathrm{C}$ & $420^{\circ} \mathrm{C}$ & $\begin{array}{l}\text { Moränenblock, } \\
\text { Chloritzone }\end{array}$ \\
\hline 102903 & Qz-Cc-Do & 3,0293 & 2,9 & 440 & 400 & Biotit-Isograd \\
\hline 102906 & Qz-Cc-Do & 3,0328 & 1,7 & 380 & 340 & - \\
\hline 102907 & Qz-Cc-Do & 3,0293 & 1,9 & 400 & 360 & - \\
\hline 102816 & Qz-Tc-Cc-Do & 3,0332 & 1,6 & 380 & 340 & - \\
\hline 102871 & Qz-Cc-Do & 3,0318 & 2,0 & 400 & 360 & Biotitzone \\
\hline 102911 & $\mathrm{Qz}-\mathrm{Cc}-\mathrm{Do}$ & 3,0278 & 3,4 & 460 & 420 & - \\
\hline 102912 & $\mathrm{Qz}-\mathrm{Cc}-\mathrm{Do}$ & 3,0330 & 3,2 & 460 & 420 & - \\
\hline NW 171 & Qz-Cc-Do & 3,0283 & 3,3 & 460 & 420 & - \\
\hline 102892 & Qz-Cc-Do & 3,0332 & 1,6 & 380 & 340 & - \\
\hline 102890 & Qz-Cc-Do & 3,0310 & 2,3 & 430 & 390 & - \\
\hline NW 152 & Qz-Cc-Do & 3,0319 & 2,0 & 430 & 390 & Chloritoidzone \\
\hline 102974 & Qz-Cc-Do & 3,0327 & 1,7 & 380 & 340 & Staurolithzone \\
\hline 102972 & Tr-Cc-Do & 3,0240 & 4,8 & 520 & 480 & Tremolit-Isogra \\
\hline 102982 & Tr-Cc-Do & 3,0213 & 5,6 & 550 & 510 & Disthenzone \\
\hline
\end{tabular}

Tabelle 7. Magnesiumgehalt des Calcites in dolomitfreien Marmoren mit Kalk-Magnesium Silikaten.

\begin{tabular}{|c|c|c|c|c|}
\hline Probe Nr. & Paragenese $^{1}$ ) & $d_{11 \overline{2}}-$ Calcit $\left.^{2}\right)$ & $\begin{array}{c}\mathrm{Mol}_{0} \% \mathrm{MgCO}_{3} \mathrm{im} \\
\left.\mathrm{CaIcit}^{3}\right)\end{array}$ & Mineralzone \\
\hline 102901 & Cc-Tr-Ta & 3,0226 & 5,2 & Biotitisograd \\
\hline 102782 & $\mathrm{Cc}-\mathrm{Qz}-\mathrm{Ta}$ & 3,0296 & 2,9 & Talkisograd \\
\hline 102803 & $\mathrm{Cc}-\mathrm{Q} z-\mathrm{Ta}$ & 3,0332 & 1,6 & Talkisograd \\
\hline 102704 & $\mathrm{Cc}-\mathrm{Qz}-\mathrm{Tr}$ & 3,0251 & 4,2 & Staurolithzone \\
\hline 117362 & $\mathrm{Cc}-\mathrm{Qz}-\mathrm{Tr}$ & 3,0239 & 4,7 & Disthenzone \\
\hline 117364 & $\mathrm{Cc}-\mathrm{Qz}-\mathrm{Tr}$ & 3,0291 & 3,0 & Disthenzone \\
\hline
\end{tabular}

1) $\mathrm{Cc}=$ Calcit, $\mathrm{Do}_{0}=$ Dolomit, $\mathrm{Qz}=$ Quarz, $\mathrm{Ta}=\mathrm{Talk}, \mathrm{Tr}=$ Tremolit.

2) Bestimmung auf Philips-Röntgen-Diffractometer, Interner Standard Silicium.

3) Ermittlung des Magnesiumgehaltes des Calcites nach Gold smith, Graf \& Joensu u (1955, Fig. 1, S. 215).

4) Die Bildungstemperatur wurde unter Verwendung der polybaren Calcit-Dolomit Solvuskurve Fig. 6 in Goldsmitн \& Newron, 1969 unter Berücksichtigung der Druckabhängigkeit der Löslichkeit von Magnesit in Calcit (Fig. 4 und Fig. 5 in Goldsмitн et al.) für 1 und $5 \mathrm{~kb}$ abgeschätzt. 


\section{ISOGRADE IN QUARZITEN UND GLIMMERSCHIEFERN}

Ungefähr zu einem Drittel besteht die Charcot Land Serie aus metamorphen sandig-tonigen bis tonig-mergeligen Sedimenten. Im Aufschlussbereich wechseln Bänder von verschiedenen Mineralparagenesen miteinander $a b$, welche eine präexistierende sedimentäre Schichtung nachzeichnen. Diese Metamorphite sind also chemisch sehr inhomogen. Um die wichtigsten Mineralreaktionen ableiten zu können, sollten unbedingt chemische Reihenanalysen an Proben von Gesteinen und einzelnen Mineralphasen durchgeführt werden. Aus zeitlichen Gründen beschränken wir uns vorläufig auf optische und röntgenographische Untersuchungsmethoden. Wir hoffen, das gesammelte Material später noch chemisch bearbeiten zu können. Mit den angewandten Methoden gelang es uns einige wichtige Isograde auf der geologischen Karte zu fixieren.

Eine weitere Schwierigkeit bei der petrologischen Analyse der Metapelite ergab sich aus einer häufig beobachteten retrograden Kristallisation, in den leicht deformierbaren Glimmerschiefern an der Basis der Hinks Land Ueberschiebung. Ein älterer Mineralbestand entspricht stets dem höchsten Grad der Metamorphose. Dieser wurde synkinematisch von retrograden Umwandlungen betroffen.

\section{Die Hellglimmer}

Mit dem Röntgendiffraktometer bestimmten wir an orientierten (sedimentierten) Pulverpräparaten von 56 Glimmerschieferproben die Glimmermineralien. Als Hellglimmer liessen sich nur Muskoxwit und Paragonit identifizieren. Pyrophyllit, Talk und Margarit fehlen in röntgenographisch nachweisbarer Menge. Auch optisch konnten letztere Phyllosilikate nicht gefunden werden. Muskowit tritt als gewöhnlicher Hauptgemengteil in fast allen metamorphen Peliten auf, während Paragonit nur in 7 Proben koexistierend mit dem Kaliglimmer auftritt und zwar vom BiotitIsograd bis hinauf in die Disthenzone. In der Zone der Grünschiefer mit dem Indexmineral Stilpnomelan scheint der Natriumglimmer zu fehlen. Rosenfeld, Thompson \& E-an Zen (1958) beschreiben, dass bei koexistierenden Muskowit-Paragonitpaaren die Differenz der d (002) Werte 


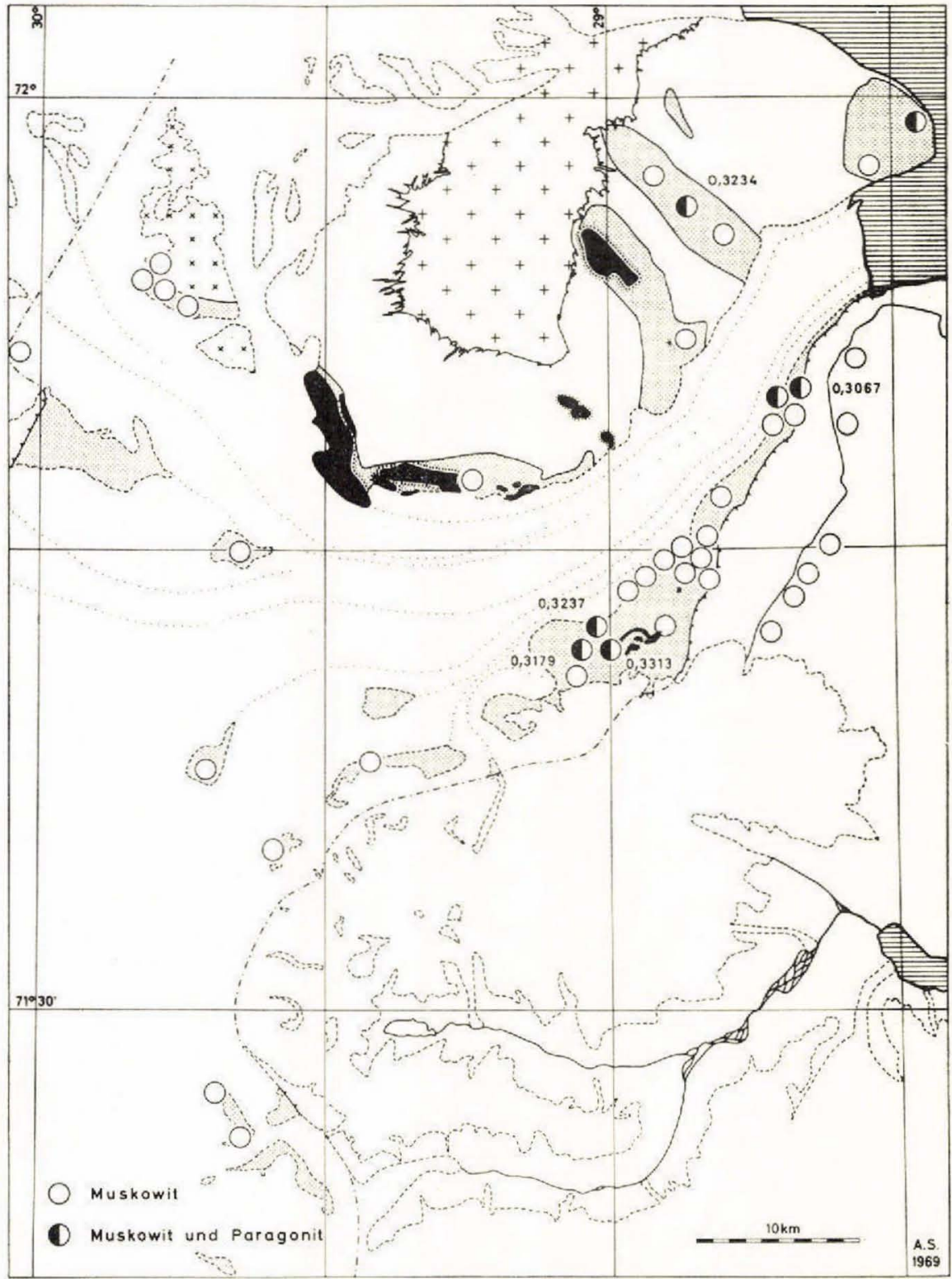

Fig. 12. Verbreitung von Muskowit und Paragonit, mit Angabe der 20(002) $\mathbf{M u}^{-}$ $2 \theta\left({ }_{(002}\right)_{\mathrm{Pa}}(\mathrm{Cu}-\mathrm{K} \alpha)$-Werte von Muskowit-Paragonitpaaren.

Fig. 12. Distribution of muscovite and paragonite, with $2 \theta\left({ }_{002}\right)_{\mathrm{Mu}}-2 \theta(002) \mathrm{Pa}(\mathrm{Cu} \mathrm{K} \alpha$ ) values of coexisting muscovite-paragonite pairs.

der beiden Glimmer mit steigender Bildungstemperatur graduell abnimmt. Eigene Messdaten an nur 5 Paaren der Charcot Land Serie zeigen keine gesetzmässige Abhängigkeit vom Metamorphosegrad (Fig. 12). Die Mine- 
ralien, welche neben Paragonit und Muskowit in den 7 Proben nachgewiesen wurden, sind in der Fig. 13 zusammengestellt. Der Natriumglimmer tritt nur in den Albit- und Kalifeldspat-freien Paragenesen NW 191, NW 183, NW 184, 102899, 102944, 102717 auf und verdrängt in den Proben 117300 und 117359 primär kristallisierten Oligoklas und Andesin.

\section{Die Paragenesen der Stilpnomelan-Chlorit-Zone (Zone der Grünschiefer)}

Die Mineralbestände von 27 Glimmerschieferproben aus der Stilpnomelan-Chlorit-Zone sind in der Fig. 13 zusammengestellt. Es sind die Paragenesen:

1) Quarz - Muskowit - Chlorit

2) Quarz - Muskowit - Chlorit -- Calcit

3) Quarz - Muskowit - Chlorit - Albit

4) Quarz - Muskowit - Chlorit -- Albit - Calcit

5) Quarz - Muskowit - Chlorit - Albit - Mikroklin

6) Quarz - Muskowit - Chlorit - Albit - Mikroklin - Calcit

Paragonit tritt in folgenden Paragenesen auf :

7) Quarz - Muskowit - Chlorit - Paragonit

8) Quarz - Muskowit - Chlorit - Paragonit - Calcit

9) Quarz - Muskowit - Paragonit - Calcit

Fig. 13. Mineralbestand von 66 Metasemipeliten.

Signaturenlegende:

Punkt: eindeutig bestimmtes Mineral.

Kreis: Oligoklaszeile: Plagioklas nur auf Grund der Lichtbrechung gegenüber Quarz und Einbettungsmittel $(\mathrm{n}=1,532)$ identifiziert.

Muskowitzeile: Hellglimmer welcher nicht röntgenoptisch bestimmt wurde.

Chloritzeile: Chlorit nach Überschreiten der Metamorphosekulmination, sekundär, diaphtoritisch kristallisiert.

Monazitzeile: blassgelbliches Mineral mit hohem Relief und schiefer Auslöschung im Kern von pleochroitischen Höfen.

Erzzeile: Erzmineral nicht identifiziert.

Kreuz: Relikt eines präexistierenden Altbestandes.

In Biotitzeile:

weisses Quadrat: olivgrüner Biotit

schwarzes Quadrat: brauner Biotit

$\mathrm{C}$ : Cummingtonit

A: Anthophyllit

Fig. 13. Mineral contents of 66 meta-semipelites.

Legend: infilled circle: clearly identified mineral.

open circle: for oligoclase: determination of the plagioclase only by comparison of the refractive index with quartz and Canada balsam $(\mathrm{n}=1.532)$.

for muscovite: white mica, not determined with an X-ray diagram.

for chlorite: diaphthoretic chlorite. 


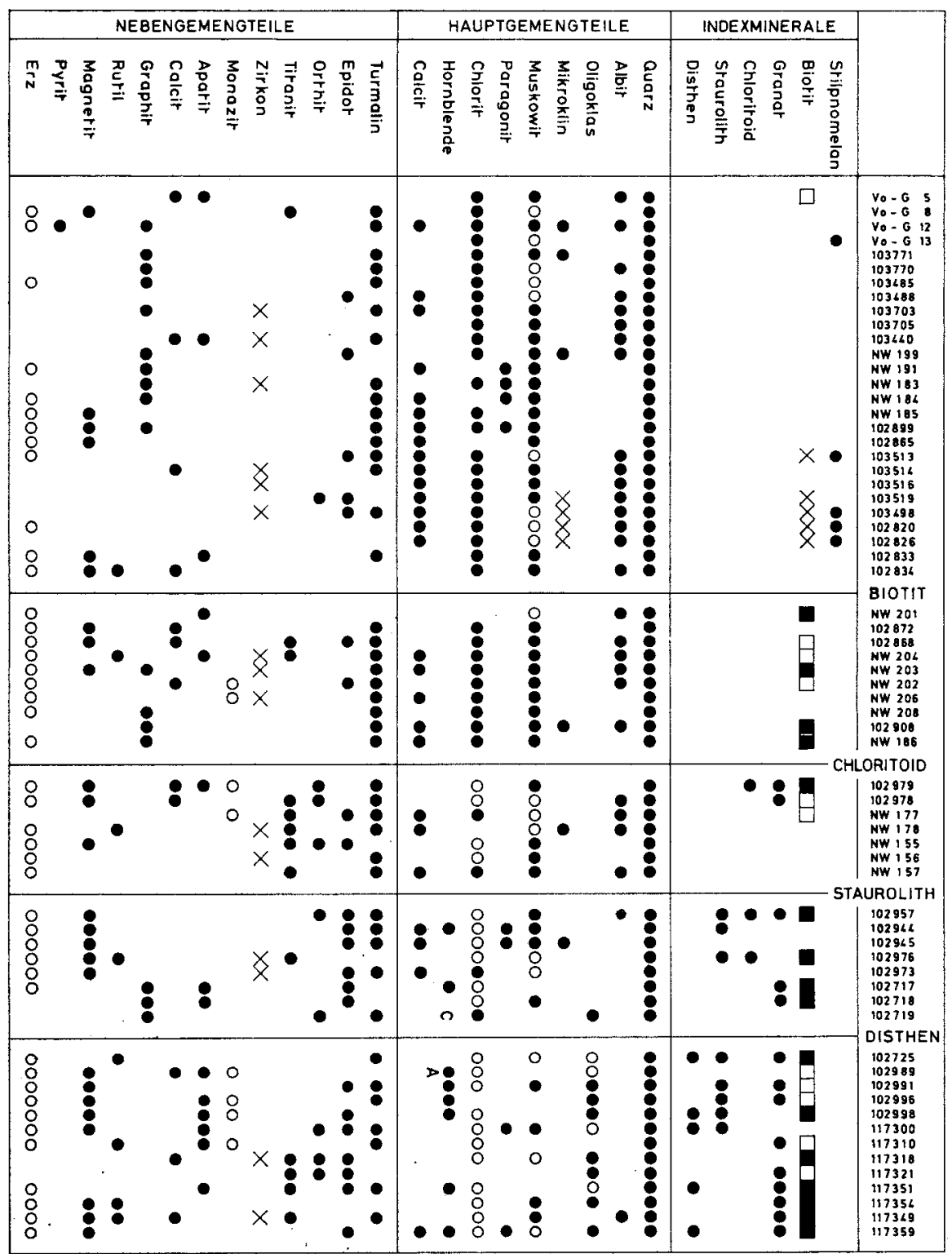

Fig. 13.

for monazite: pale yellow mineral with high refractive index and oblique extinction in the centre of pleochroic halos.

for ore: unidentified ore-mineral.

cross: relict mineral.

open square: brown-green biotite.

infilled square: brown biotite.

$\mathrm{C}$ : cummingtonite.

A : anthophyllite. 
Das Indexmineral Stilpnomelan finden wir in den zwei Mineralgesellschaften:

10) Quarz - Muskowit - Chlorit - Stilpnomelan

11) Quarz - Muskowit - Chlorit - Stilpnomelan - Albit - Calcit - Mikroklin.

Der Stilpnomelan ist in den K- und Al-reichen Glimmerschiefern viel seltener als in den Grünschiefern der gleichen Zone (vergl. S. 22) Er kristallisierte besonders in sternförmigen, spiessigen Aggregaten als Ein schluss im Mikroklin und Albit von Meta-Biotitgraniten des Tillitnunataks in der Mineralgesellschaft Nr. 11). Gleichartige Vorkommen beschreiben JäGER et al. (1961) und Steck $(1966 ; 1968)$ aus dem westlichen Aarmassiv der Schweizeralpen. Nach dem heterogenen Gefüge der Meta-Biotitgranite liegen wohl kaum Gleichgewichtsparagenesen vor.

\section{Die Biotitzone}

Mit dem ersten Auftreten von Biotit verschwindet Stilpnomelan. Die beiden Mineralien sind nie als kaledonische Neubildungen im gleichen Dünnschliff beobachtet worden. Chlorit tritt stark zurück, findet sich aber in fast allen Glimmerschiefern bis hinauf in die Disthenzone. Nach dem Mineralgefüge vermuten wir, dass sich der Chlorit bis hinauf zum Chloritoid-Isograd meist gleichzeitig mit Biotit bildete. (Weiter nördlich kristallisierte er sekundär nach Biotit, Hornblende, Chloritoid oder Staurolith). Bestimmt nicht zufällig zeigen die Biotit-Isograde in den Glimmerschiefern und in Grüngesteinen den gleichen Verlauf.

Wahrscheinlich bildet sich der Biotit durch komplexe Reaktionen zwischen den Mineralphasen Chlorit, Muskowit, Stilpnomelan, Kalifeldspat und Erz. Bei den Metapeliten nehmen wir mit TiLley (1924) an, dass der Biotit im wesentlichen infolge einer Reaktion zwischen den häufigen Phasen Chlorit, Muskowit und Eisenerz kristallisierte. Die Farbe der Biotite wechselt zwischen olivgrün und rotbraun; eine zonale Verteilung der einzelnen Varietäten lässt sich nicht nachweisen.

\section{Chloritoid}

An drei Stellen am rechten Ufer des Daugaard-Jensen Gletschers fanden wir Chloritoid (Fig. 15). Das Mineral tritt in Wirklichkeit wohl sehr viel häufiger auf. Weitere Beobachtungen fehlen, da die Region zwischen den drei untersuchten Aufschlüssen nicht begangen wurde. Mit Röntgenpulveraufnahmen bestimmten wir nach den Angaben von HaLferd aHL (1961) die Chloritoide aus 5 verschiedenen Handstücken als monokline Modifikationen. In den Glimmerschiefern bilden die Chloritoide bis zu 


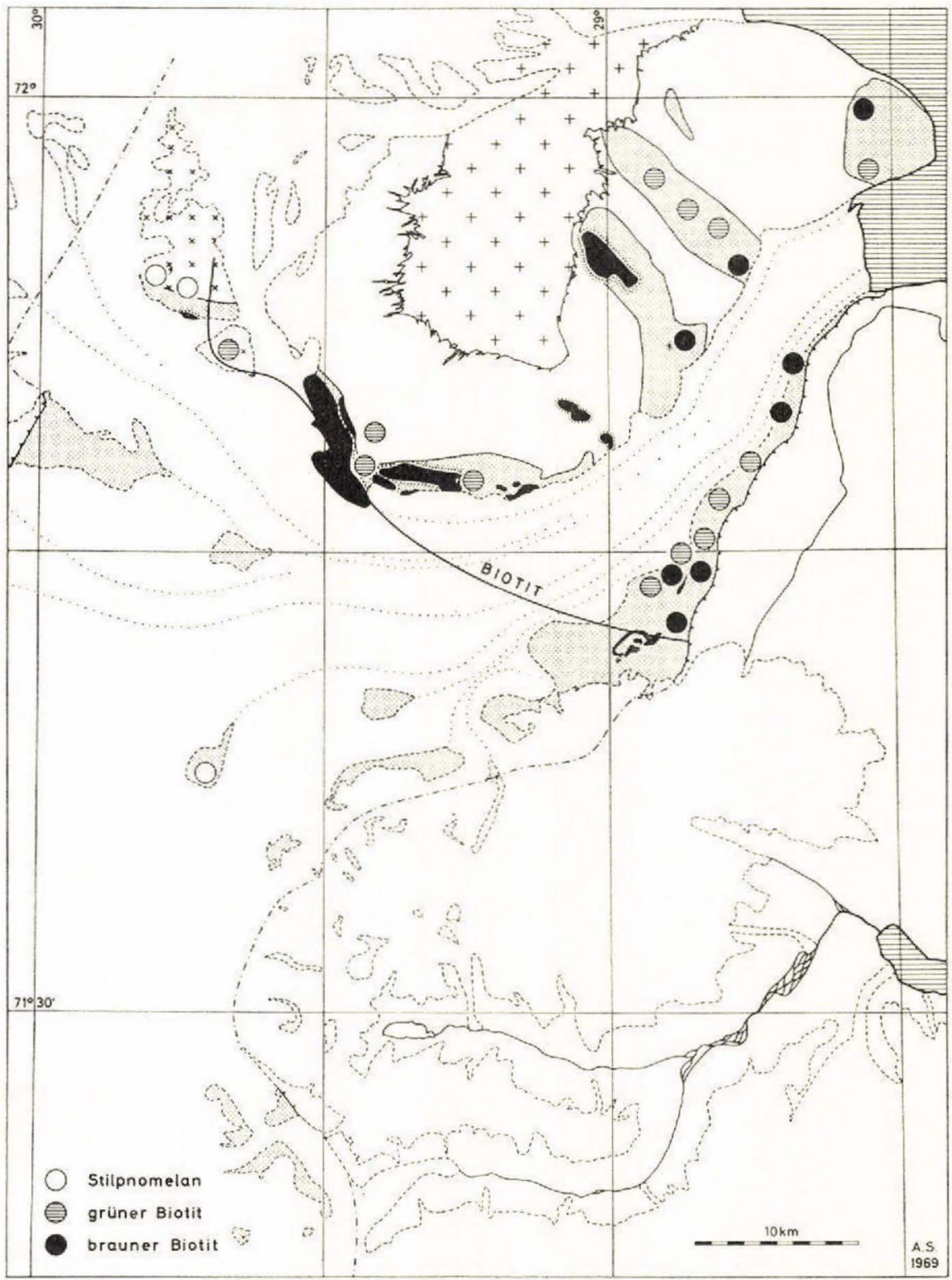

Fig. 14. Verbreitung von Stilpnomelan, grünem und braunem Biotit in Metasemipeliten und Metagraniten.

Fig. 14. Distribution of stilpnomelane, and of green and brown biotite in metasemipelites and meta-granites.

centimeter-grosse dunkelgrüne Porphyroblasten. Im Dünnschliff erscheint das Mineral stets intensiv pleochroitisch und polysynthetisch verzwillingt. Wir bestimmten folgende Mineralbestände: 


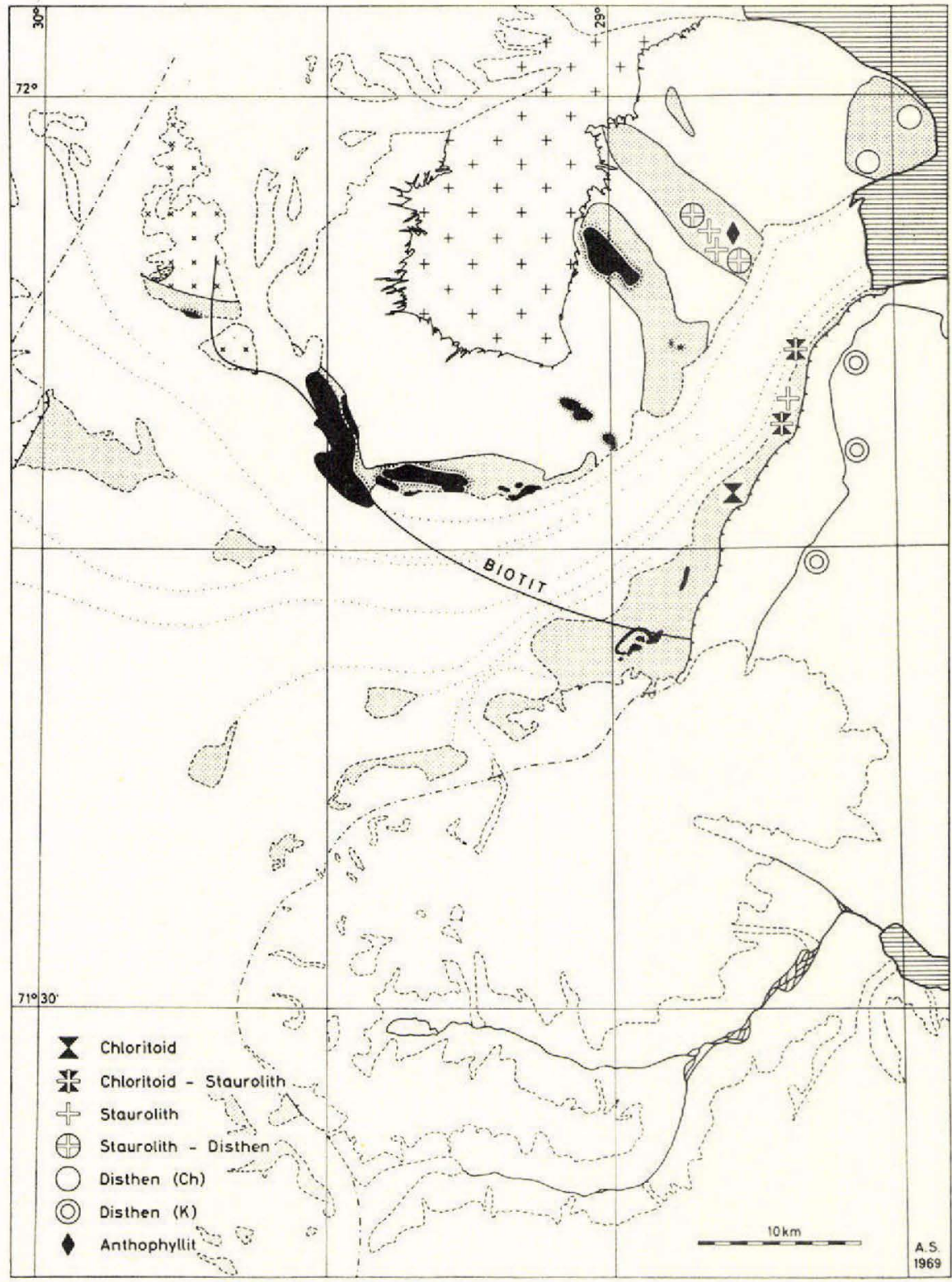

Fig. 15. Verbreitung von Chloritoid, Staurolith und Disthen in Metasemipeliten. Auf der Karte ist ausserdem der Fundort eines Anthophyllit-Hornblendeglimmerschiefers eingetragen.

$$
(\mathrm{Ch})=\text { Charcot Land Serie, }(\mathrm{K})=\text { Krummedal Serie. }
$$

Fig. 15. Distribution of chloritoid, staurolite and kyanite in meta-semipelites. The location of an anthophyllite-hornblende-mica schist outcrop is also shown on this map.

$(\mathrm{Ch})=$ Charcot Land sequence, $(\mathrm{K})=$ Krummedal sequence. 
Probe 102979: Quarz, Muskowit, Biotit, Chloritoid, Granat, Turmalin, Apatit, Magnetit, (Chlorit, Calcit)

Probe 102957: Quarz, Albit, Muskowit, Biotit, Chloritoid, Staurolith, Granat, Epidot, Turmalin, Magnetit, (Chlorit)

Probe 102976: Quarz, Muskowit, Biotit, Chloritoid, Staurolith, Titanit, Magnetit, (Chlorit)

Die in Klammern aufgeführten Mineralien Chlorit und Calcit kristallisierten wahrscheinlich diaphtoritisch. Der Chloritoid tritt in den zwei nördlichen Vorkommen zusammen mit Staurolith auf. Nach dem Gefügebild liegen bestimmt Gleichgewichtsparagenesen vor. Der Chlorit verdrängt Chloritoid, Staurolith und Biotit. Ob dabei auch Magnetit neu kristallisierte ist schwer zu sagen, da alle drei Gesteine viel Erz enthalten.

Nach Winkler (1967) soll Chloritoid niemals mit Stilpnomelan, Albit, Kalifeldspat oder Biotit koexistieren. In Bezug auf die Feldspäte und den Stilpnomelan kann ich seine Aussage bestätigen. Kalifeldspat fehlt in den Chloritoidparagenesen und nur die Probe 102957 führt accessorisch Albit. Dagegen enthalten alle Chloritoidglimmerschiefer in der gleichen Paragenese Chloritoid und Biotit. Paragenesen von Chloritoid und Biotit beschreiben auch Hoscher (1967), Halferdahl (1961) und schon P. Niggli (1912). Das sich gegenseitige Ausschliessen von Stilpnomelan und Chloritoid erklärt Win KLER durch chemische Unterschiede in der ursprünglichen Sedimentzusammensetzung (»chemical control»). Er schliesst dies aus den Untersuchungen einer regionalmetamorphen Zone von Zen (1960). Diese Feststellung wird auch durch die Untersuchungen von FrEY (1968) der metamorphen isochemischen Quartenschiefer der Schweizeralpen bestätigt, welche Chloritoid als alpidische Neubildung, aber keinen Stilpnomelan führen. Nach den neuen Untersuchungen von FrEY istellt die heutige Nordgrenze der Chloritoid-Zone im Bereich der östlichen Urseren-Zone wahrscheinlich keine Isograde dar, sondern ist chemisch bedingt, denn im Autochthon des östlichen Aarmassivs fehlen die höheren, chloritreichen QS, welche für die Chloritoidbildung notwendig sind«. In Hinks Land und Charcot Land tritt der Stilpnomelan in der $40 \mathrm{~km}$ breiten niedrig temperierten Zone der Grünschiefer auf, während der Chloritoid nach dem Hornblende- und dem Biotit-Isograde gleichzeitig mit Granat in Peliten erstmals erscheint. Wir vermuten, dass verschiedene Gesteinschemismen und Metamorphosetemperaturen (und Drucke) die Kristallisation entweder von Stilpnomelan oder von Chloritoid ermöglicht. 


\section{Granat}

Gleichzeitig mit Chloritoid tritt erstmals Granat auf. Er bildet einen regelmässigen Gemengteil der Glimmerschiefer bis hinauf in die Disthenzone. Nach der Lichtbrechung und den Gitterkonstanten handelt es sich durchwegs um Almandin-Spessartinmischkristalle mit nur kleinen Calcium- und Magnesium-Gehalten (Tabelle 8). Einige Granate bestehen aus Zonen mit verschiedenen Gitterkonstanten.

In der Granat-Chloritoid-Zone verschwindet Chlorit als primärer Metamorphitgemengteil. An seiner Stelle kristallisieren die zunehmend Wasser-ärmeren und -freien Phasen Biotit, Chloritoid und Granat. Die Bildungsreaktionen sind wahrscheinlich sehr komplexer Art.

Tabelle 8. Lichtbrechung und Gitterkonstante von Granaten

i) aus der metamorphen Charcot Land Serie, ii) aus der metamorphen Krummedal Serie

i) Charcot Land Serie

\begin{tabular}{llll}
\hline Probe Nr. & $\begin{array}{c}\text { Lichtbrechung } \\
\mathrm{n}_{(\mathrm{Na})}\end{array}$ & $\begin{array}{c}\text { Gitterkonstante } \\
\mathrm{a}_{0}(\AA)\end{array}$ & Mineralzone \\
\hline 102979 & $\mathbf{1 , 8 1 0 \pm 0 , 0 0 3}$ & $\mathbf{1 1 , 5 5 5 \pm 0 , 0 0 2}$ & Chloritoid \\
102957 & $\mathbf{1}, 805$ & $\mathbf{1 1 , 5 6 7}$ & Chloritoid-Staurolith \\
102717 & 1,805 & $\mathbf{1 1 , 5 8 5}$ & Staurolith (?) \\
102718 & 1,805 & $\mathbf{1 1 , 5 6 6}$ & Staurolith (?) \\
102725 & 1,805 & $\mathbf{1 1 , 5 5 1}$ & Staurolith-Disthen \\
102991 & 1,800 & $\mathbf{1 1 , 5 7 1}$ & Staurolith-Disthen \\
102992 & 1,805 & $\mathbf{1 1 , 5 6 1}$ & Staurolith-Disthen \\
102996 & 1,805 & $\mathbf{1 1 , 5 5 0}$ & Staurolith-Disthen \\
$\mathbf{1 1 7 3 1 0}$ & 1,817 & $\mathbf{1 1 , 5 2 8}$ & Staurolith-Disthen \\
$\mathbf{1 1 7 3 5 1}$ & 1,7925 & $\mathbf{1 1 , 5 6 0}$ & Disthen \\
$\mathbf{1 1 7 3 5 4}$ & 1,805 & $\mathbf{1 1 , 5 5 2}$ & Disthen \\
& & $\mathbf{1 1 , 5 9 7}$ & \\
117349 & 1,805 & $\mathbf{1 1 , 5 5 5}$ & Disthen \\
\hline
\end{tabular}

ii) Krummedal Serie

\begin{tabular}{llll}
\hline Probe Nr. & $\begin{array}{c}\text { Lichtbrechung } \\
\mathrm{n}_{(\mathrm{Na})}\end{array}$ & $\begin{array}{r}\text { Gitterkonstante } \\
\mathrm{a}_{0}(\AA)\end{array}$ & Mineralzone \\
\hline 102920 & 1,805 & $\mathbf{1 1 , 5 8 6}$ & Disthen \\
102921 & 1,805 & $\mathbf{1 1 , 5 2 9}$ & Disthen \\
102947 & 1,810 & $\mathbf{1 1 , 5 7 8}$ & Disthen \\
102949 & 1,789 & $\mathbf{1 1 , 5 7 4}$ & Disthen \\
& 1,805 & $\mathbf{1 1 , 5 3 7}$ & \\
102950 & $\mathbf{1 , 8 0 4}$ & $\mathbf{1 1 , 5 5 3}$ & Disthen \\
& & $\mathbf{1 1 , 5 2 5}$ & \\
102951 & 1,805 & $\mathbf{1 1 , 5 9 1}$ & Disthen \\
102963 & 1,805 & $\mathbf{1 1 , 5 8 1}$ & Disthen \\
& & $\mathbf{1 1 , 5 3 0}$ & \\
\hline
\end{tabular}




\section{Staurolith}

Staurolith kristallisierte zuerst gleichzeitig mit Chloritoid im höher temperierten Bereich der Metamorphose zusammen mit Disthen. In der nördlichsten Paragesteinsmulde am Nordvestfjord scheint er zu fehlen. Staurolith fehlt auch in den Disthen-führenden Granat-Zweiglimmerschiefern der Krummedal Serie. Möglicherweise fehlen an beiden Orten Gesteine mit geeigneter Zusammensetzung. Es ist aber auch nicht ausgeschlossen, dass wie beim Barrow-Typ auch in dieser metamorphen Serie eine staurolithfreie Disthenzone existiert. Die Staurolith-grenze sollte aber nach den Beobachtungen in andern metamorphen Serien: z.B. Zentralalpen, Grampian Highlands, viel weiter nördlich nach dem ersten Auftreten von Diopsid in Marmoren liegen.

\section{Disthen}

Disthen ist ein häufiger Gemengteil der Hornblende-Granat-Glimmerschiefer in den beiden nördlichsten Mulden der Charcot Land Serie in Charcot Land und in den Granat-Zweiglimmerschiefern der Krummedal Serie in Hinks Land. In der Charcot Land Serie tritt er zuerst gemeinsam mit Staurolith, im nördlichsten Vorkommen am Nordvestfjord nur noch allein auf.

\section{Die Nebengemengteile der Metapelite}

Turmalin ist der verbreiteste akcessorische Gemengteil in metamorphen Peliten, man trifft ihn nur ausnahmsweise in den basischen Metamorphiten und in den Marmoren fehlt er gänzlich. In allen Vorkommen, welche auf dem Diagramm (Fig. 3) zusammengestellt sind, kristallisierte er während der kaledonischen Metamorphose neu in idiomorphen trigonalen Prismen. Der unter dem Mikroskop erkennbare Turmalingehalt der Glimmerschiefer nimmt beim Biotit-Isograd, d.h. an der Grenze der Zone der Grünschiefer und der Zone der Amphibolite sprunghaft zu (Fig. 3) und die Kornquerschnitte der Turmalinporphyroblasten werden bedeutend grösser. Die durchschnittliche Dicke der Stengel bleibt aber von der Stilpnomelan bis hinauf in die Disthenzone konstant. FREY (1968, S. 831) zeigt, dass der Turmalin in den metamorphen Quartenschiefern des Lukmaniergebietes in den Schweizeralpen als Metamorphoseindikator benützt werden kann: "Mit zunehmender Metamorphose beginnen die klastischen Turmalinkerne weiter zu wachsen, wobei das Turmalinwachstum von der Lukmanier-Passhöhe bis Frodalera durchschnittlich gleichmässig vor sich geht." In unseren Turmalinen konnten nirgends mit Sicherheit detritische Kerne nachgewiesen werden. Die Kristalle zeigen aber häufig eine Farbzonierung. Ein blauer Saum umschliesst dann in der Regel einen olivbraunen Kern. Daneben beobachtet man aber alle Farbübergänge zwischen farblosen, braunen und blauen Varietäten. 


\section{ZUSAMMENFASSUNG DER FELD- UND LABORDATEN}

\section{Aufbau und regionale Stellung der metamorphen Serie}

In einem $80 \mathrm{~km}$ langen Profilstreifen zwischen dem Krummedal und dem Nordvestfjord ist eine progressiv metamorphe Gesteinserie aufgeschlossen. Die Isograde sind um ein hochmetamorphes Gebiet mit dem Indexmineral Disthen im nördlichen Chareot Land konzentrisch nach Art von Zwiebelschalen angeordnet. Die grossräumige Verbiegung der isograden Flächen dürfte im Wesentlichen während der postmetamorphen spätkaledonischen Aufwölbung des Charcot Land Komplexes erfolgt sein; d.h. die Gesteine im zentralen und nördlichen Teil von Charcot Land sind gegenüber dem Rand des tektonischen Fensters um mindestens 5000 $\mathrm{m}$ postmetamorph herausgehoben worden.

Unter den Isograden schneidet einzig die Linie des ersten Auftretens von Oligoklas in Amphiboliten die übrigen Mineralzonen diskordant. Es liess sich nachweisen, dass diese abweichende Lage im Wesentlichen auf eine spätmetamorphe Diaphtorese der Gesteine am rechten Ufer des Daugaard-Jensen Gletschers zurückzuführen ist, welche mit der Ueberschiebung der Hinks Land Decke im Zusammenhang steht.

\section{Die Ursache der Regionalmetamorphose}

Eine weiträumige domförmige Aufwärmung des Unterbaues des kaledonischen Gebirgszuges NE-Grönlands betrachten wir als Ursache der Metamorphose. Eine Erwärmung über den Schmelzpunkt granitischer Gesteine führte zu einer ausgedehnten Anatexis in zentralen Teilen des Gebirges nordöstlich des hier beschriebenen Gebietes. Die dort verbreiteten Migmatitkörper und Intrusivgranite werden nicht als Ursache, sondern als Produkt der Erwärmung angesehen. Die Pegmatitmasse im Zentrum von Charcot Land ist spätmetamorph aus dem Bereich der Anatexis bis in die Zone der Albit- und Oligoklasamphibolite emporgestiegen ohne bei der Platznahme einen sichtbaren Kontakthof zu erzeugen. 


\section{Die Abfolge der Isograde und Paragenesenzonen}

Die schwachmetamorphe Zone der Grünschiefer mit den Indexmineralien Stilpnomelan, Chlorit und Aktinolith reicht über eine Breite von $40 \mathrm{~km}$ vom Krummedal bis an den Südrand von Charcot Land. Hier wechselt die Struktur und Mineralfazies der metamorphen basischen Tuffe und Pelite. Die Metamorphite werden allgemein grobkörniger (Fig. 3). Die verschiedenen Mineralien bilden regelmässig Porphyroblasten. Als neue Mineralien kristallisierten hier Biotit und Al-reiche Hornblende, während Stilpnomelan nicht mehr vorkommt. In den an Stelle der Grünschiefer auftretenden Amphiboliten sind die Paragenesen Quarz-ChloritEpidot und Quarz-Chlorit-Calcit nicht mehr stabil und in den Glimmerschiefern tritt der Chlorit wegen der Biotitbildung stark zurück. Aktinolith und Hornblende koexistieren in einem $4 \mathrm{~km}$ breiten Streifen. Weiter nördlich finden wir den Aktinolith in den Amphiboliten nicht mehr. Die blaugrünen und grünen Hornblendevarietäten kommen innerhalb der Zone der Amphibolite unregelmässig verteilt nebeneinander vor. Es lässt sich nach zunehmendem Metamorphosegrad geordnet eine Zone der Albit-, der Oligoklas- und der Oligoklas-Andesin-Amphibolite unterscheiden. Epidot ist ein verbreiteter Gemengteil aller Zonen, der Gehalt nimmt aber mit zunehmendem Anorthitgehalt des Plagioklases generell ab. Granat tritt nur vereinzelt auf.

In pelitischen Metamorphiten erscheint der Biotit gleichzeitig mit Hornblende und Biotit in Metabasiten. Am rechten Ufer des DaugaardJensen Gletschers durchschreitet man anschliessend nacheinander die Granat-Chloritoid- und die Chloritoid-Staurolithzone. In Charcot Land folgen eine Staurolith-Disthen- und zuoberst am Nordvestfjord eine Disthenzone.

Die Paragenese Quarz-Dolomit-Calcit in Marmoren reagierte weit innerhalb der Zone der Oligoklas-Amphibolite zu Quarz-Tremolit-Calcit und Tremolit-Calcit-Dolomit. Die Talkparagenesen Quarz-Talk-Calcit, Talk-Calcit-Dolomit und Talk-Tremolit-Calcit bildeten sich schon früher lokal in der nördlichen Quarz-Dolomitzone.

Bei den vorliegenden Untersuchungen waren wir bestrebt die genaue räumliche Lage der verschiedenen Isograde, Mineral- und Paragenesenzonen mit möglichst vielen Daten zu belegen. Gut bestimmt wurde der Verlauf des Biotit- und des Hornblende-Isogrades in Metabasiten, des Biotit-Isogrades in Metapeliten und der Linie des ersten Auftretens der zwei Paragenesen Quarz-Tremolit-Calcit und Tremolit-Calcit-Dolomit in metamorphen kieseligen Dolomiten. Das südlichste nachgewiesene Vorkommen eines Oligoklas-Amphibolites rechtsufrig des Daugaard-Jensen 


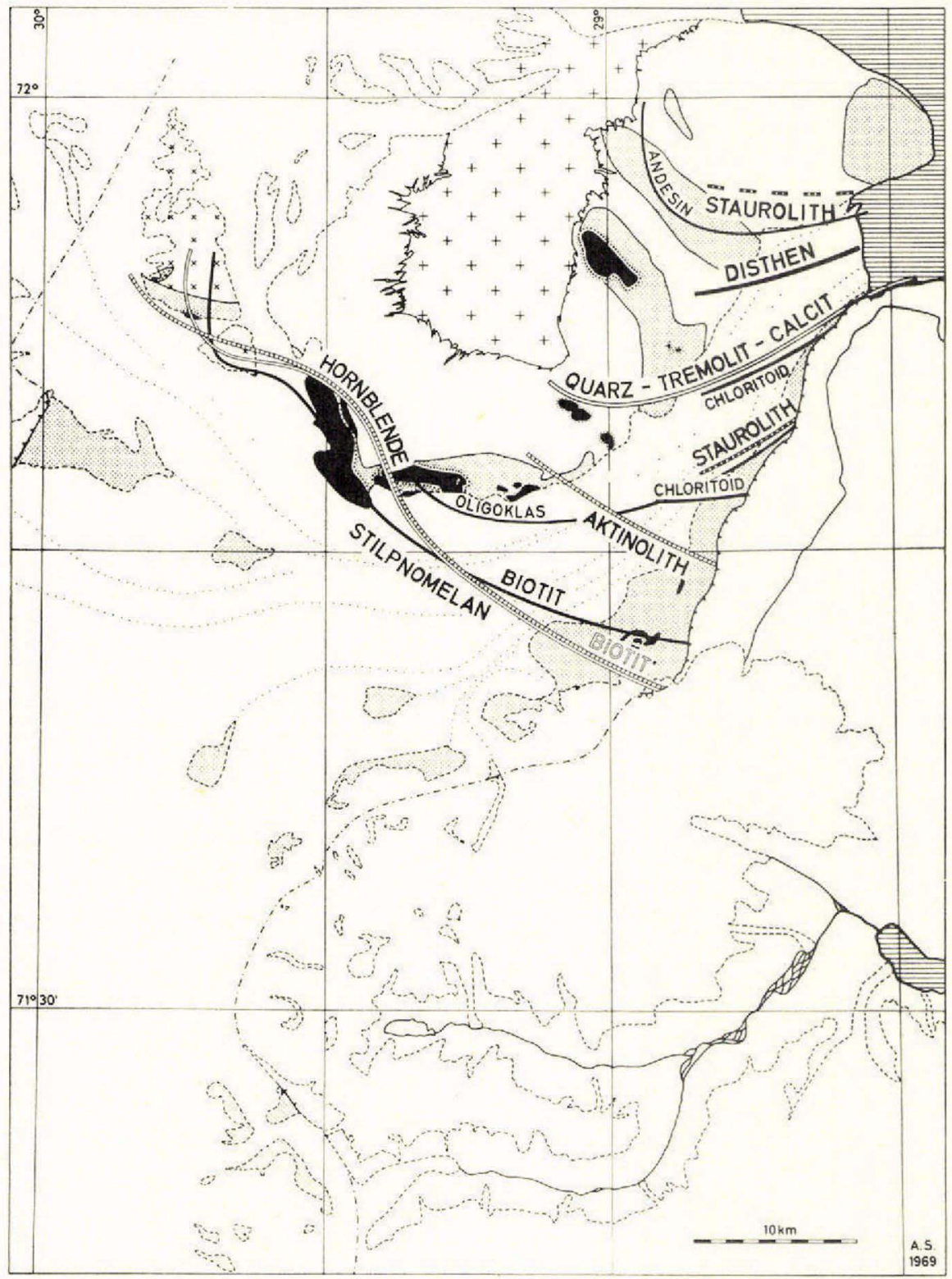

Fig. 16. Karte mit einer Zusammenstellung der Isograden in Metabasiten, kieseligen Dolomiten und in Metapeliten. Die meisten Linien auf dieser Karte sind Isograde, welche den Verlauf der Südgrenze des Verbreitungsgebietes eines Minerals zeigen. Der Biotit-Isograd in Metabasiten ist als Doppellinie, derjenige in Metasemipeliten und Metagraniten als ausgezogene dicke Linie dargestellt. Für die Verbreitungsgebiete von Chloritoid und Staurolith ist sowohl die Süd- als auch die Nordgrenze angegeben und für das Verbreitungsgebiet von Aktinolith ist nur die Nordgrenze gezeichnet.

Fig. 16. Map showing a compilation of the isograds in the basic metamorphites, metamorphosed siliceous dolomites and semipelites. Most of the lines of this map are 
Gletschers liegt einige Kilometer innerhalb des Oligoklasfeldes, wie es nach unserer Vorstellung unmittelbar nach Erreichen des höchsten Metamorphosegrades vorgelegen haben musste. Nur mit wenigen Fundpunkten sind die Stilpnomelan-, Chloritoid-, Staurolith- und Disthenzonen in Metapeliten und der Andesin-Isograd in Amphiboliten belegt.

\section{Folgerungen aus den Beziehungen zwischen Deformation und Kristallisation}

Sowohl im Felde am Aufschluss, als auch beim Mikroskopieren der Dünnschliffe versuchten wir, wo immer es möglich war, das Verhältnis von Kristallisation und Deformation zu bestimmen. Alle Beobachtungen und Daten werden später ausführlich in den Erläuterungen zur geologischen Karte dargestellt. Einige Schlussfolgerungen, welche uns für das Verständnis der in der vorliegenden Arbeit diskutierten Probleme als wichtig erscheinen, sind hier zusammengefasst:

Eine oft sehr intensive Schieferung und Faltung deformierte die Gesteine am intensivsten im Handstück- bis Aufschlussbereich. Im Kartenbereich bildeten sich nur offene Falten, und die Metamorphite blieben in ihrer autochthonen Lage auf dem kristallinen Grundgebirge. Es konnten auch keine grösseren Verwerfungen nachgewiesen werden, welche die Charcot Land Serie verstellen. Scherbewegungen an den postkristallinen Mylonitzonen parallel zum sedimentären $\mathrm{S}$ haben die Mineralzonen nicht erkennbar versetzt.

Typische plurifazielle Metamorphite oder Polymetamorphite, wie sie von verschiedenen Geologen in den Schweizeralpen (BEARTH, 1959 \& 1967; Steck, 1966, 1968) und von ZwART (1962) in den Pyrenäen nachgewiesen wurden, fehlen. Nur eine schwache Chloritisierung der Biotite, Hornblenden, Staurolithe und Chloritoide unmittelbar im Anschluss an die Metamorphosekulmination erfasste die meisten Metamorphite. Die Diaphtorese, welche an der Basis der Hinks Land Decke durch Bewegungen beschleunigt wurde, führte lokal zu einer Albitisierung der Oligoklase.

In der Charcot Land Serie konnten wir nur zwei Hauptkristallisationsphasen nachweisen: Schöne Kontaktkalksilikatfelse und

isograds showing the southern boundaries of the range of distribution of different minerals. A double line shows the biotite isograd in metabasites and a full line this isograd in meta-semipelites and granites. For the occurrence of chloritoid and staurolite the southern and the northern limit has been drawn. For actinolite only the northern limit of distribution is shown, the southern limit lies south of this map. 


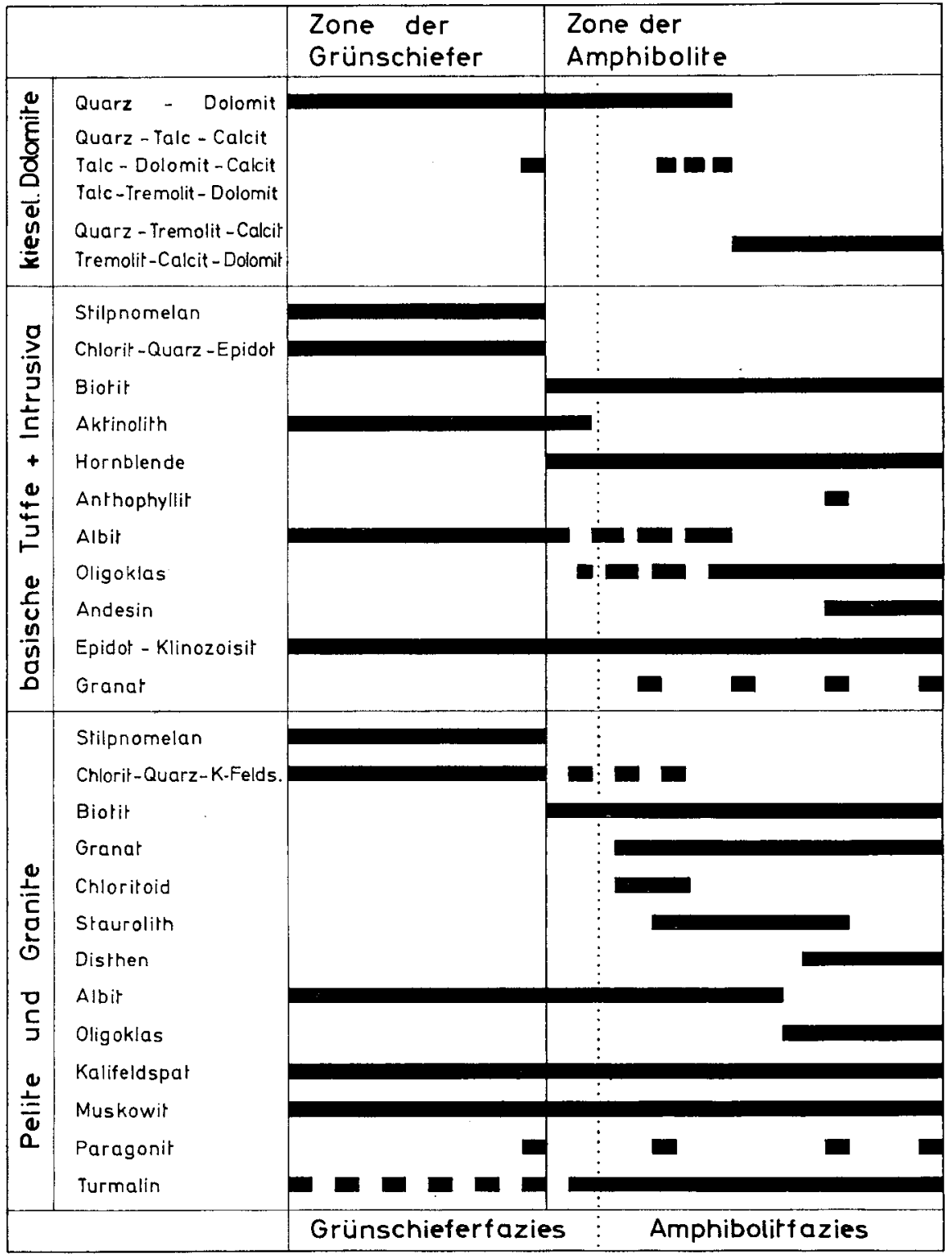

Fig. 17. Abfolge der Mineralien und Paragenesen in metamorphen kieseligen Dolomiten, basischen Tuffen und Intrusiva und Peliten und Graniten.

Fig. 17. Compilation of the sequence of minerals and their parageneses in the different rock-types.

-skarne folgen als schmale Säume den präkambrischen Gabbrointrusionen. Eine jüngere regionale progressive Metamorphose - die kaledonische Regionalmetamorphose - überprägte alle Gesteinstypen der Charcot Land Serie. 


\section{DISKUSSION}

\section{Physikalische Bedingungen (Vergleich mit andern metamorphen Serien, P-T-Gradient, Zusammensetzung der mobilen Phasen oder Phasengemische)}

Das Diagramm (Fig. 18) zeigt die geschätzten P-T-Gradienten und die relative Abfolge von Isograden in der Charcot Land Serie und - zum Vergleich - von vier weiteren metamorphen Serien. Der Konstruktion des Diagrammes gingen folgende Ueberlegungen voraus:

Die Stabilitätsfelder der Alumosilikate und von Staurolith gelten als gut untersucht. Die univarianten Gleichgewichtskurven, welche die Stabilitätsfelder des Staurolithes (Hoschek (im Druck), und Richardson, 1968) und der Alumosilikate (Richardson, Gilbert \& Bell, 1969) begrenzen, wurden als Konstruktionsbasis in die Figur eingetragen. Das Fehlervieleck, in welchem der invariante Tripelpunkt der Alumosilikatstabilitätsfelder liegt, ist angedeutet.

Turner \& Verhoogen (1960) diskutieren die Geometrie von univarianten Gleichgewichtskurven im P-T-Diagramm. Generell gilt, dass mit zunehmenden Drucken die Gleichgewichtstemperatur einer Dehydratationsreaktion ebenfalls zunimmt, und zwar bei niedrigen Drucken (Kontaktmetamorphose) in grösserem, bei höheren (Regionalmetamorphose) in zunehmend geringerem Masse.

Aufgrund der bisher bekannten Faziesabfolgen wurde angenommen, dass auch die Gleichgewichtskurven, welche Isograden der Paragenese Plagioklas-Hornblende entsprechen, einen analogen Verlauf im P-TDiagramm haben.

Der geothermale Gradient ist nicht in allen Gebieten der gleiche, Temperatur und Belastungsdruck nehmen im Allgemeinen gleichzeitig zu bei der Regionalmetamorphose.

In Hinks Land und Charcot Land beobachteten wir die gleiche Abfolge, der Indexmineralien Chlorit, Biotit, Granat, Staurolith, Disthen, wie sie von den Bearbeitern der Dalradian-schists des Schottischen Hochlandes, aus jener erstmals von BARRow (1893) entdeckten und untersuchten progressiv metamorphen Serie, beschrieben wurde. Sillimanit fehlt in 
Charcot Land. Dieses Alumosilikat wurde aber von F. Keller (mündliche Mitteilung) $100 \mathrm{~km}$ östlich von Charcot Land in metamorphen Peliten nachgewiesen, welche wahrscheinlich während der gleichen kaledonischen Regionalmetamorphose umkristallisierten. Typische Hochdruckindikatoren, wie Eklogite, die Jadeit-Quarz-Paragenese, Glaukophan und Lawsonit einerseits, aber auch Mineralien, welche bei mittleren und niedrigen Drucken kristallisierten, wie Cordierit und Andalusit andererseits, konnten nicht nachgewiesen werden. Stilpnomelan, welcher häufig in den Grünschiefern der Charcot Land Serie auftritt, ist in Mittel- und Hochdruckgesteinen sehr verbreitet. JAMES (1955) beschreibt ihn aber auch aus den Metamorphiten von Northern Michigan, welche wahrscheinlich bei relativ niedrigen Drucken umkristalliserten. Nach diesen Ueberlegungen dürften bei der Charcot Land-Metamorphose, wie beim BarrowTyp, mittlere Drucke, und zwar höhere Drucke als etwa in den Zentralalpen, geherrscht haben.

Ueber die Temperaturverteilung sind ebenfalls nur qualitative Aussagen möglich. Sicher nahm die maximale Temperatur, welche sich während der Metamorphose einstellte, von Süden nach Norden zu. Dies geht klar aus der Aenderung des Kristallgefüges, der Zunahme der Korngrösse (Fig. 3), dem Wechsel in den Mineralparagenesen in isochemischen Gesteinserien hervor. Das von Süden nach Norden zunehmende EisenMagnesiumverhältnis in sekundär kristallisierten Chloriten, zeigt an, dass auch während der anschliessenden Diaphtorese ein gleich gerichtetes Temperaturgefälle bestanden haben muss.

Das Mineral Staurolith bildete sich nach den Experimenten von Ganguly \& Newton (1969) und Hoscheк (1967) bei Drucken um 5 kbar erstmals bei etwa $550^{\circ} \mathrm{C}$. Eine Erwärmung, welche zur partiellen Aufschmelzung der Gesteine geführt hätte, wurde nicht erreicht. Zwar treten bereits in der Staurolith-Disthenzone pegmatoide Mobelisate in granitoiden Gneissen auf. Nirgends beobachteten wir aber eindeutige Aufschmelzungserscheinungen.

Zur Frage der Zusammensetzung der mobilen Phasen oder Phasengemische, lässt sich folgendes sagen. Die Gasphase setzte sich wahrscheinlich im Wesentlichen aus den Komponenten $\mathrm{H}_{2} \mathrm{O}, \mathrm{CO}_{2}$ und $\mathrm{O}_{2}$ zusammen. Wasser war sicher reichlich vorhanden, den bei den verschiedenen Dehydratationsreaktionen in Metapeliten und Metabasiten wurde ja in grösserer Menge Wasser frei. Anders verhält es sich mit den Karbonatgesteinen. Bei der Bildung von Tremolit aus kieseligen Dolomiten wird Wasser verbraucht und $\mathrm{CO}_{2}$ geht in die Gasphase. Daher stellt sich nach TromusdorfF (1966) sofort ein hohes $\mathrm{X}_{\mathrm{CO}_{2}}$ ein. In einigen Marmoren bildete sich zuerst Talk und nicht direkt Tremolit. Nach dem Gleichgewichtsdiagramm des Systems $\mathrm{CaO}-\mathrm{MgO}-\mathrm{SiO}_{2}-\mathrm{CO}_{2}-\mathrm{H}_{2} \mathrm{O}$ von Metz \& Trommsdorff (1968) muss an jenen Stellen ein grösserer $\mathrm{H}_{2} \mathrm{O}$-Partial- 


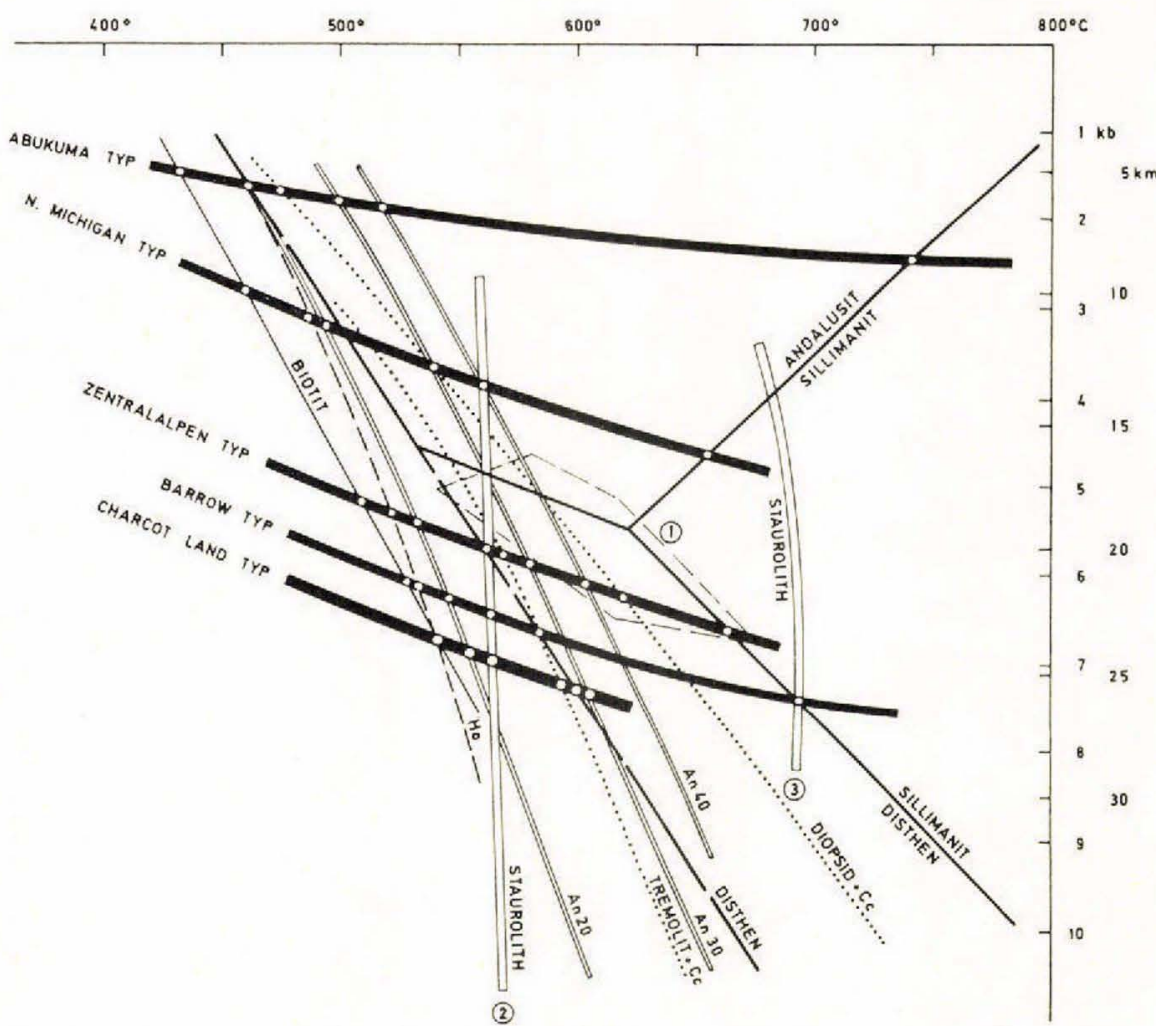

Fig. 18. Zusammenstellung der P-T-gradienten und der Isogradenabfolgen (weisse Punkte) von 5 regionalmetamorphen Serien.

Fig. 18. Proposed P-T gradients of five regional metamorphic series, including that of Charcot Land. For full explanation see the German text.

druck der Gasphase vorgelegen haben. Bestimmt hat auch der Sauerstoffpartialdruck variiert. Dies geht aus den Beobachtungen hervor, wonach in Marmoren als Erzmineralien entweder Hämatit, Magnetit oder Pyrit und gelegentlich auch Graphit auftritt.

\section{Chemisches Gleichgewicht}

Sind die beobachteten Mineralgesellschaften im chemischen Gleichgewicht kristallisiert?

Diese zentrale und schwierige Frage kann nicht endgïltig beantwortet, muss aber diskutiert werden. Bei den bisherigen Betrachtungen setzten wir voraus, dass sich die meisten untersuchten Mineralien im Gleichgewicht mit ihren Paragenesepartnern bildeten.

Eine stabile oder metastabile Gleichgewichtsparagenese kann - aber muss nicht - dann vorliegen, wenn: 
1. die Gibbs'sche Phasenregel erfüllt ist, und alle Phasen einer Paragenese gemeinsame Grenzflächen bilden.

2. die verschiedenen Mineralphasen mit regelmässigen Flächen aneinander grenzen.

3. die Elemente bei variierendem Gesteinschemismus, aber bei gleichem Druck, gleicher Temperatur und gleicher Zusammensetzung der mobilen Phasen gesetzmässig auf koexistierende Mineralien verteilt sind.

4. die Isograde einen regelmässigen Verlauf zeigen.

Die Gibbs'sche Phasenregel, bzw. die mineralogische Phasenregel von V. M. Goldschmidt (Turner \& Verhoogen, 1960) ist bei allen Paragenesen der kieseligen Dolomite, welche auf der Verteilungskarte (Fig. 11) ausgewertet sind, erfüllt. Sie gilt auch für die meisten Amphibolite und Grünschiefer und für die meisten Metapelite.

Als sehr problematisch erweist sich die Anwendung der zweiten Regel, da in natürlichen Gesteinen die Geometrie des Mineralgefüges durch zahlreiche unbekannte Faktoren beeinflusst wird. Regelmässige Grenzflächen, oder mit anderen Worten, polygonale Mosaikgefüge beobachtet man praktisch nur in Marmoren und in seltenen Fällen in OligoklasAmphiboliten.

Das dritte Kriterium lässt sich nur an Mineralien anwenden, deren Chemismus bekannt ist. Eine solche Untersuchung am koexistierenden Mineralpaar Hornblende-Aktinolith der 2-Amphibol-Amphibolite ist im Gange.

Der 4. Punkt ist in der untersuchten Region sehr schön erfüllt. Einzig die Linie des ersten Auftretens von Oligoklas in Amphiboliten schneidet die Isograde, welche konzentrisch um ein höchstmetamorphes Gebiet im Norden von Charcot Land angeordnet sind, diskordant. Dieses abweichende Verhalten erklären wir damit, dass diaphtoritische Albitamphibolite als Ungleichgewichtsparagenesen innerhalb der Oligoklas-Amphibolitzone auftreten.

\section{Systematische Stellung der metamorphen Serie}

In Uebereinstimmung mit EsкоLA (1920) haben neuerdings Wenk \& Keller (1969) eine Gliederung metamorpher Serien anhand von Isograden in intermediären und basischen Gesteinen angeregt.

Die Verhältnisse in der metamorphen Charcot Land Serie lassen sich am besten durch eine Unterteilung in eine Zone der Grünschiefer und eine Zone der Amphibolite beschreiben. Für diese Zonen sind die Kriterien der metamorphen Fazies (Eskola, 1920) erfüllt. Es ist aber nicht meine Absicht hier neue Namen für metamorphe Fazies einzuführen, welche allgemeine Gültigkeit haben sollen. 
Nach Turner (1968) werden die Gesteine der Zone der Grünschiefen und der Albit-Amphibolite zur Grünschieferfazies und die Metamorphite der Zone der Oligoklas- und Andesin-Amphibolite zur Amphibolitfazies gerechnet. An einer solchen Unterteilung stört, dass die Faziesgrenze im Verbreitungsgebiet amphibolitischer Gesteine verläuft, an einer Stelle, welche weder durch einen besonders auffälligen Wechsel in der Gesteinsbeschaffenheit noch in den Mineralparagenesen charakterisiert ist. Dieser Tatsache trägt meine Unterteilung in eine Zone der Grünschiefer und eine Zone der Amphibolite, die sich zwangslos mit derjenigen Turner's korrelieren lässt, Rechnung. 


\section{SUMMARY}

This paper deals with the regional metamorphism (Barrovian type) of the Precambrian Charcot Land supracrustal sequence in Charcot Land and Hinks Land, Scoresby Sund, East Greenland.

\section{General geology}

The region investigated consists of two tectonic units: the dome-like Charcot Land complex, which appears in a tectonic window, and the Hinks Land thrust sheet which lies above it. In both units an old gneissic basement and a younger Precambrian cover series of supracrustal rocks can be distinguished.

The Charcot Land supracrustal sequence is exposed in great synclines in the Charcot Land basement and follows the western border of Hinks Land between Krummedal and Nordvestfjord over a distance of $80 \mathrm{~km}$. The main rock types of this Charcot Land sequence are metamorphosed limestones, siliceous dolomites, semipelites, and quartzitic rocks; these are associated with basic extrusives (with pillow lavas) and tuffs, followed by intrusions of hornblende gabbros and biotite granites which are probably all comagmatic.

A tillite or tilloid of likely Eocambrian age was unconformably deposited on the porphyritic biotite granite west of Charcot Land.

The above-mentioned rocks of the Charcot Land complex have been folded and overprinted by progressive regional metamorphism of probable Caledonian age. During this metamorphic recrystallisation, the Hinks Land nappe was overthrust on to the Charcot Land complex.

The Hinks Land thrust sheet consists of old gneissic Precambrian basement overlain by the highly metamorphosed Krummedal supracrustal sequence.

After this period of thrusting and the Caledonian recrystallisation, a great mass of pegmatites intruded the central part of the Charcot Land complex probably simultaneously with the dome-like uplift of the basement.

The geology of the region investigated will be described in further detail and published together with a geological map at a scale of 1:100 000 in a separate paper. 


\section{The progressive metamorphism of the Gharcot Land sequence}

It must be pointed out that in general only one principal phase of regional recrystallisation is detectable in the different rock-types of the Charcot Land sequence. The main phase of metamorphism has been locally followed by a very weak retrograde metamorphism indicated by partial chloritisation of biotite and hornblende, and albitisation of basic plagioclase; this occurred particularly along some post-crystalline mylonite zones.

Around the gabbro intrusions zones of contact metamorphism, usually only some tens of metres across, predate the regional metamorphism. Mineral assemblages of these polymetamorphic rocks are excluded from the maps showing the distribution of the regional metamorphic minerals and their parageneses.

\section{The metamorphism of basic rocks}

About sixty per cent of the volume of the rocks belonging to the Charcot Land sequence consist of basic metamorphites of a very constant chemical composition. The analyses (Tabelle 1) show major variations only with respect to the potassium - sodium ratio.

Relict structures suggest the character of the pre-existing rock-types; these must have included banded basic tuffs (hyaloclastites) and extrusives (pillow lavas), and sills, dykes and stocks of pyroxene and hornblende gabbros. In the basic rocks the field geologist can distinguish between a southern zone of generally fine-grained greenschists, and a zone of rather coarse grained and massive amphibolites in the north (fig. 2). In the zone of greenschists, quartz-chlorite-epidote ( \pm calcite \pm sphene \pm stilpnomelane) and quartz-albite-chlorite-actinolite ( \pm stilpnomelane \pm epidote \pm calcite \pm sphene) occur as characteristic mineral assemblages.

The beginning of the zone of amphibolites is characterised by the appearance of green or blue-green hornblende. Here, in this zone, chlorite coexisting with quartz and calcic minerals such as calcite or epidote, is no longer stable. The hornblende coexists with actinolite in a zone about $8 \mathrm{~km}$ wide and is followed to the north by an actinolite-free hornblende zone. Biotite and hornblende appear simultaneously in the amphibolites and in the metapelites, replacing in both rock-types stilpnomelane or the chlorite-muscovite paragenesis.

In the basic metamorphites the anorthite content of the plagioclase increases with grade of metamorphism. From south to north, zones of albite, albite-oligoclase, oligoclase and oligoclase-andesine amphibolites can be distinguished. 


\section{Decarbonation reactions in siliceous dolomites}

In the metamorphosed siliceous dolomites two zones have been mapped. In the south, quartz-calcite-dolomite is the common mineral assemblage, even in strongly deformed and recrystallised marbles. In a few places within this zone, the presence of talc assemblages, i.e. talc-quartz-calcite, talc-calcite-dolomite or talc-tremolite-calcite, has been noted, indicating a locally higher partial pressure of water in the fluid phase. North of a line situated between the staurolite and kyanite isograds, the siliceous dolomites have been converted into tremolite-quartz-calcite or tremolitecalcite-dolomite marbles.

In fifteen samples with coexisting calcite and dolomite, the $d_{12 \overline{2}}$-values of calcite have been measured using an X-ray diffractometer to determine the $\mathrm{mol}^{\%} \mathrm{MgCO}_{3}$ in calcite. From these data the temperature of formation of this magnesian-calcite has been estimated after Goldsmith \& Newton, 1969 and Goldsmith, Graf \& Joensud, 1955 (Tabelle 6).

\section{Isograds in mica schists}

The micas of 56 samples of the meta-semipelites, covering the whole investigated area, have been determined using an X-ray diffractometer. Muscovite and paragonite are the white micas. Paragonite was found only in six samples, always coexisting with muscovite. The $2 \theta_{002 \mathrm{Mu}}-2 \theta_{002 \mathrm{~Pa}}$ values show no characteristic relationship to the grade of metamorphism. On the other hand, chlorite and biotite are widespread. Pyrophyllite, talc and margarite were not detected in the metamorphites.

$\mathrm{The} \mathrm{Mg} / \mathrm{Mg}+\mathrm{Fe}$ ratio of the chlorites increases with grade of metamorphism. The biotite isograd of the mica schists is apparently situated at the same place as in the basic metamorphites. I suggest that the same reactions, under similar physico-chemical conditions, have led to the formation of biotite principally by replacement of chlorite and muscovite and subordinately stilpnomelane.

The distribution of the index minerals chloritoid, staurolite and kyanite is shown in fig. 15.

\section{Conclusions}

In the metamorphosed Charcot Land supracrustal sequence the isograds occur in roughly concentric arcs around a centre of highest metamorphism in the northern area.

The metamorphic series may be characterised by a sequence of isograds (fig. 16). This succession suggests conditions of temperature and 
pressure during the main phase of recrystallisation similar to those of the Barrovian type (moderate pressure of metamorphism) (fig. 18).

The "magnesian calcite-dolomite thermometer" indicates a temperature of approximately $380^{\circ} \mathrm{C}(5 \mathrm{~kb})$ for the biotite isograd.

\section{Verdankungen}

Bei dieser Gelegenheit möchte ich allen jenen danken, welche zum Gelingen der vorliegenden Arbeit beigetragen haben.

Vorab gilt mein Dank Herrn K. EllitsGaArd-Rasmussen, Direktor des »Grønlands Geologiske Undersøgelse«, welcher mir die Teilnahme an der Expedition in den Scoresby Sund ermöglichte, mir eine finanzielle Unterstützung gewährte, und auf Kosten von "Grønlands Geologiske Undersøgelse« zahlreiche Dünnschliffe, chemische und Mikrosondenanalysen durchführen liess. Ich danke auch dem Direktor für die Erlaubnis, meine Resultate zu publizieren.

Besonders möchte ich auch dem Expeditionsleiter, NiELs HENriKSEs, und den dänischen und englischen Kollegen für ihre rege Unterstützung meiner Arbeit herzlich danken. Dieser Dank gilt insbesondere meinem Assistenten Claus And ersen. Den Herren Prof. Dr. H. SchwanDER und Dr. W. Stern aus Basel danke ich vielmals für die Ausführung von Gesteins- und Mineralanalysen, ebenso Herrn T. Fischer für die sorgfältige Herstellung der Dünnschliffe.

Von den Mineralogischen Instituten der Universitäten Basel, Bern und Zürich erhielt ich manche wertvolle Anregung und Unterstützung durch die Herren Proff. E. Wenk, P. Bearth und E. NiggLI und meine Kollegen M. Frey, F. Keller, V. Dietrich, T. Peters und V. TrommsDORFF; ihnen allen gilt mein bester Dank.

Basel, den 3. April 1970

Gegenwärtige Adresse:

Institut de Minéralogie,

Palais de Rumine

Lausanne

Schweiz 


\section{LITERATURVERZEICHN IS}

Albee, A. L. 1962 : Relationship between the mineral association, chemical composition and physical properties of the chlorite series. Am. Miner. 47, 851-870.

Bambauer, H. U., Corlett, M., Eberhard, E. \& Viswanathan, K. 1967: Diagrams for the determination of plagioclases using X-ray powder methods. Schspeiz. miner. petrogr. Mitt. 47, 333-364.

Barrow, G. 1893: On an intrusion of muscovite-biotite-gneiss in the south-eastern Highlands of Scotland and its accompanying metamorphism. Q. $\mathrm{Jl}$ geol. Soc. Lond. 49, 330-358.

Barth, T. F. W., Correns, C. W. \& Eskola, P. 1939: Die Entstehung der Gesteine. Berlin: Springer.

Bearth, P. 1959: Ueber Eklogite, Glaukophanschiefer und metamorphe Pillowlaven. Schweiz. miner. petrogr. Mitt. 39, 267-286.

- 1967: Die Ophiolithe der Zone von Zermatt-Saas Fee. Beitr. geol. Karte Schweiz, N.F., 132.

Bowen, N. L. 1940: Progressive metamorphism of siliceous limestone and dolomite. J. Geol. 48, 225-274.

Brown, E. H. 1967: The greenschist facies in part of eastern Otago, New Zealand. Beitr. Miner. Petrogr. 14, 259-292.

Chayes, F. 1955: Potash feldspar as a by-product of the biotite-chlorite transformation. $J$. Geol. 63, 75-82.

Deer, W. A., Howie, R. A. \& Zussmann, J. 1962/63: Rock-forming minerals. London: Longmans Green.

Dietrich, V. 1969: Die Ophiolithe des Oberhalbsteins (Graubünden) und das Ophiolithmaterial der ostschweizerischen Molasseablagerungen, ein petrographischer Vergleich. Europ. Hochschulschriften, Reihe XVII Erdw. I.

EngeL, A. E. J. \& ENGEL, C. G. 1958: Progressive metamorphism and granitization of the major paragneiss, northwest Adirondack Mountains. New York. Part I : Total rock. Bull. geol. Soc. Am. 69, 1369-1414.

- 1960: Progressive metamorphism and granitisation of the major paragneiss, northwest Adirondack Mountains. New York, Part II: Mineralogy. Bull. geol. Soc. Am. 71, 1-58.

EnGeL, A. E. J., EngeL, C. G. \& Havens, R. G. 1965: Chemical characteristics of oceanic basalts and the upper mantle. Bull. geol. Soc. Am. 76, 719-734.

Es k olA, P. 1920: The mineral facies of rocks. Norsk geol. Tidsskr. 6, 143-194.

FrankL, E. 1953: Die geologische Karte von Nord-Scoresby Land (NE-Grönland). Meddr Grønland $\mathbf{1 1 3}^{6}, 56 \mathrm{pp}$.

Frey, M. 1968: Zur Metamorphose des Keupers vom Tafeljura bis zum Lukmaniergebiet. Schweiz. miner. petrogr. Mitt. 48, 829-831.

GaNGULY, J. \& Newton, R. C. 1968: Thermal stability of chloritoid at high pressure and relatively high oxygen fugacity. J. Petrology 9, 444-466.

Goldsmith, J. R., Graf, D. L. \& Joensud, O. I. 1955: The occurrence of magnesian calcites in nature. Geochim. cosmochim. Acta 7, 212-230. 
Goldsmith, J. R. \& Newton, R. C. 1969: P-T-X relations in the system $\mathrm{CaCO}_{3}$ $\mathrm{MgCO}_{3}$ at high temperatures and pressures. Am. J. Sci. 267 a, 160-190.

Graf, D. L. \& Goldsmith, J. R. 1955: Dolomite-magnesian calcite relations at elevated temperatures and $\mathrm{CO}_{2}$ pressures. Geochim. cosmochim. Acta 7, 109-112.

GREENWOOD, H. J. 1962: Metamorphic reactions involving two volatile components. Yb. Carnegie Instn Wash. 61, 82-85.

GuitaRD, M. G. 1966: Le métamorphisme et les faciès minéralogiques des marbres dérivant des dolomies dans les massifs du Canigou et de la Carança (PyrénéesOrientales). C. r. hebd. Séanc. Acad. Sci. Paris 262, 245-247.

Halferdahl, L. B. 1961: Chloritoid: its composition, X-ray and optical properties, stability, and occurrence. J. Petrology 2, 49-127.

Haller, J. \& Kulp, J. L. 1962: Absolute age determinations in East Greenland. Meddr Gronland 171', $77 \mathrm{pp}$.

Henriksen, N. \& Higgins, A. K. 1969: Preliminary results of mapping in the crystalline complex around Nordvestfjord, Scoresby Sund, East Greenland. Rapp. Gronlands geol. Undersøgelse 21, 5-20.

Hex, M. H. 1954: A new review of the chlorites. Mineralog. Mag. 30, 277-292.

Hoscheк, G. 1967: Untersuchungen zum Stabilitätsbereich von Chloritoid und Staurolith. Beitr. Miner. Petrogr. 14, 123-162.

- (im Druck): Zur Stabilität von Staurolith und Chloritoid mit Bemerkungen über die mittelgradige Metamorphose pelitischer Gesteine.

Hutron, C. O. 1940: Metamorphism in the Lake Wakatipu region, western Otago, New Zealand. Geol. Mem. N.Z. 5.

Jäger, E., Kempter, E., Niggli, E. \& Wüthrich, H. 1961: Biotit Varietäten und Stilpnomelan im alpin metamorph überprägten Mittagfluh-Granit. Schspeiz. miner. petrogr. Mitt. 41, 117-126.

JAMES, H. L. 1955: Zones of regional metamorphism in the Precambrian of Northern Michigan. Bull. geol. Soc. Am. 66, 1455-1488.

Katz, H. R. 1961: Late Precambrian to Cambrian stratigraphy in East Greenland. In RaAsch, G. H. (edit.) Geology of the Arctic 1, 299-328. University of Toronto Press.

Metz, P. W. 1966: Untersuchungen eines heterogenen bivarianten Gleichgewichtes mit $\mathrm{CO}_{2}$ und $\mathrm{H}_{2} \mathrm{O}$ als fluider Phase bei hohen Drucken. Ber. Bunsenges. phys. Chem. 70, 1043-1045.

- 1967: Experimentelle Bildung von Forsterit und Calcit aus Tremolit und Dolomit. Geochim. cosmochim. Acta 31, 1517-1532.

Metz, P. W., Puhan, D. \& Winkler, H. G. F. (im Druck): Equilibrium reactions on the formation of talc and tremolite by metamorphism of siliceous dolomite. Naturwissenschaften.

METZ,P.W. \& TROMMSD ORFF,V. 1968: On phase equilibria in metamorphosed siliceous dolomites. Beitr. Miner. Petrogr. 18, 305-309.

Metz, P. W. \& Winkler, H. G. F. 1963: Die Bildung von Talk aus kieseligem Dolomit. Geochim. cosmochim. Acta 27, 431-457.

Miyashiro, A. 1958: Regional metamorphism of the Gesaisyo-Takanuki District in the Central Abukuma Plateau. J. Fac. Sci. Tokyo Unio., Sect. II, 21, 219-272.

- 1961: Evolution of metamorphic belts. J. Petrology 2, 277-311.

NigGLI, E. 1960: Mineral-Zonen der alpinen Metamorphose in den Schweizer Alpen. Rep. 21st intern. geol. Congr. Norden 13, 132-138.

NiGGLI, E. \& NIGGLI, C. 1965: Karten der Verbreitung einiger Mineralien der alpidischen Metamorphose in den Schweizer Alpen. Eclog. geol. Hels. 58, 335-368.

Niggli, P. 1912: Die Chloritoidschiefer und die sedimentäre Zone am Nordostrande des Gotthardmassivs. Beitr. geol. Karte Schweiz, NF. 36. 
Righardson, S. W. 1968: Staurolite stability in a part of the system Fe-Al-Si-O-H. J. Petrology 9, 467-488.

Righardson, S. W., Gilbert, M. C. \& Bell, P. M. 1969: Experimental determination of kyanite-andalusite and andalusite-sillimanite equilibria; the aluminium silicate triple point. Am. J. Sci. 267, 259-272.

Rosenfeld, J. R. 1956: Paragonite in the schist of Glebe Mountain, southern Vermont. Am. Miner. 41, 144-147.

Rosenfeld, J. R., Thompson, J. B. jr. \& Zen, E-An 1958: Data on coexisting muscovite and paragonite. Bull. geol. Soc. Am. 69, 1637.

Snid ô, F. 1958: Plutonic and metamorphic rocks of the Nakoso and Iritono districts in the Central Abukuma Plateau. J. Fac. Sci. Tokyo Uniø., Sect. II, 11, 132-217.

Steck, A. 1966: Petrographische und tektonische Untersuchungen am Zentralen Aaregranit und seinen altkristallinen Hüllgesteinen im westlichen Aarmassiv. Beitr. geol. Karte Schweiz, N.F. 130.

- 1968: Die alpidischen Strukturen in den Zentralen Aaregraniten des westlichen Aarmassivs. Eclog. geol. Helv. 61, 19-48.

StreGKeISEn, A. 1968: Stilpnomelan im Kristallin der Ostkarpathen. Schweiz. miner. petrogr. Mitt. 48, 751-780.

Thompson, J. B. 1955: The thermodynamic basis for the mineral facies concept. Am. J. Sci. 253, 65-103.

Tilley, C. E. 1924: The facies classification of metamorphic rocks. Geol. Mag. 61, 167-171.

- 1925: Metamorphic zones in the southern Highlands of Scotland. Q. Jl geol. Soc. Lond. 81, 100-112.

- 1938: The status of hornblende in low grade metamorphic zones of green schists. Geol. Mag. 75, 497-511.

- 1948: Earlier stages in the metamorphism of siliceous dolomites. Mineralog. Mag. 28, 272-277.

Trommsdorf, V. 1966: Progressive Metamorphose kieseliger Karbonatgesteine in den Zentralalpen zwischen Bernina und Simplon. Schweiz. miner. petrogr. Mitt. 46, 431-460.

TuRner, F. J. 1967: Thermodynamic appraisal of steps in progressive metamorphism of siliceous dolomitic limestones. Neues Jb. Miner. Mh. 1967, 1-22.

- 1968: Metamorphic petrology. 403 pp. New York: McGraw-Hill.

Turner, F. J. \& Verhoogen, J. 1960: Igneous and metamorphic petrology. (2nd ed.), $694 \mathrm{pp}$. New York: McGraw-Hill.

VoGt, P. 1965: Zur Geologie von Südwest Hinks Land (Ostgrönland $71^{\circ} 31^{\prime} \mathrm{N}$ ). Meddr Gronland 154, $24 \mathrm{pp}$.

Vogt, TH. 1927: Geology and petrology of the Sulitelma district. Norg. geol. Unders. 121, $315 \mathrm{pp}$.

Watanabe, T. 1943: Geology and mineralisation of the Suian district, Tyôsen Korea. J. Fac. Sci. Hokkaido Univ., 4th ser., 6, 117-303.

WeEks, H. F. 1956: A thermochemical study of equilibrium relations during metamorphism of siliceous carbonate rocks. J. Geol. 64, 245-270.

Wegmann, C. E. 1935: Zur Deutung der Migmatite. Geol. Rdsch. 26, 305-350.

Wenк, E. 1956: Alpines und ostgrönländisches Kristallin, ein tektonisch-petrogenetischer Vergleich. Verh. Naturf. Ges. Basel 67, 75-102.

- 1961 a: Tertiary of East Greenland. In RAAsch, G. H. (edit.) Geology of the Arctic 1, 278-284. University of Toronto Press.

- $1961 \mathrm{~b}$ : On the crystalline basement and the basal part of the Pre-Cambrian Eleonore Bay Group in the southwestern part of Scoresby Sund. Meddr Gronland $168^{1}, 54 \mathrm{pp}$. 
Wenk, E. \& Haller, J. 1953: Geological explorations in the Petermann Region, western part of Frænkels Land, East Greenland. Meddr Gronland 111 ${ }^{3}, 48 \mathrm{pp}$.

Wenk, E. \& Keller, F. 1969: Isograde in Amphibolitserien der Zentralalpen. Schweiz. miner. petrogr. Mitt. 49, 157-198.

Wrn k Ler, H. G. F. 1967: Die Genese der metamorphen Gesteine. 218 pp. Berlin: Springer-Verlag.

Wiseman, J. D. H. 1934: The central and South-West Highland epidiorites: A study in progressive metamorphism. Quart. $J l$ geol. Soc. Lond. 90, 354-417.

ZEN, E-AN 1960: Metamorphism of lower Paleozoic rocks in the vicinity of the Taconic Range in west-central Vermont. Am. Miner. 45, 129-175.

Zen, E-An \& Albee, A. L. 1964: Coexistent muscovite and paragonite in pelitic schists. Am. Miner. 49, 904-925.

Zwart, H. J. 1962: On the determination of polymetamorphic mineral associations and its application to the Bosost area (Central Pyrenees). Geol. Rdsch. 52, 38-65. 
Færdig fra trykkeriet den 16. december 1971. 